\title{
Uso de informações de contexto em segurança computacional
}

\section{Francisco Gomes Milagres}



SERVIÇO DE PÓS-GRADUAÇÃO DO ICMC-USP

Data de Depósito: $\quad$ 20.08.2004

Assinatura:

\title{
Uso de informações de contexto em segurança computacional
}

\author{
Francisco Gomes Milagres
}

Orientador: Prof. Dr. Edson dos Santos Moreira

Dissertação apresentada ao Instituto de Ciências Matemáticas e de Computação - ICMC-USP, como parte dos requisitos para obtenção do título de Mestre em Ciências de Computação e Matemática Computacional.

USP - São Carlos

Agosto/2004 

A meus pais e irmãos, pela torcida e confiança de sempre, apesar da distância.

A Andrea, por ser meu porto seguro, minha esposa e amiga. 


\section{Agradecimentos}

Agradeço à Deus, pela força e pela proteção.

Ao meu orientador, Edson Moreira, pela confiança e pela amizade desde a minha chegada a São Carlos.

À Andrea, pelo carinho, companheirismo, dedicação e compreensão, mesmo nos momentos de distância em razão do trabalho.

Aos grandes amigos Rudinei Goularte e Rodrigo Felicio dos Santos, pela imensa colaboração durante a execução deste trabalho, durante madrugadas, feriados e fins de semana.

Aos amigos do Laboratório Intermídia, grupo de pesquisas (e festas) que fiz parte desde 1998, em especial, Aires, Boni, Bulcão, Dilvan, Fabrício, Graça, Gusfaria, Kamarão, Mauro, Robson, Roger, Stênio, Taboca e Tanão.

À Juliana Moraes, pela revisão das referências bibliográficas e pela colaboração de sempre na biblioteca do ICMC.

Aos demais amigos, funcionários e colaboradores do ICMC, pela amizade e colaboração, da graduação ao mestrado.

Aos mais novos amigos, no CPqD: Emilio, Marcelo, Fabrício, Helen, Nelson, Renata, Sérgio, Kowask, Tatiana, Cleison, Nádia e Leonardo.

À CAPES, pelo apoio financeiro. 
"Não existem erros. Os acontecimentos que atraímos para nós, por mais desagradáveis que sejam, são necessários para ensinar o que necessitamos aprender. Quando iniciamos a vida, cada um de nós recebe um bloco de mármore e as ferramentas necessárias para converter este bloco em escultura. Podemos arrastá-lo intacto a vida toda, podemos reduzi-lo a cascalho ou podemos dar-lhe uma forma gloriosa."

\section{Richard Bach, A Ponte Para Sempre}




\section{Resumo}

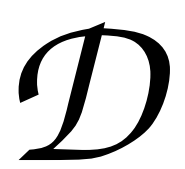

iariamente, novos sistemas ubíquos são desenvolvidos e integrados ao nosso cotidiano, cuja presença às vezes não é percebida pelos seus usuários. O objetivo deste trabalho é investigar as questões de segurança e privacidade existentes nos paradigmas de computação ubíqua e ciente de contexto. Utilizando um protótipo de TV interativa - TV-I (Goularte, 2003) - que possui características de mobilidade e ciência de contexto, este trabalho define um conjunto de requisitos mínimos para a garantia de segurança e privacidade em sistemas ubíquos. É também objetivo deste trabalho utilizar informações contextuais para gerenciamento dinâmico de requisitos de segurança e privacidade por meio de políticas expressas em linguagem EPAL. Para validar os resultados desta pesquisa, foi implementado o Gerente de Segurança como um serviço do protótipo TV-I. A principal característica desse gerente é controlar o acesso a informações pessoais por meio de informações de contexto fornecidas pelo Gerente de Contexto, de autoria de Santos (2004). 


\section{Abstract}

$\mathcal{E}$

very day, new ubiquitous systems are being developed and integrated into our daily routines, whose presence is sometimes not even perceived by the casual user. The aim of this work is to investigate questions of security and privacy in ubiquitous and context aware computing. Using a prototype for interactive television - TV-I (Goularte, 2003) - that has characteristics of mobility and contextual-awareness, this work defines a set of basic requirements that are fundamental in order to guarantee security and privacy in ubiquitous systems. Furthermore, this work uses contextual information in order to dynamically manage security and privacy requirements according to security and privacy policies that are expressed in the EPAL language. In order to validate the experimental results, a Security Manager has been implemented as a service of the TV-I prototype. The principal characteristic of this manager is to enforce access control over the personal information using contextual information of the ubiquitous system, and which is supplied via the Context Manager, designed by Santos (2004). 


\section{Lista de Figuras}

1.1 Gerente de Segurança e demais módulos do Gerenciador de Serviços do TV-I. . . . . . . . . . . . . . . . . . . 3

2.1 Exemplos de um PDA (Palm Tungsten T) e de um tablet (Tablet PC). 8

2.2 Parte do alfabeto Grafitti2, usado nos PDAs da empresa PalmOne. 9

2.3 Aula com os recursos de captura e acesso do projeto eClass. . . . 11

2.4 Exemplo de um crachá utilizado no projeto Active Badge, durante a década de 90, na Universidade da Cambridge. . . . . . . . . 12

2.5 Modelo resumido da arquitetura do protótipo TV-I (Goularte, 2003). 19

2.6 Exemplo de representação de contexto de usuário. . . . . . . . . . 21

2.7 Diagrama representando os componentes do contexto do Sistema (Goularte, 2003). . . . . . . . . . . . . . . . . . 22

3.1 Prejuízos devido a incidentes de segurança nos EUA por categorias (em US\$) (Berinato, 2003). . . . . . . . . . . . . . . 27

3.2 O período de validade de um certificado digital. . . . . . . . . . 31

4.1 Balanceamento de privacidade para personalização (adaptação de Abelson et al. (1998)). . . . . . . . . . . . . . . . . . . 37

4.2 O mapa mundial das leis de proteção de privacidade (Laurant et al., 2003). . . . . . . . . . . . . . . . . . . 39

4.3 Camadas de exposição para proteção de privacidade (Ishitani et al., 2003). . . . . . . . . . . . . . . . . . . 44

5.1 Componentes do contexto do sistema TV-I (Goularte, 2003). . . . 51

5.2 Diagrama de classes UML representando o contexto primário. . . 52

5.3 Modelagem em UML dos sistemas de gerenciamento cientes de contexto. . . . . . . . . . . . . . . . . . . 54

5.4 Modelagem em UML do serviço Web de Gerenciamento de Segurança. . . . . . . . . . . . . . . . . . . 54 
5.5 Segmento do vocabulário da política de privacidade . . . . . . . 56

5.6 Regra de acesso gerada dinamicamente pelo serviço de gerenciamento de segurança. . . . . . . . . . . . . . . 57

5.7 Modelo resumido da arquitetura do protótipo TV-I (Goularte, 2003). 58

5.8 Tela da aplicação ciente de contexto, com as opções de login, senha e localização. . . . . . . . . . . . . . . . . 59

5.9 Fluxograma da interação entre a aplicação ciente de contexto e os gerentes de segurança e contexto. . . . . . . . . . . . 59 


\section{Lista de Tabelas}

5.1 Elementos classificados no vocabulário EPAL. . . . . . . . . . . . 55

5.2 Definições de elementos de um vocabulário EPAL. . . . . . . . . 56 


\section{Sumário}

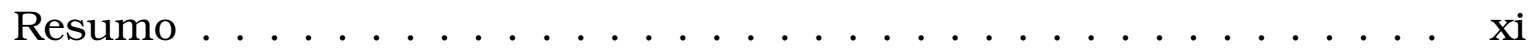

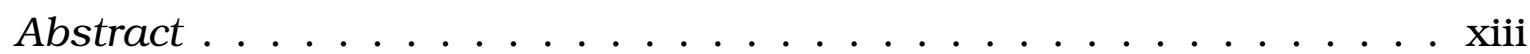

Lista de Figuras . . . . . . . . . . . . . . . . . . xvi

Lista de Tabelas . . . . . . . . . . . . . . . . . . . xvii

1 Introdução 1

1.1 Motivações ...................... . 2

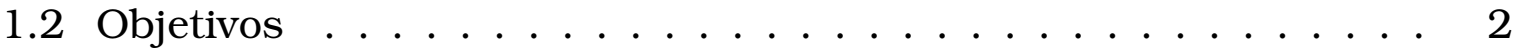

1.3 Histórico do grupo de pesquisas . . . . . . . . . . . . . 4

1.4 Organização da dissertação . . . . . . . . . . . . . . . 5

2 Computação Ubíqua $\quad 7$

2.1 Interfaces naturais . . . . . . . . . . . . . . . . 8

2.2 Captura e acesso . . . . . . . . . . . . . . . . . . 10

2.3 Computação ciente de contexto . . . . . . . . . . . . . 10

2.3.1 Projetos relacionados . . . . . . . . . . . . 11

2.3.2 Definindo ciência de contexto . . . . . . . . . . . . . . . . . 13

2.3.3 Aplicações cientes de contexto . . . . . . . . . . . . . . . . 14

2.3.4 Classificação de contexto . . . . . . . . . . . . . . . 15

2.3.5 Representação de contexto . . . . . . . . . . . . . 16

2.4 Protótipo de TV interativa . . . . . . . . . . . . . . . 18

2.4 .1 Arquitetura . . . . . . . . . . . . . . . 18

2.4 .2 Representação de contexto . . . . . . . . . . . . . 19

2.4.3 Gerenciamento de informações de contexto . . . . . . . 21

2.5 Considerações finais . . . . . . . . . . . . . . . . . . . 22

3 Segurança da Informação $\quad 25$

3.1 Pesquisas em segurança da informação . . . . . . . . . . . . 25

3.2 Conceitos de segurança da informação . . . . . . . . . . . . . 27

3.3 Segurança em computação ubíqua . . . . . . . . . . . . . . . . 29 
3.3.1 Trabalhos relacionados . . . . . . . . . . . . 29

3.4 Considerações finais . . . . . . . . . . . . . . . . . 33

4 Privacidade na Sociedade da Informação 35

4.1 Conceitos de privacidade e proteção de dados . . . . . . . . . . . 36

4.2 Perspectiva histórica e legal . . . . . . . . . . . . . . . 38

4.3 Princípios básicos de privacidade . . . . . . . . . . . . . . . 40

4.4 Ameaças à privacidade . . . . . . . . . . . . . . . . . . . 42

4.4.1 Informações em navegadores . . . . . . . . . . . . . . 42

4.4 .2 Cookies . . . . . . . . . . . . . . . 43

4.4 .3 Código móvel . . . . . . . . . . . . . . . . 43

4.4 .4 Ataques a cache ... . . . . . . . . . . 44

4.5 Controle de privacidade . . . . . . . . . . . . . . . . . 44

4.5.1 Banco de dados Hipocráticos . . . . . . . . . . . . . . 45

4.5.2 Linguagens para representação de políticas . . . . . . . . 46

4.5.3 Autorização baseada em políticas de privacidade . . . . . . 47

4.6 Considerações finais . . . . . . . . . . . . . . . . . . . . . 48

5 Gerenciamento de Segurança 49

5.1 Segurança no Projeto TV-I . . . . . . . . . . . . . . 50

5.1 .1 Serviço de Gerenciamento de Contexto . . . . . . . . . . . . 52

5.1.2 Serviço de Gerenciamento de Segurança . . . . . . . . . . . 53

5.2 Políticas de privacidade . . . . . . . . . . . . . 55

5.2 .1 Vocabulário EPAL . . . . . . . . . . . . . . 55

5.2 .2 Política de privacidade EPAL . . . . . . . . . . . 56

5.2 .3 Regras de validação XACML . . . . . . . . . . . . . . 57

5.3 Exemplo de uso . . . . . . . . . . . . . . . . . . 57

5.4 Considerações finais . . . . . . . . . . . . . . . 61

6 Conclusões $\quad 63$

6.1 Contribuições . . . . . . . . . . . . . . . 63

6.2 Limitações . . . . . . . . . . . . . . . . . . . . 64

6.3 Trabalhos futuros . . . . . . . . . . . . . . 65

6.4 Considerações finais . . . . . . . . . . . . . . . 65

$\begin{array}{ll}\text { A Vocabulário EPAL } & 77\end{array}$

$\begin{array}{ll}\text { B Politica de Segurança EPAL } & 79\end{array}$ 

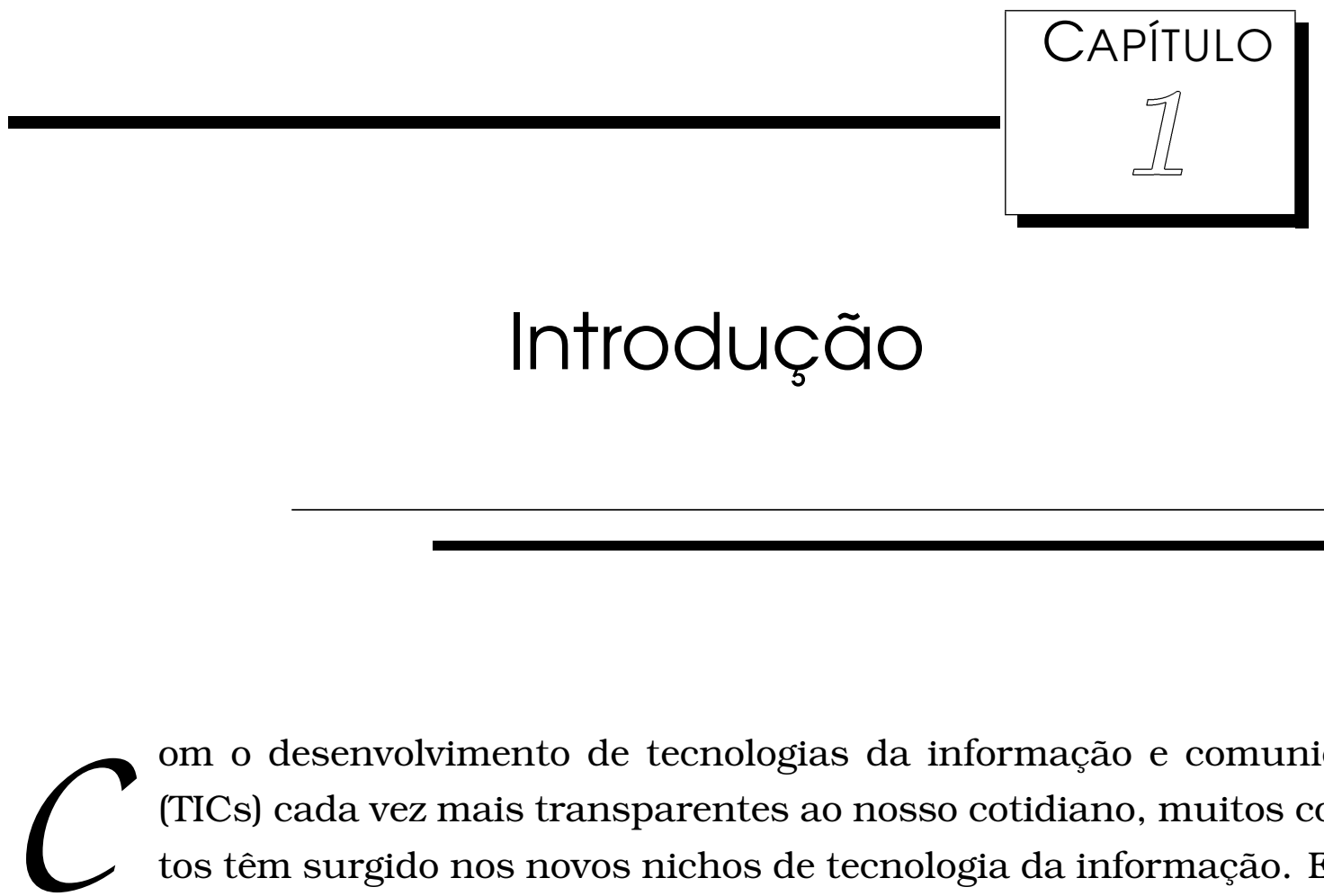

om o desenvolvimento de tecnologias da informação e comunicação (TICs) cada vez mais transparentes ao nosso cotidiano, muitos conceitos têm surgido nos novos nichos de tecnologia da informação. Exemplos mais comuns vão desde os dispositivos portáteis multifuncionais - que substituem as agendas, telefones, pagers ou computadores pessoais - até as avançadas redes ad hoc de micro sensores com capacidade de processamento e comunicação - a Smart Dust (Culler e Mulder, 2004), alvo de pesquisas em universidades de destaque e que, até então, figurava apenas como tema em livros de ficção científica (Crichton, 2003).

Apesar de muitas dessas idéias ainda estarem distantes dos lares e de nosso cotidiano, algumas delas já influenciaram o surgimento de novas áreas de pesquisa que, atualmente, são responsáveis por investigar novos modos de interação entre humanos e máquinas. Uma dessas áreas é a computação ubiqua, idealizada por Mark Weiser (1991), que previu o desenvolvimento de dispositivos capazes de reconhecerem seus donos e se adaptarem às mudanças do ambiente em que se encontram.

Informações como identificação, preferências e histórico dos usuários são monitoradas, armazenadas, processadas e compartilhadas entre aplicações em diferentes domínios e em ambientes ubíquos e com redes de comunicação sem fio. Assim, paralelamente ao desenvolvimento de TICs inseridas em nosso cotidiano, surgem também questões sobre segurança e privacidade dos usuários e suas informações pessoais em ambientes dotados de facilidades cada vez maiores. 


\subsection{Motivações}

As características únicas diferem cada indivíduo dos demais na sociedade. Informações como cor de cabelo, idade ou um número único de identificação permite uma melhor aproximação da realidade dependendo dos parâmetros que possam ser relacionados.

A identificação de elementos em uma rede de computadores pode ser feita por meio de um conjunto de informações dos usuários, das aplicações e da infra-estrutura envolvida, por exemplo, incluindo identificação de perfis de preferências e de características da própria infra-estrutura de comunicação.

Apesar de existirem soluções de segurança consideradas eficientes para controle de privacidade, por exemplo, não há características de adaptação das necessidades de segurança aos anseios dos usuários em relação à computação ubíqua como há em código móvel, por exemplo (Hashii et al., 2000). Com essa necessidade de adaptação das necessidades de segurança de maneira dinâmica, um novo paradigma deve ser adotado: a segurança baseada em contexto, integrando soluções de segurança da informação com soluções baseadas em ciência de contexto na computação ubíqua.

Para tratar os requisitos de segurança em sistemas que exigem cada vez mais a personalização e o conhecimento detalhado de informações de seus usuários, das aplicações e da infra-estrutura de redes, esta pesquisa foi concebida, no escopo do Projeto TV-I.

\subsection{Objetivos}

Com o crescimento de infra-estruturas de comunicação a cada dia integrando novas ferramentas, tarefas para gerenciamento de tais elementos conectados estão se tornando cada vez mais desafiadoras. A adoção de dispositivos móveis e o constante aumento de riscos exigem que a infra-estrutura possa ser gerenciada sem grandes dificuldades, o que ainda não é possível.

A primeira característica desta pesquisa é a utilização de técnicas das áreas de computação ubíqua e segurança computacional com intuito de investigar questões relacionadas a problemas de segurança em infra-estruturas que, além de estarem inseridas no cotidiano, também devem ser seguros.

Para explorar as áreas de computação ubíqua interativa e segurança computacional, esse trabalho foi definido no escopo de um projeto em desenvolvimento no Laboratório Intermídia ${ }^{1}$ : o protótipo de TV interativa denominado TV-I, que possui características de mobilidade e ciência de contexto (Goularte,

\footnotetext{
${ }^{1}$ Para informações sobre as linhas de pesquisa e projetos em desenvolvimento no Intermídia, visite o site do grupo: http://www.intermidia.icmc.usp.br/
} 
2003).

Este trabalho tem como objetivo inicial o levantamento das principais questões de segurança existentes no paradigma de computação ubíqua interativa. Após a apresentação do levantamento dos requisitos de segurança para sistemas ubíquos interativos, o objetivo seguinte é a apresentação da modelagem e implementação de um Gerente de Segurança que, utilizando informações de contexto disponibilizadas por um módulo denominado Gerente de Contexto (Santos, 2004), deve garantir um nível desejado de segurança para o sistema e seus usuários.

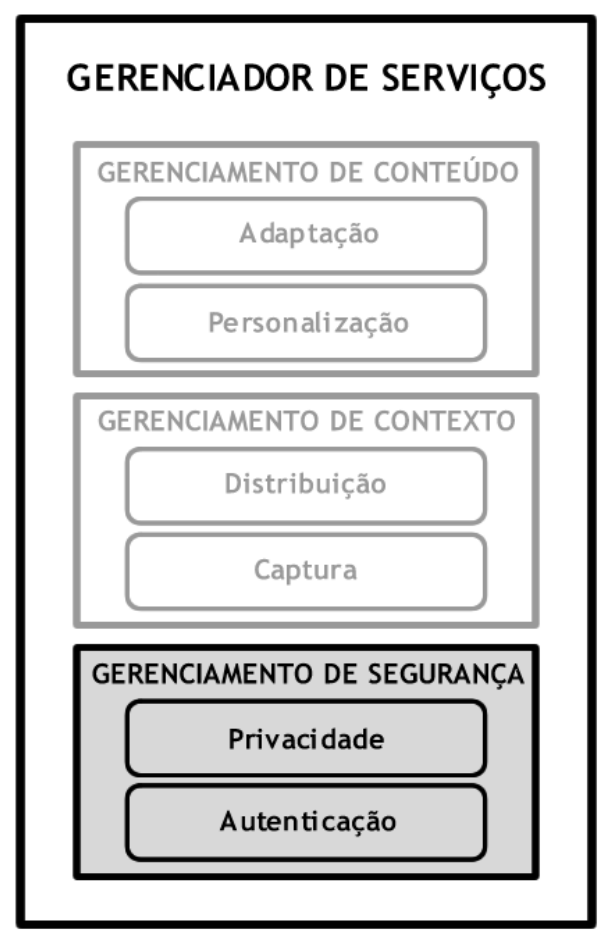

Figura 1.1: Gerente de Segurança e demais módulos do Gerenciador de Serviços do TV-I.

A metodologia de desenvolvimento deste trabalho é de característica exploratória, visando explorar pesquisas em áreas que anteriormente eram tratadas separadamente no Laboratório Intermídia - segurança computacional e computação ubiqua. A investigação integrada dessas áreas de pesquisas, com integração ainda incipiente conforme a literatura científica pôde confirmar, permitiu uma análise dos trabalhos relacionados a este, que possuem como objetivo comum a investigação de requisitos de segurança e privacidade em sistemas ubíquos.

Inicialmente foi feita uma pesquisa das tecnologias para controle de privacidade inserida em projetos de computação ubíqua. Posteriormente, foi definido o escopo da pesquisa como o projeto TV-I para a aplicação dos resultados dessa pesquisa e sua conseqüente validação em conjunto com o trabalho de Santos (2004). 
Os resultados das pesquisas foram aplicados na implementação de um serviço Web (Web Service) de Gerenciamento de Segurança que utiliza informações contextuais disponibilizadas pelo Gerente de Contexto (Figura 1.1) .

\subsection{Histórico do grupo de pesquisas}

No grupo de pesquisas do Laboratório Intermídia no Instituto de Ciências Matemáticas e de Computação (ICMC) ${ }^{2}$ da Universidade de São Paulo (USP) vem sendo desenvolvidos, dentre outros temas, projetos em duas frentes importantes na área da computação: Segurança Computacional e Sistemas Multimídia Distribuídos.

Tendo iniciado seus trabalhos no início da década de 1990 com projetos relacionados ao gerenciamento de redes de computadores (Oda, 1994; Cicilini, 1994; Lieira, 1995; Moraes, 1995; Morishita, 1997), o grupo de pesquisas em segurança computacional desenvolveu pesquisas nas áreas de sistemas detectores de intrusões com suporte de redes neurais para o reconhecimento de padrões de ataques (Cansian, 1997; Bonifácio Júnior, 1998; Tavares et al., 1999), aplicação de conceitos de agentes móveis para o gerenciamento da segurança (Reami, 1998) e verificação de anomalias (Bernardes, 1999; Milagres e Moreira, 2001). Também foram desenvolvidas pesquisas nas áreas de ambientes servidores para agentes móveis (Pereira Filho, 2001) e ferramentas que conferiam inteligência a tais agentes (Ambrósio, 2002) bem como estudos para implementação de sistemas detectores de intrusão em dispositivos de segmentação de redes (Tavares, 2002).

A partir do segundo semestre de 2001, o Laboratório Intermídia, juntamente com o NUMA (Núcleo de Manufatura Avançada) ${ }^{3}$ e financiados pelo CNPq (Conselho Nacional de Desenvolvimento Científico e Tecnológico) ${ }^{4}$, passou a integrar a iniciativa brasileira de cooperação com o projeto internacional DEEPSIA (Dynamic on-linE IntErnet Purchasing System based on Intelligent Agents) ${ }^{5}$.

O projeto DEEPSIA foi estabelecido por um consórcio entre diversas instituições e empresas européias com o apoio da Information Society Technologies (IST) ${ }^{6}$, com objetivo principal de promover o ingresso das Pequenas e Médias Empresas no comércio eletrônico, utilizando uma solução centrada no comprador e tratando-as não somente como fornecedoras de produtos, mas também como consumidoras de bens e serviços (Garção et al., 2002). As

\footnotetext{
2 http: / / www.icmc.usp.br/

3 http: / / www. numa.org.br/

4 http://www. cnpq.br/

5 http://www.deepsia.com/br/

6 http: //www.cordis.lu/ist/
} 
principais pesquisas desenvolvidas no âmbito do projeto DEEPSIA foram de segurança para o seu sistema multi-agentes (Milagres et al., 2002), mineração de dados nas informações do catálogo (Herrera, 2002), implementação de técnicas de extração de informações de produtos em páginas da Web brasileira para inclusão em catálogos eletrônicos (Oliveira, 2002) e navegação em ontologias visando facilitar a interação do usuário com a ontologia dos produtos (Herrera et al., 2002; Santa Eulália et al., 2002).

A segunda frente de trabalho do grupo está relacionada ao desenvolvimento de pesquisas em sistemas multimídia distribuídos, aplicando estudos em padrões para a representação de informações e metadados na identificação de fluxos de mídia contínua e técnicas adequadas para transmissão e distribuição de vídeo na Internet (Goularte, 1998). Estudos com padrões de transmissão de vídeo com controle de qualidade de serviço e informações de contexto em multimídia são também temas de pesquisas desenvolvidas no Intermídia, que aplica os resultados destas em projetos de televisão interativa e multimídia distribuída (Faria et al., 2001; Goularte e Moreira, 2002; Goularte, 2003). É na união de esforços dos dois grupos de pesquisas que este trabalho foca, incluindo requisitos de segurança em sistemas multimídia distribuídos e cientes de contexto, no Projeto TV-I.

\subsection{Organização da dissertação}

Esta dissertação está estruturada em seis capítulos e dois apêndices. O capítulo um consiste desta introdução. Nos capítulos de dois a quatro são apresentadas as revisões da literatura em aspectos importantes para desenvolvimento do trabalho. No capítulo cinco são apresentados o desenvolvimento e as contribuições do trabalho e no capítulo seis são apresentadas as considerações finais.

No capítulo dois são apresentados os principais conceitos de computação ubíqua, com as descrições das áreas de pesquisa de interfaces naturais, de captura e acesso de atividades humanas e, com mais detalhes, os conceitos de computação ciente de contexto, por ser essa a área explorada neste trabalho.

No capítulo três são apresentados os conceitos de segurança da informação, alguns resultados de pesquisas mais recentes realizadas no Brasil e no exterior e a metodologia adotada para gerenciamento dos riscos envolvidos de informações pessoais em sistemas ubíquos.

No capítulo quatro são apresentados os conceitos de privacidade, os principais trabalhos relacionados e os tipos de ferramentas para controle de privacidade em sistemas computacionais mais importantes.

No capítulo cinco é apresentado o Gerente de Segurança, serviço do protó- 
tipo de TV interativa TV-I modelado e implementado para gerenciamento de privacidade baseado em informações de contexto.

No capítulo seis são apresentadas as contribuições e limitações deste trabalho, bem como sugestões de trabalhos futuros em decorrência desta pesquisa e as considerações finais.

Foram incluídos os códigos fontes do vocabulário e da política de segurança respectivamente nos Apêndices A e B. 


\section{CAPÍTULO 2 Computação Ubíqua}

expressão computação ubiqua ${ }^{1}$ foi idealizada pelo pesquisador 7 Mark Weiser (1991), quando vislumbrou a expansão do paradigma L de interação tradicional entre usuário e máquina - teclado, mouse e monitor - para uma abordagem que vai além do modelo humano de interação natural.

Weiser vislumbrou ambientes acrescidos de recursos computacionais capazes de fornecerem informações e serviços quando e onde fossem desejados. Sem a imposição de dispositivos como teclados e controles-remotos, a interação com as novas ferramentas fica mais próxima da maneira como os seres humanos gesticulam, falam ou escrevem para se comunicarem (Abowd et al., 2002).

Houve então a proliferação de dispositivos heterogêneos e de escalas variadas, como PDAs (Personal Digital Assistants), tablets digitais (dispositivos computacionais portáteis semelhantes a uma prancheta com telas sensiveis ao toque), lousas eletrônicas, laptops, telefones celulares e, assim, um enriquecimento na infra-estrutura e nas aplicações capazes de sustentar a computação ubíqua (Figura 2.1).

Para se comunicarem, as pessoas não usam somente a fala mas também o olhar, a escrita, gestos e qualquer outra maneira de comunicação implícita que tenha como objetivo complementar a demonstração de seus anseios. Do mesmo modo que esta comunicação é realizada naturalmente pelos seres humanos, a computação ubíqua busca facilitar a interface entre sistemas computacionais e seus usuários (Weiser, 1993).

O entendimento dos hábitos humanos, a criação de novos dispositivos in-

\footnotetext{
${ }^{1}$ Do latim ubique: que está ao mesmo tempo em toda a parte, onipresente (Webster, 2003).
} 


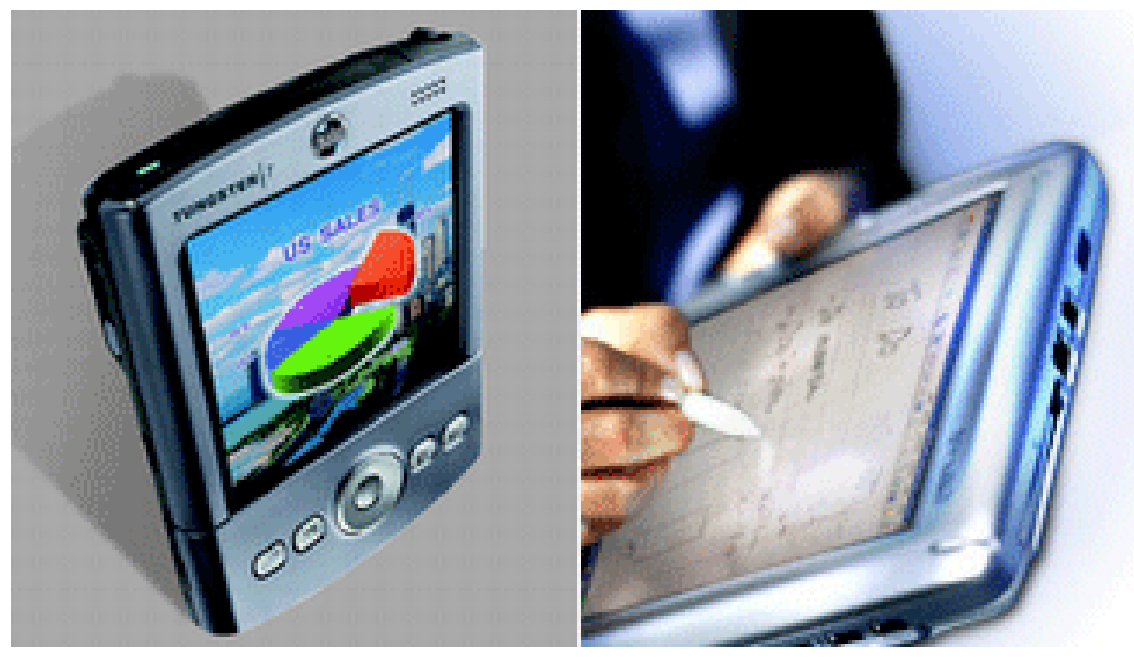

Figura 2.1: Exemplos de um PDA (Palm Tungsten T) e de um tablet (Tablet $P C)$.

terativos e a interação entre os dispositivos para permitirem uma experiência realística são fatores essenciais para a evolução das diferentes maneiras de captura de informações exigidas em computação ubíqua (Abowd et al., 2002).

Com o desenvolvimento desses fatores, é possivel fornecer capacidades bastante próximas à comunicação humana e efetivamente incorporar ações implícitas à computação. Assim, a comunicação realizada entre o ambiente e o usuário também apresentará grandes melhorias, tornando-se cada vez mais natural para as gerações futuras.

O projeto de aplicações capazes de explorarem o uso desses novos dispositivos, nos últimos anos, direcionou o foco das pesquisas em computação ubíqua para as três principais áreas: interfaces naturais, captura e acesso de atividades humanas e computação ciente de contexto (Abowd e Mynatt, 2000).

O objetivo nesse capítulo é a apresentação dos principais conceitos e áreas de pesquisa em computação ubíqua, com destaque para a computação ciente de contexto, que é o foco deste trabalho. Na Seção 2.1 serão apresentados os conceitos e exemplos de pesquisas na área de interfaces naturais e na Seção 2.2 será apresentada a área de captura e acesso de atividades humanas em computação ubíqua. Na Seção 2.3, em mais detalhes, será apresentada a área de pesquisas de computação ciente de contexto. O protótipo de TV interativa, trabalho de Santos Júnior (2002) e Goularte (2003), que é o alicerce para esta pesquisa, será apresentado na Seção 2.4.

\subsection{Interfaces naturais}

Um dos principais desafios da computação ubíqua está na adaptação das interações entre os usuários e seus sistemas computacionais. As interfaces 
computacionais mais próximas das formas humanas de comunicação estão substituindo, gradativamente, os elementos do paradigma tradicional de interação usuário-máquina composto pelos monitores de vídeo, teclado e mouse. Essas interfaces são de fácil utilização, possibilitando que tarefas (autoria, por exemplo) sejam desempenhadas sem a necessidade de grandes mudanças no comportamento humano (Abowd e Mynatt, 2000).

Aproximar a interação usuário-computador da interação natural que ocorre entre pessoas - de maneira não intrusiva - é o ideal para a computação ubíqua. Por essa razão, projetos voltados para interfaces mais amigáveis investigam técnicas de reconhecimento de escrita e de gestos, interação com canetas, técnicas de voz e percepção computacional, interação com sensores e manipulação de artefatos eletrônicos, por exemplo (Abowd et al., 2002).

Dentre as pesquisas relevantes que buscam a definição de melhores interfaces entre usuários e máquinas, há estudos de técnicas baseadas em manipulação de dispositivos eletrônicos para a criação do conceito de interfaces tangiveis (Ishii e Ullmer, 1997), utilização de sensores em dispositivos computacionais para a interpretação em aplicações (Harrison et al., 1998), reconhecimento de voz (Witbrock e Hauptmann, 1998) e de escrita (Schilit et al., 1998), por exemplo, o alfabeto Grafitti2, da empresa PalmOne ${ }^{2}$ (Figura 2.2).

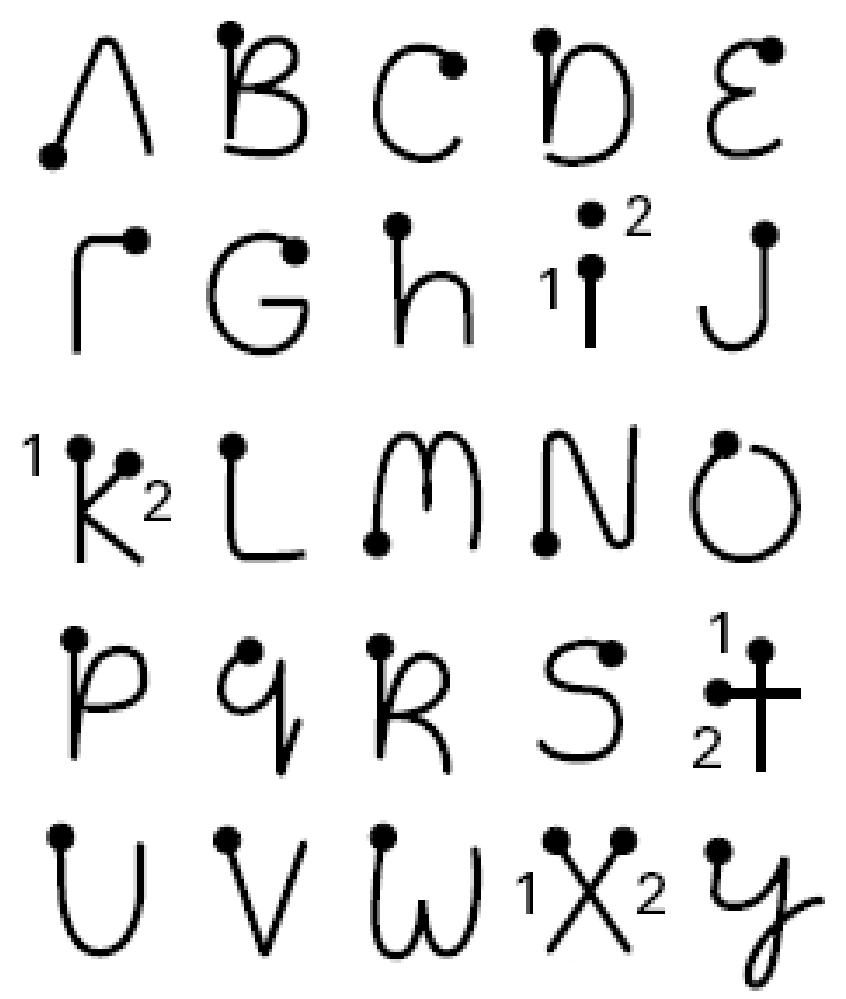

Figura 2.2: Parte do alfabeto Grafitti2, usado nos PDAs da empresa PalmOne.

${ }^{2}$ http://www.palmone.com/us/products/input/graffiti2.html 


\subsection{Captura e acesso}

Em diversas atividades do cotidiano, a maior parte do tempo das pessoas é gasto registrando informações sobre os acontecimentos dos quais participam. Para isso, é necessário absorver a informação da melhor maneira possível para facilitar sua recordação quando esta for necessária. No entanto, os humanos não são capazes de registrarem e reterem todas as informações relevantes, mesmo se tratando de assuntos de grande interesse. Com o advento de recursos como anotações e gravações em áudio e vídeo, a tarefa de registrar fatos tornou-se menos árdua. Com a utilização de multimídia em ambientes computacionais, é possível focar a atenção exclusivamente na atividade de maior interesse para, posteriormente, revisar a informação armazenada em diversas mídias, quantas vezes forem necessárias (Abowd e Mynatt, 2000; Abowd et al., 2002).

A área de pesquisas de captura e acesso de atividades humanas em computação ubíqua é responsável pelo desenvolvimento de soluções capazes de preservar a gravação de alguma experiência para acesso futuro. Há diversas aplicações que visam facilitar a captura e acesso a informações, como gravação de áudio, vídeo e anotações de aulas na forma de hiperdocumentos multimídia disponibilizados por meio da Web. Isso é explorado no projeto eClass, desenvolvido no Georgia Institute of Technology ${ }^{3}$, como ilustrado na Figura 2.3 (Abowd, 1999; Pimentel et al., 2001). No escopo do mesmo projeto, Brotherton e Abowd (1998) propõem o uso de informações de contexto para a inicialização de sessões de captura de aulas no eClass.

\subsection{Computação ciente de contexto}

Ao interagirmos com outras pessoas, transmitimos idéias, pensamentos e opiniões, ou seja, reagimos de maneira apropriada. Fatores que possibilitam tal interação são uma linguagem rica e compartilhada e há o entendimento implícito e recíproco de diversas maneiras de expressão. Logo, quando conversamos com outras pessoas, compartilhamos informações implícitas referentes à situação, ou seja, referentes ao seu contexto.

No entanto, ao fazerem parte de interações com pessoas, os computadores não são capazes de obterem total proveito da situação contextual justamente por não haver uma troca rica de informações como ocorre na interação entre pessoas (Dey, 2001). Portanto, a utilização de contexto num conceito mais amplo e direcionado à computação torna-se fundamental para melhorar as interações humano-máquina.

\footnotetext{
3 http://www.gatech.edu/
} 


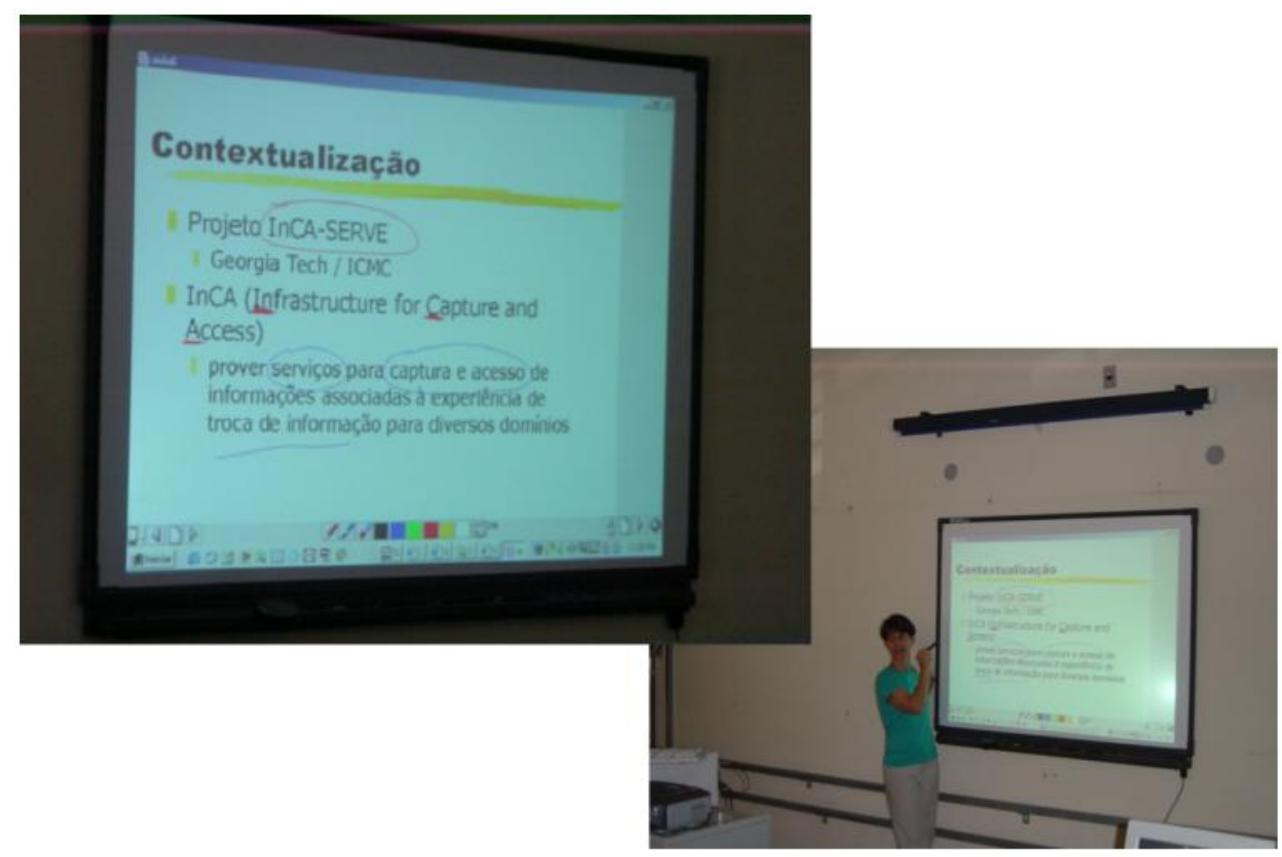

Figura 2.3: Aula com os recursos de captura e acesso do projeto eClass.

É possível perceber que, com o uso de informações de contexto que anteriormente não eram utilizadas nos sistemas computacionais, é possível enriquecer bastante as interações entre humano e máquina.

Atualmente, não há muitas pesquisas sobre computação ubíqua no Brasil, de modo que a tradução de termos da área para o português ainda é controversa. Os termos context-awareness e context-aware são empregados na área de computação ubíqua no sentido de se ter o conhecimento ou estar ciente do contexto em uma determinada situação. No presente trabalho, tais termos serão traduzidos, respectivamente, como ciência de contexto e ciente de contexto, observando-se o sentido original dos termos no idioma onde as expressões foram originalmente cunhadas (Webster, 2003).

Dentre os objetivos nas seções a seguir estão a apresentação de alguns trabalhos relevantes (Seção 2.3.1), a definição do conceito de ciência de contexto (Seção 2.3.2), a apresentação de requisitos para aplicações cientes de contexto (Seção 2.3.3), a apresentação das maneiras de classificação (Seção 2.3.4) e de representação de informações contextuais (Seção 2.3.5).

\subsubsection{Projetos relacionados}

Um exemplo de projeto pioneiro na área de computação ciente de contexto é o Active Badge (Want et al., 1992), do Olivetti Research Lab's ${ }^{4}$. Projetado no início da década de 90 , consiste de um sistema que auxilia no reconhecimento da localização e identificação de pessoas com base em crachás de

\footnotetext{
${ }^{4}$ http://www.uk.research.att.com/ab.html
} 


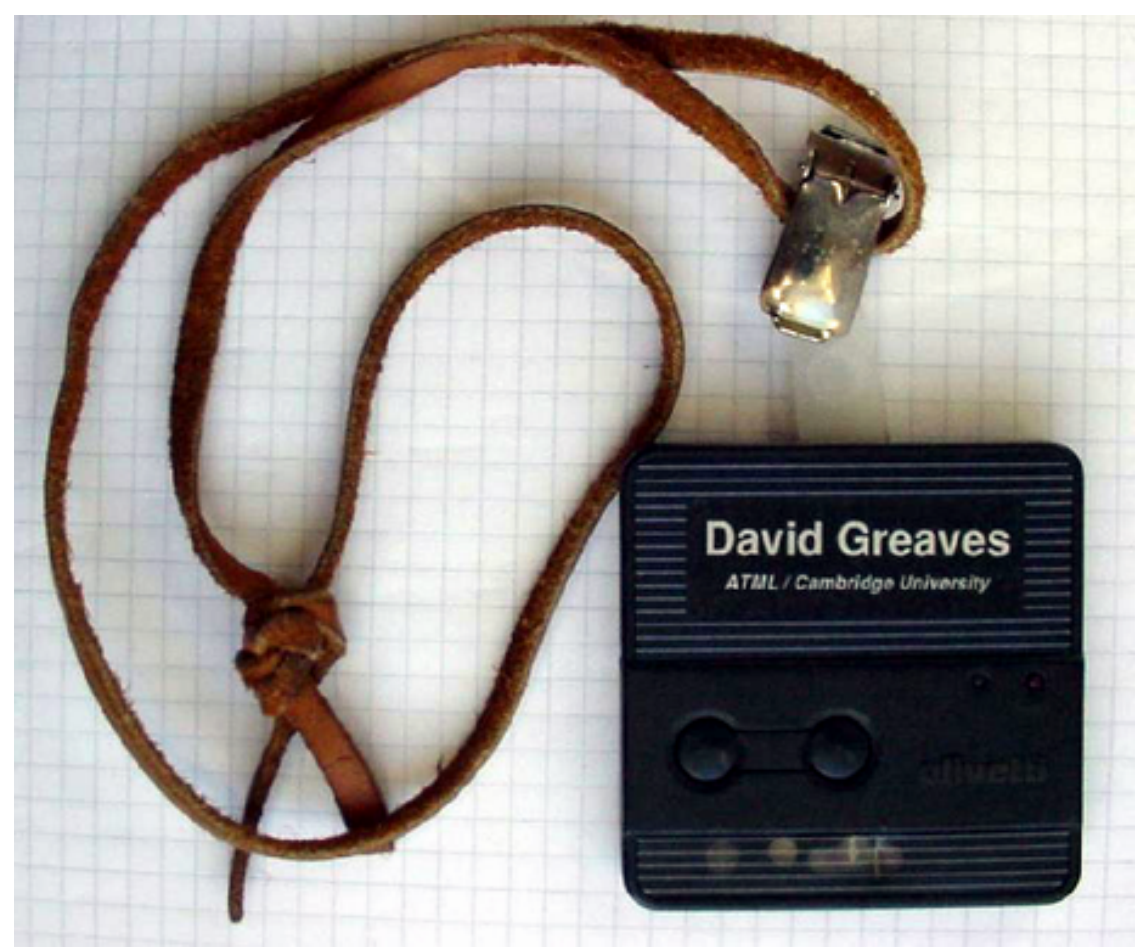

Figura 2.4: Exemplo de um crachá utilizado no projeto Active Badge, durante a década de 90, na Universidade da Cambridge.

identificação.

Outro projeto na área de ciência de contexto é de autoria de Dey (2000), que projetou o Context Toolkit, um framework que fornece serviços como descoberta de recursos, captura, armazenamento, conversão, agregação, interpretação, acesso e distribuição de informações contextuais. Um exemplo de aplicação do Context Toolkit é apresentado por Salber et al. (1999): o In/Out Board, consistindo de um quadro de avisos que lista, por exemplo, os pesquisadores presentes em determinado prédio.

O Context Fabric, de autoria de Hong e Landay (2001), é outro projeto na área de computação ciente de contexto. Essa aplicação disponibiliza quatro tipos de serviços para aplicações cientes de contexto: gerenciamento de sensores, criação automática de caminho, serviço de eventos e serviços de consulta. Além desses serviços, o Context Fabric possui uma linguagem declarativa de especificação de informações contextuais denominada Context Specification Language (CSL), que utiliza o padrão XML para declaração de informações contextuais.

Outro exemplo de projeto relacionado é o Context Kernel, desenvolvido por Arruda Júnior (2003) no ICMC-USP, que consiste de um serviço Web para recuperação e armazenamento de informações contextuais. O protótipo de TV Interativa TV-I, desenvolvido por Goularte (2003) também no ICMC-USP, tem como objetivo personalizar conteúdo multimídia baseado em informações de contexto. O trabalho de Goularte será apresentado em mais detalhes na 
Seção 2.4 .

\subsubsection{Definindo ciência de contexto}

O primeiro trabalho a adotar o termo ciência de contexto foi o de Schilit e Theimer (1994), os quais se referem a contexto como localização, identidades pessoais, objetos e suas alterações. Outras abordagens definem contexto como o ambiente ou situação em que uma determinada interação ocorre. Dey (2001) argumenta que tanto a definição de Schilit e Theimer (1994) - a qual enfatiza que "os principais aspectos do contexto são: onde você está, quem está com você, e quais recursos estão próximos” - quanto a de Pascoe (1998) "contexto é o subconjunto de estados fisicos e conceituais de interesse de uma entidade particular" - são muito específicas, já que contexto é toda situação relevante a uma aplicação e seu conjunto de usuários.

Desse modo, Abowd et al. (1999) e Dey (2001) definem contexto como "qualquer informação que possa ser usada para caracterizar a situação de uma entidade. Uma entidade é uma pessoa, lugar ou objeto que é considerado relevante para a interação entre um usuário e uma aplicação, incluindo ambos”. Se uma parte de informação pode ser usada para caracterizar a situação de um participante em uma interação, então tal informação pode ser classificada como contexto. Informações como um nome, um documento de identificação, a localização, uma ação e o horário atual são exemplos de informações contextuais.

Salber et al. (1998) definem contexto como informações sobre pessoas ou dispositivos que podem ser utilizados para definir a maneira como um sistema disponibiliza seus serviços, usando por exemplo, informações como históricos de acesso, localização e foco do usuário.

Ainda segundo Abowd et al. (1999), outras definições de contexto podem ser incluídas em duas categorias: o uso de contexto e a adaptação ao contexto. Esses autores acrescentam que, nas duas categorias, as definições são muito específicas e definem, de maneira geral, um sistema ciente de contexto como sendo "um sistema que utiliza contexto para prover informação relevante e/ou serviços ao usuário, onde a relevância depende da tarefa do usuário”.

Há autores também que apresentam o conceito de contexto primário (Schilit et al., 1994; Brown et al., 1997; Pascoe, 1998; Abowd et al., 1999; Dey, 2001), com destaque para alguns grupos de informações contextuais, incluindo informações como localização, atividade, tempo e identidade. Essas informações são consideradas mais importantes pois, além de responderem as questões básicas para identificação de um contexto (o quê, quando, onde e quem), elas permitem a descoberta de informações adicionais como e-mail, número de telefone e número IP, por exemplo. Alguns requisitos para desenvolvimento de aplicações cientes de contexto serão descritos na Seção 2.3.3. Informações de- 
talhadas sobre classificação e representação de informações contextuais serão apresentadas respectivamente nas Seções 2.3.4 e 2.3.5.

\subsubsection{Aplicações cientes de contexto}

Dey (2000) apresentou em seu trabalho sugestões para um conjunto de requisitos para o desenvolvimento de aplicações cientes de contexto e de infraestruturas de suporte a tais aplicações. Os recursos definidos pelo autor são descritos a seguir:

Especificação de informações de contexto: deve existir um mecanismo que permita aos desenvolvedores expressarem informações de contexto em fragmentos simples ou múltiplos, expressarem relacionamentos entre informações contextuais, notificarem a disponibilização de informações de contexto atualizadas e proverem suporte a especificações originadas de diversas aplicações.

Captura e uso de informações de contexto: aplicações cientes de contexto devem utilizar técnicas de implementação eficientes para facilitar o reuso e generalização das informações capturadas, implementando, por exemplo, técnicas de consulta e de notificação de informações atualizadas. As informações devem ser também classificadas de acordo com sua relevância.

Interpretação de informações de contexto: as informações de contexto devem ser interpretadas antes de serem utilizadas por aplicações, bem como devem ser classificadas corretamente para que a recuperação das informações seja facilitada quando necessária.

Comunicação distribuída e transparente: os sensores responsáveis pela captura de informações de contexto devem disponibilizá-las de maneira transparente e por meio de protocolos de comunicação e sistemas de codificação e decodificação padronizados.

\section{Disponibilidade de componentes de captura de informações de contexto:}

os componentes responsáveis pela captura de informações contextuais devem estar sempre disponíveis, executando a captura de forma independente e com capacidade de disponibilização de informações para diversas aplicações simultaneamente.

Armazenamento de informações de contexto: a importância de manter informações históricas é um requisito relacionado à disponibilidade dos componentes responsáveis pela captura de informações de contexto. As 
aplicações devem ser capazes de inferirem outros valores de contexto ou estabelecerem tendências baseadas em históricos. Para manter um histórico contextual, os componentes devem estar aptos a capturarem informações contextuais continuamente, mesmo quando as informações não são solicitadas.

Descoberta de recursos: dispositivos de captura de informações de contexto devem especificar quais tipos de informações de contexto disponibilizam, sua localização e interfaces. O mecanismo de descoberta de recursos pode ser combinado com o mecanismo de especificação e com os componentes de captura, com objetivo de determinar quais situações podem ser capturadas ou se uma determinada requisição de informação de contexto pode ser realizada pela infra-estrutura em execução.

É importante observar que não há soluções completas para todas as aplicações cientes de contexto. Para que as informações contextuais possam ser utilizadas de maneira dinâmica e personalizada, neste caso, no protótipo TV-I, é necessário haver uma aplicação que disponibilize as informações de contexto de maneira estruturada e padronizada. No escopo deste trabalho, as informações de contexto são disponibilizadas por um módulo do protótipo TV-I denominado Gerente de Contexto (Santos, 2004). Para efeitos desta pesquisa, foram considerados como principais para a validação do Gerente de Segurança os requisitos especificação de informações de contexto e comunicação distribuída e transparente.

\subsubsection{Classificação de contexto}

As definições de Abowd et al. (1999) incluem a classificação de contexto no sentido de disponibilizar aos usuários informações relevantes para que determinadas ações ou serviços possam ser executados de maneira personalizada. Essa classificação é considerada relativa ao contexto dos usuários.

De modo diferente à definição relativa ao contexto dos usuários no trabalho de Abowd et al., os trabalhos de Schilit (1995), Dix et al. (2000), Chalmers (2002) e Crowley et al. (2002) classificam o conjunto de informações de contexto relativos a Infra-Estrutura, Sistema, Domínio e Ambiente.

O contexto relativo a Infra-Estrutura, segundo Schilit (1995) e Dix et al. (2000), é um requisito para a representação de estado da comunicação entre aplicações e os dispositivos utilizados para o acesso. Com tal modo de representação, é possível obter subsídios para que seja diagnosticado qualquer tipo de mudança ocorrida nas condições da comunicação, como alteração de dispositivos no ambiente ou mudanças de estado devido a falhas. 
O contexto relativo ao Sistema disponibiliza informações que permitem aos dispositivos receberem informações de outros dispositivos que se encontram no mesmo contexto e, relacionado à ciência dos dispositivos, quais aplicações estão cientes de outras aplicações que também oferecem serviços compartilhados aos seus usuários (Dix et al., 2000; Chalmers, 2002; Crowley et al., 2002). Aplicações para esse contexto incluem, por exemplo, a possibilidade dos dispositivos poderem se combinar, resultando em serviços mais avançados. Os autores destacam ainda que o contexto relativo ao Sistema é composto pelo contexto do usuário acrescido ao estado dinâmico de dispositivos e serviços. É possível perceber que não há uma separação clara entre contextos de Sistema e da Infra-Estrutura, já que ambos podem incluir aplicações e dispositivos.

O contexto relativo a informações do Domínio disponibiliza informações referentes a semântica do domínio da aplicação. São considerados os relacionamentos entre dispositivos e seus usuários e, a partir dessas relações, é determinada a natureza das interfaces ou serviços a serem apresentados. Dix et al. (2000) e Abowd et al. (2002), por exemplo, apresentam considerações de níveis de exposição de informações pessoais e privacidade em casos de disponibilização de informações sobre usuários inseridos em um mesmo domínio.

Dix et al. (2000) destacam ainda que o contexto relativo a informações do Ambiente deve disponibilizar informações sobre as características do ambiente onde uma determinada entidade se encontra. Alguns exemplos dessas características são luminosidade e umidade, podendo inclusive serem características para ambientes reais quanto virtuais.

Apesar das classificações de informações relativas ao contexto de InfraEstrutura, Sistema, Domínio e Ambiente serem relevantes, seus respectivos autores não apresentaram esforços para uma separação entre os tipos de contextos mencionados e para a compatibilidade dos modelos propostos com as aplicações cientes de contexto já existentes em outras classificações.

\subsubsection{Representação de contexto}

Intrinsecamente relacionada à definição de contexto está a questão de como representá-lo. Sem boas representações, desenvolvedores de aplicações cientes de contexto são forçados a desenvolverem métodos limitados de armazenamento e manipulação de informações relevantes. Com o surgimento de representações mais sofisticadas, uma gama maior de capacidades surgirá e a separação da percepção de contexto da reação será mais fácil (Abowd et al., 2002).

Diversas pesquisas já foram realizadas na tentativa de definirem a melhor representação de contexto para cada aplicação ciente de contexto. Para que seja possível diferenciar entre o que é contexto ou não, Truong et al. (2001) 
propuseram uma diretriz para auxiliar projetistas de aplicações a descobrirem prováveis elementos de contexto, conhecida como os cinco W's ou cinco dimensões semânticas de contexto (Abowd et al., 1999):

Who (quem): os sistemas atuais focam as interações na identidade de um usuário em particular e raramente incorporam informações referentes a outras pessoas também pertencentes ao mesmo ambiente;

What (o quê): a interação dos sistemas convencionais supõe o quê o usuário está fazendo. Perceber e interpretar a atividade humana não é um problema elementar, apesar disso, dispositivos que suportem contexto devem incorporar interpretações de atividades humanas para serem capazes de proverem informação relevante;

Where (onde): é referente a localização e é a dimensão mais explorada. Em particular, pesquisas apontam as relações de noções das dimensões Where e When mescladas, com objetivo de agregar novas funcionalidades;

When (quando): embora poucos sistemas tenham suporte a esta dimensão, é geralmente utilizada em associação com Where para, por exemplo, determinar onde e quando um usuário realizou uma determinada ação;

How (como): é relevante para casos de definição de modo de acesso a informações e em associação com outras dimensões contextuais.

Uma dimensão adicional (Why, porquê), que pode ser inferida por associação entre as dimensões What e How, geralmente está associada a reconhecimento de informações vitais do usuário como humor, batimento cardíaco ou pressão arterial.

Apesar de existirem definições de contexto reconhecidas e uma diretriz para mapeamento de informações contextuais nas cinco dimensões (Who, What, Where, When e How), os projetistas de aplicações cientes de contexto necessitam de suporte para a modelagem de informações dentro das dimensões contextuais.

A maioria dos projetos de pesquisa envolvidos com representação contextual está envolvida na abstração de informações contextuais para outras aplicações cientes de contexto. Os trabalhos de Salber et al. (1999), Hong e Landay (2001) e Arruda Júnior (2003), citados na Seção 2.3.1, são alguns exemplos.

Outros projetos têm como objetivo a modelagem de informações contextuais para aplicações cientes de contexto, por exemplo, os trabalhos de Schilit et al. (1994), que utilizam servidores dinâmicos para distribuição de informações contextuais e Crowley et al. (2002), que representam essas informações como um conjunto de variáreis relativas a ambientes com ciência de contexto. 
Grande parte dos trabalhos citados possuem limitações quanto a flexibilidade no compartilhamento e quanto a ausência de uma classificação estruturada e abrangente de informações contextuais. Para contornar algumas das limitações dos modelos em uso atualmente, será considerada a abordagem adotada por Goularte (2003), que será apresentado na Seção 2.4.

\subsection{Protótipo de TV interativa}

O Projeto de TV interativa TV-I tem como objetivo o desenvolvimento de um protótipo no qual usuários podem interagir com vídeos distribuídos a partir de uma variedade de sistemas, como transmissão terrestre, streaming em redes cabeadas ou sem fio e via redes de telefonia celular. Entre as características do projeto estão a utilização de padrões como MPEG-4 e MPEG-7 no auxílio à personalização de conteúdo de acordo com as preferências do usuário, características dos dispositivos de acesso e condições do sistema (Faria et al., 2001).

Com a necessidade de adição de características de mobilidade e ciência de contexto para o protótipo, novas pesquisas foram desenvolvidas para adicionar tais requisitos. Desenvolvido cooperativamente com o trabalho de Goularte (2003), o trabalho de Santos (2004) e esta pesquisa visam adicionar capacidades de ciência de contexto e de gerenciamento de segurança ao protótipo de TV interativa. Na seção a seguir será inicialmente apresentada a arquitetura do protótipo (Seção 2.4.1). Nas seções seguintes, serão detalhadas sua representação de contexto (Seção 2.4.2) e o módulo de gerenciamento de contexto (Seção 2.4.3).

\subsubsection{Arquitetura}

A arquitetura do protótipo de TV interativa modelada por Goularte (2003) (ilustrada na Figura 5.7) já previa o suporte à descrição de mídias e ciência de contexto em seu trabalho. Tal arquitetura está atualmente dividida em serviços para objetos multimídia e de suas descrições (respectivamente Servidor de Objetos Multimídia (SOM) e um Servidor de Descrições Multimídia (SDM)), além de um Gerenciador de Serviços que atua como interface entre alguns de seus serviços, para gerenciamento de contexto (Santos, 2004) e de segurança, por exemplo.

Neste trabalho, será adotada somente a representação de contexto do protótipo do projeto TV-I. Para a implementação do Gerente de Segurança, que é a validação do trabalho em questão, será utilizado como suporte o trabalho de (Santos, 2004), que implementou o Gerente de Contexto no mesmo projeto. 


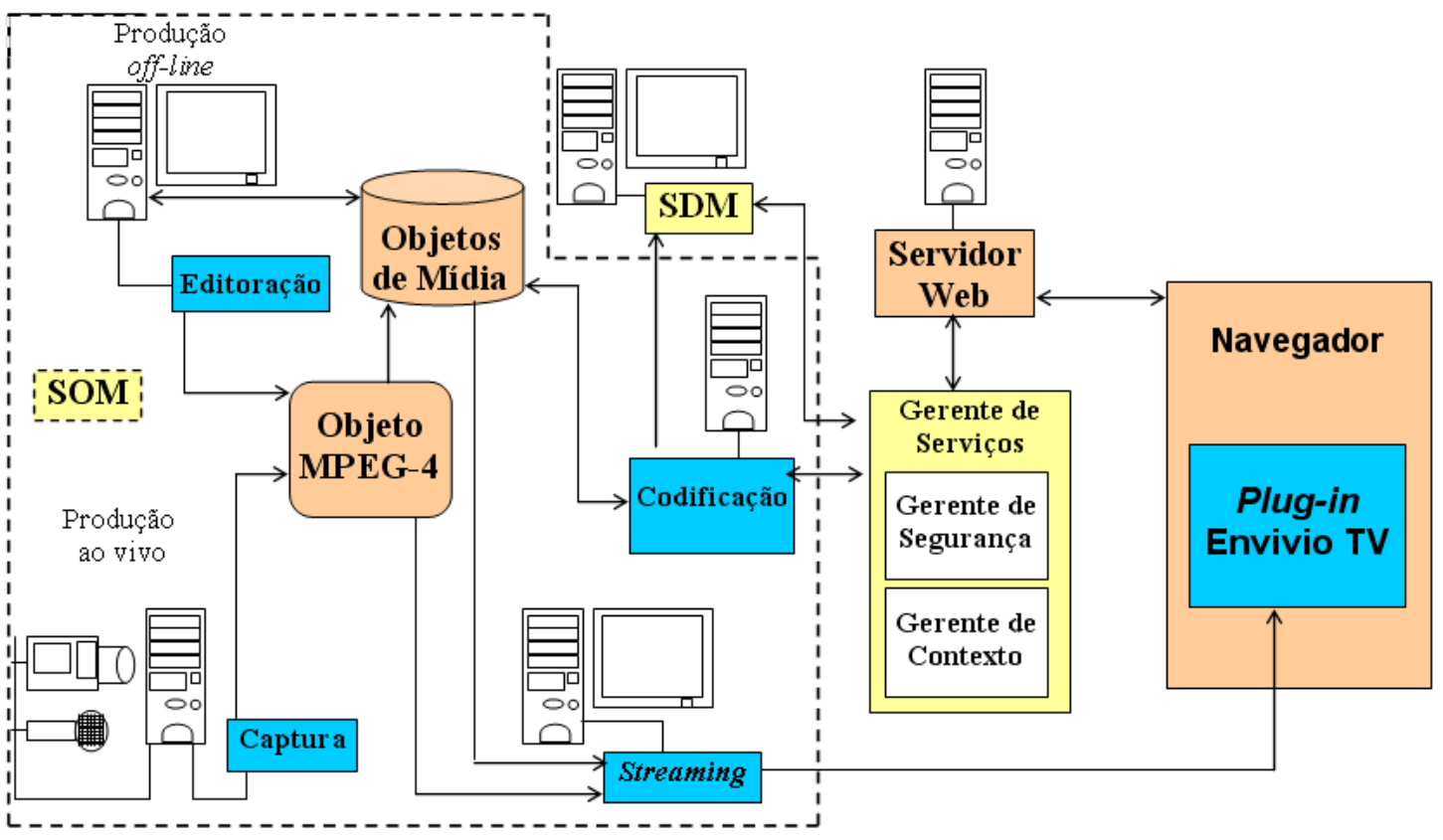

Figura 2.5: Modelo resumido da arquitetura do protótipo TV-I (Goularte, 2003).

O detalhamento do protótipo do projeto TV-I está fora do escopo deste trabalho. Para informações detalhadas sobre esse projeto, a principal referência é Goularte (2003).

\subsubsection{Representação de contexto}

Para contornar as limitações das representações de contexto encontradas na literatura, como destacado na Seção 2.3.5, Goularte (2003) classificou as informações contextuais e as utilizou para o gerenciamento de interações entre elementos móveis. O pesquisador também levanta questões de vantagens em relação aos trabalhos ao dele relacionados, por exemplo, em casos de ambientes que permitem a seus usuários definirem preferências em determinados serviços.

Os trabalhos que provêem suporte às aplicações cientes de contexto mencionados na Seção 2.3.1, por exemplo, exploram a representação de contexto. No entanto, esses trabalhos apresentam limitações em suas representações de contexto, como carência de flexibilidade para o compartilhamento dessas informações entre as aplicações e falta de estruturação das informações de contexto.

Segundo Goularte (2003), a definição de Dey (2000) é limitada por restringir as informações contextuais a interações entre usuários e aplicações. Santos Júnior (2002) já destacava em seu trabalho a necessidade do conhecimento de um conjunto de informações contextuais mais rico, incluindo informações do estado da rede de comunicação, informações de interações entre aplicações 
e o sistema ciente de contexto e também informações do contexto do usuário (Santos Júnior et al., 2001). Goularte (2003), por sua vez, adiciona novas características ao trabalho de Santos Júnior (2002), definindo contexto como "qualquer informação que possa ser usada para caracterizar a situação de uma entidade. Uma entidade é uma pessoa, lugar ou objeto fisico ou software que é considerado relevante para a interação entre um usuário e uma aplicação e/ou entre uma aplicação e o sistema, incluindo usuário, aplicação e sistema em si".

Considerando a definição de Goularte (2003) e as definições apresentadas na Seção 2.3.2, os tipos de contextos são classificados então como: InfraEstrutura, Sistema, Usuário, Aplicação, Domínio e Ambiente. A representação de contexto de Goularte (2003) é formada por um Elemento Raiz chamado Context, por Tipos de Contexto e pelo Contexto Primário. O Elemento Raiz encapsula toda a hierarquia de representação de contexto. Já os Tipos de Contexto compõem o contexto do Usuário, da Infra-Estrutura, da Aplicação e do Sistema. A abordagem dos contextos da Aplicação e do Sistema serão temas de trabalhos futuros. O contexto de Infra-Estrutura é o conjunto formado pelos contextos de dispositivos e de rede. Por fim, o Contexto Primário é responsável pela caracterização das entidades contextuais. Por meio do contexto primário, Goularte (2003) representa tipos de informações contextuais classificadas na literatura como mais relevantes: informações de localização, identidade, atividade e tempo (Schilit et al., 1994; Brown et al., 1997; Abowd et al., 1999; Dey, 2001). Demais detalhes sobre o gerenciamento de contexto no projeto TV-I serão apresentados na Seção 2.4.3.

Goularte (2003) adota a construção de esquemas de descrição por meio de padrões para representação, como XML Schema (Bates, 2003). O objetivo é fornecer uma biblioteca extensivel de elementos contextuais estruturados, pois devido à variação das informações contextuais de aplicação para aplicação, torna-se impossível abranger todas as possibilidades de uso de contexto. Assim, a representação contextual utilizada deve ser capaz de prover subsídios aos desenvolvedores de aplicações cientes de contexto para que seja possível a criação de representações contextuais próprias, caso haja necessidade.

Na Figura 2.6 é apresentada uma instância de representação de contexto de usuário. O Elemento Raiz < Context $>$ encapsula a representação (linhas 1 e 21). Os elementos $\langle$ Users $>$ e $<$ User $>$ evidenciam o Tipo de Contexto, nesse caso, o contexto do Usuário. Na seqüência o Contexto Primário é apresentado, formado pelos elementos que representam as informações contextuais de identidade (elemento <Identity>, linhas 4 e 10), localização (elemento <Location>, linhas 11 e 14) e tempo (elemento <Time>, linhas 15 e 18). É importante esclarecer que a presença de todas as informações consideradas de contexto primário não é obrigatória no modelo de representação de contexto 
$1<$ Context xmlns:context="http://www. in stitutoayrtonsenna. com. br/Context/" ... >

$<$ Users>

$<$ User >

<Identity xsi :type="WhoType" ID=" funcionario-01" >

$<$ Name $>$

$<$ GivenName >Ayrton</Given Name>

$</$ Name $>$

$<$ Role>analista $</$ Role $>$

$</$ ldentity $>$

$<$ Location xsi :type="WhereType" >

$<$ LocationName>Interlagos</Location Name>

$<$ LocationDescription>dependências da empresa</Location Description> $<$ /Location $>$

< Time xsi:type="context:When Type" >

<Date>2004-03-18</Date>

$<$ Time $>08: 00-22: 00</$ Time $>$

$</$ User $>$

$</$ Users $>$

$</$ Context $>$

Figura 2.6: Exemplo de representação de contexto de usuário.

(Goularte, 2003).

Esses elementos que formam o Contexto Primário são compostos por outros elementos, os quais foram classificados previamente nas devidas categorias. Por exemplo, o elemento de contexto primário <Identity > é composto pelos elementos <Name> (linhas 5 e 8) e $<$ Role $>$ (linha 9). O elemento $<$ Name $>$, por sua vez, é composto pelos elementos <GivenName $>$ e $<$ FamilyName $>$ (linhas 6 e 7). Por meio dessa representação contextual, pode-se concluir que o usuário (Who) Ayrton Senna, analista (identidade), está (Where) nas dependências da empresa Interlagos (localização), num dado momento (When), no caso, no dia 26 de maio de 2004, às 8 h00 (tempo). Este trabalho é baseado no modelo de representação descrito nesta seção para abordar contexto. Maiores detalhes sobre a representação de contexto utilizada podem ser encontrados em Goularte (2003).

\subsubsection{Gerenciamento de informações de contexto}

Com o desenvolvimento do projeto de TV interativa, houve a necessidade de adição de características de adaptação de distribuição multimídia para corresponder às necessidades dinâmicas dos usuários, de suas aplicações e de suas respectivas infra-estruturas de rede, dispositivos e serviços. Devido ao grande número de informações contextuais que precisam ser capturadas, processadas e disponibilizadas aos serviços no mesmo projeto, foi desenvolvido paralelamente a este trabalho o protótipo de um módulo responsável por manipular essas informações denominado Gerente de Contexto (Santos, 2004).

O gerenciamento dessas informações de contexto é essencial para permitir a adaptação de conteúdo disponibilizado pelo protótipo de TV interativa. Essa adaptação pode ser feita considerando diversas variáveis como preferências 
dos usuários, características de suas aplicações de acesso e da infra-estrutura de comunicação.

As informações contextuais que são capturadas, processadas e distribuídas pelo sistema de gerenciamento de contexto do protótipo TV-I são divididas em três conjuntos principais: Informações de usuários, das Aplicações e da Infra-estrutura de Rede, Dispositivos e Serviços. Os tipos de informações contextuais de Domínio e Ambiente foram suprimidos da representação de Goularte (2003), apesar de estarem presentes na sua classificação original, já que os trabalhos baseados no TV-I em desenvolvimento não possuem objetivos de explorar tais tipos de informações contextuais. Na Figura 2.7 são ilustrados os componentes de contexto utilizados no presente trabalho.

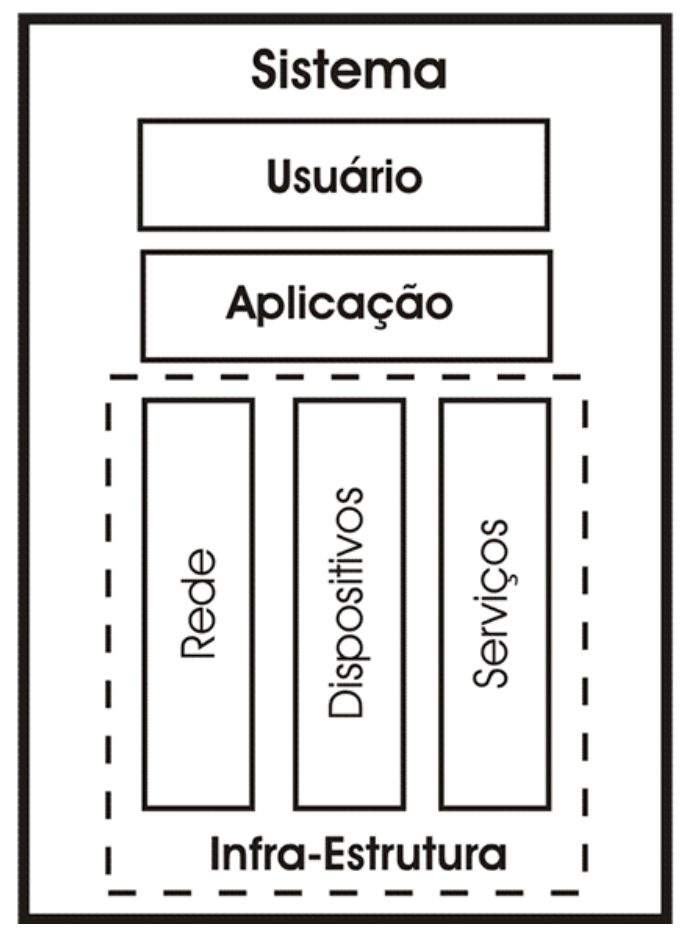

Figura 2.7: Diagrama representando os componentes do contexto do Sistema (Goularte, 2003).

O sistema ciente de contexto ilustrado na Figura 2.7 é composto por elementos classificados como usuários, aplicações e a infra-estrutura de rede, dispositivos e serviços. Os usuários das aplicações dessa natureza utilizam dispositivos que, por sua vez, executam aplicações na infra-estrutura disponível. A infra-estrutura em questão disponibiliza o acesso à rede de comunicação, aos dispositivos cientes de contexto e aos serviços.

\subsection{Considerações finais}

Neste capítulo foram apresentados os conceitos de computação ubíqua que são necessários para a execução deste trabalho. Foram apresentadas as áreas 
de pesquisa em computação ubíqua, com destaque para as pesquisas em ciência de contexto. Em seguida foi apresentado o projeto de TV interativa TV-I, do qual foi destacado o modelo de contexto que está sendo utilizado neste trabalho.

É possivel perceber que a área de pesquisa dentro da computação ubíqua definida para este projeto - a ciência de contexto - tem como alvo a representação de informações de contexto de qualquer tipo de sistema, neste caso, de um sistema computacional com segurança baseada em informações de contexto.

Nos capítulos seguintes serão apresentados os conceitos de segurança computacional e pesquisas desenvolvidas em projetos relacionados a computação ubíqua, para em seguida ser apresentado o sistema de gerenciamento de segurança baseado em informações de contexto. 


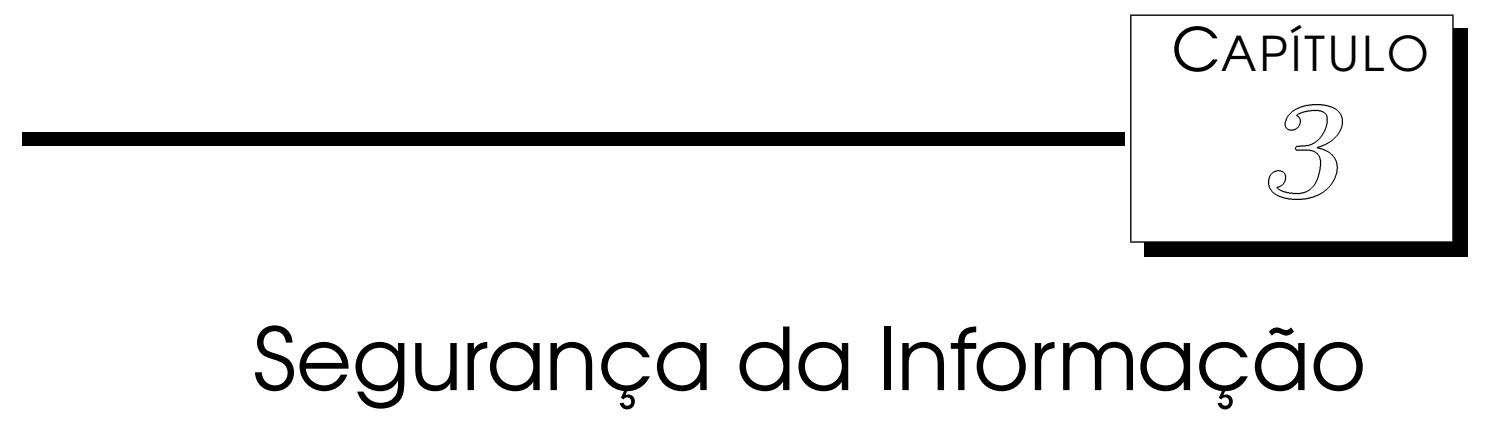

om as previsões e balanços ao fim de cada ano, as publicações especializadas em tecnologia destacam, com ênfase cada vez maior, os riscos contra o maior dos patrimônio das organizações: a informação. Paralelamente, profissionais de segurança da informação utilizam diversas maneiras para avaliarem sistemas e metodologias que visam reduzir os riscos iminentes em suas infra-estruturas de tecnologia da informação e comunicação.

Nas seções a seguir serão apresentados os resultados de algumas pesquisas recentes, no Brasil e no exterior, que justificam os crescentes investimentos em segurança da informação (Seção 3.1). Posteriormente serão explanados os principais conceitos de segurança (Seção 3.2) aplicados nesse trabalho. Finalmente serão apresentados alguns conceitos relacionados à segurança em computação ubíqua (Seção 3.3) e trabalhos relacionados a este e serão apresentadas também as considerações finais desse capítulo (Seção 3.4).

\section{1 Pesquisas em segurança da informação}

Diversas pesquisas do cenário de segurança da informação foram compiladas durante o ano de 2003 e início do ano de 2004. Dentre elas, foram escolhidas três pesquisas relevantes para ilustrar o cenário atual nessa área. A primeira - 2003 CSI/FBI Computer Crime and Security Survey - foi realizada entre empresas dos Estados Unidos pelo Instituto de Segurança Computacional CSI (Computer Security Institute) ${ }^{1}$ e a Agência Federal de Inteligência

\footnotetext{
${ }^{1}$ http://www.gocsi.com/
} 
FBI (Federal Bureau of Investigation) ${ }^{2}$, ambas instituições norte-americanas (Richardson, 2003) $^{3}$. A segunda - Pesquisa Nacional de Segurança da Informação - foi realizada entre empresas brasileiras pela Módulo Security (2003) ${ }^{4}$ enquanto a terceira pesquisa, The State of IT Security 2003, realizada pela CIO Magazine ${ }^{5}$ em parceria com a PricewaterhouseCoopers ${ }^{6}$, abrangeu 54 países e mais de 7500 entrevistados (Berinato, 2003).

Exemplos recentes do aumento de investimentos na área de segurança podem ser extraídos da pesquisa do Computer Security Institute. Segundo Richardson (2003), a grande maioria das organizações entrevistadas afirmou possuir firewalls (98\%) e controle contra vírus (99\%). É crescente também, em relação aos anos anteriores da pesquisa, a porcentagem de uso de controles para acesso físico (91\%). Apesar de serem resultados positivos em relação aos anos anteriores, ainda há uma fatia considerável de entrevistados (15\%) que afirmaram sequer saberem, por exemplo, se a empresa foi alvo de tentativa bem sucedida ou não de um ataque durante o ano de 2002. Os maiores prejuízos, segundo a pesquisa norte-americana, estão concentrados nas ameaças de roubo de propriedade intelectual e negação de serviço, como é destacado na Figura 3.1.

Segundo a pesquisa da Módulo Security (2003), 35\% das empresas entrevistadas reconheceram que tiveram perdas financeiras devido a alguma violação de segurança durante o ano de 2003. Apesar disso, 65\% das empresas entrevistadas ainda não conseguem quantificar o valor dos prejuízos causados pelos problemas com a segurança de suas informações. Um quinto das organizações entrevistadas que contabilizaram os valores do prejuízo em decorrência de incidentes de segurança avaliaram tais perdas em até um milhão de reais.

Além dos prejuízos crescentes devido a ataques bem sucedidos, na pesquisa divulgada pela CIO Magazine, é destacada a maneira incipiente como é tratada a segurança da informação nas empresas entrevistadas. Segundo Berinato (2003), apesar dos especialistas pregarem o gerenciamento de risco em tecnologia da informação e a gestão de segurança pró-ativa, a implementação de processos de segurança ainda é baseada nas exigências governamentais e de mercado e na cultura popularmente conhecida como FUD (do inglês "fear, uncertainty and doubt", que em português é traduzido por "medo, incerteza e dúvida”) (Duffy, 2003).

Com a análise de alguns resultados das pesquisas apresentadas nessa se-

\footnotetext{
2 http://www.fbi.gov/

3 Somente no período de conclusão deste trabalho foi lançada a edição 2004 da pesquisa do CSI/FBI e por essa razão, essa referência não foi incluída no trabalho.

4 http: //www . modulo.com.br/

5 http: //www.cio.com/

6 http://www.pwc.com/
} 


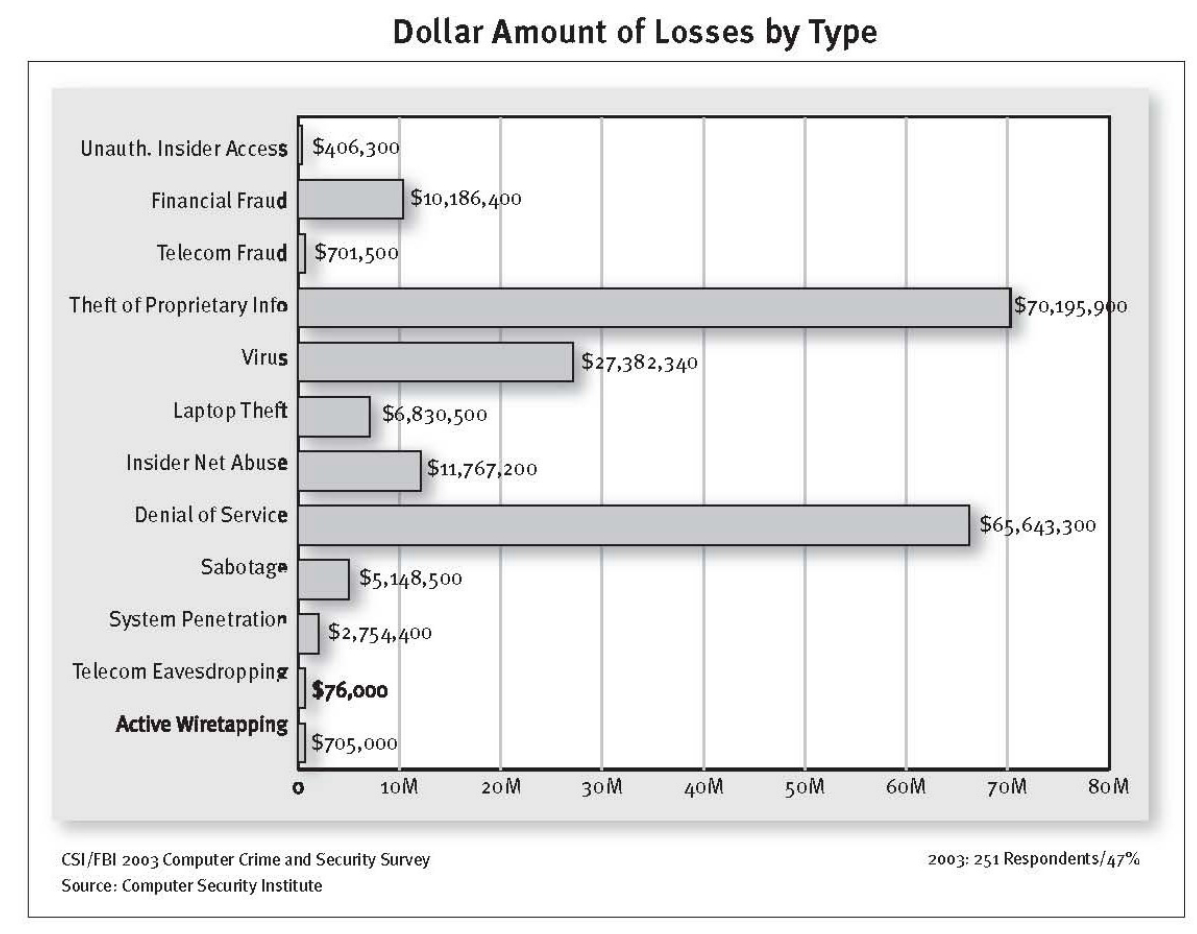

Figura 3.1: Prejuízos devido a incidentes de segurança nos EUA por categorias (em US\$) (Berinato, 2003).

ção, é possível confirmar a necessidade crescente de investimentos em segurança da informação. Esses estudos apresentam o panorama atual do mercado, no qual a segurança da informação deve ser vista como um requisito e não mais como um diferencial de negócios.

Este trabalho pretende atuar em algumas frentes de pesquisas em segurança com objetivo de diminuir riscos de aplicações em computação ubíqua interativa, em especial, utilizando técnicas de ciência de contexto. Na Seção 3.2 serão apresentados os conceitos técnicos de segurança da informação que serviram de base para o desenvolvimento deste trabalho.

\subsection{Conceitos de segurança da informação}

Os três conceitos principais que caracterizam a segurança da informação são resumidos pela sigla CIA (do inglês "Confidentiality, Integrity and Availability", que em português é traduzida para "confidencialidade, integridade e disponibilidade") ${ }^{7}$. Não há uma unanimidade na definição dos conceitos de privacidade, integridade e disponibilidade e, portanto, as definições apresentadas a seguir não devem ser consideradas definitivas e podem passar por adaptações dependendo da literatura consultada. Segundo o padrão ABNT (2001) NBR ISO/IEC 17799 de gestão de segurança da informação, os três

\footnotetext{
7 Confidencialidade: segundo Houaiss et al. (2001), qualidade do que é confidencial. Para fins deste trabalho, confidencialidade e privacidade serão usados indistintamente.
} 
conceitos principais que definem segurança são os seguintes:

Privacidade: consiste na proteção contra leitura ou cópia de informação por quem não está explicitamente autorizado pelo seu proprietário. Essa proteção deve incluir as informações de propriedade do usuário bem como as geradas em razão do uso de algum sistema e que possam permitir a inferência de informações confidenciais, por exemplo, registros de acesso ou identificações de estações de trabalho. Sigilo e confidencialidade são sinônimos de privacidade. Devido a este ser o requisito de segurança principal que será tratado neste trabalho, o Capítulo 4 foi dedicado para privacidade;

Integridade: proteção de qualquer informação ou sistema contra remoção ou alteração de qualquer espécie sem a permissão explícita de seu proprietário. Dentre as informações a serem protegidas podem constar desde o nome e a identificação de um usuário até, por exemplo, arquivos de sua propriedade com suas datas de criação e última edição;

Disponibilidade: proteção de qualquer serviço ou sistema contra degradação ou não disponibilidade sem autorização. Há casos onde a disponibilidade de informação deve ser considerada vital, por exemplo, em sistemas de tempo real ou de varejo on-line.

Há conceitos adicionais que, em conjunto com a tríade privacidade, integridade e disponibilidade, permitem a definição de regras claras para um sistema computacional seguro - uma política de segurança. Segundo Garfinkel et al. (2003), outros conceitos que complementam segurança da informação são:

Consistência: a certificação de que um sistema se comporta como é esperado por seus usuários autorizados é garantia de sua consistência. Geralmente, consistência pode ser um conceito complementar à integridade;

Controle: consiste em regular acesso a um sistema ou informação. A premissa de controle de acesso deve consistir em regras de acesso de usuários autorizados a informação ou a um sistema computacional e podem possuir capacidade de garantir a irretratabilidade de usuários que executaram alguma ação no sistema. A autenticação é o processo pelo qual um usuário prova sua identidade e está ligado diretamente com controle de acesso. A autenticidade é um conceito comumente confundido com o conceito de integridade e consiste na propriedade de algo genuíno, de confiança. O resultado de uma assinatura digital em um arquivo ou programa garante a sua autenticidade, no entanto, não garante que esse não possua objetivos contra a integridade; 
Auditoria: da mesma forma que um controle deve ser feito para evitar acesso não autorizado a um sistema, deve ser feito também um controle de ações de usuários autorizados. Controles de auditoria devem permitir a criação de históricos de acessos válidos para, eventualmente, verificação de atividades irregulares executadas por usuários devidamente autorizados.

É importante destacar que, além da tríade CIA citada anteriormente, tais conceitos adicionais de segurança da informação podem ser referenciados por outra tríade, a AAA (do inglês "Authentication, Authorization and Accountability”, que em português é traduzida para autenticação, autorização e auditoria).

\subsection{Segurança em computação ubíqua}

Apesar da computação ubíqua ser uma área de pesquisa com mais de uma década de desenvolvimento, os aspectos de segurança e privacidade em sistemas dessa natureza têm sido pouco investigados.

Segundo Schneier (1996), durante alguns anos, a criptografia e a garantia de integridade de dados foram consideradas premissas para a segurança de um sistema computacional. Com a evolução dos sistemas computacionais interligados por redes, o surgimento de novas necessidades e a conseqüente evolução de paradigmas em segurança computacional (Schneier, 2000), novas ameaças à informação passaram a acompanhar a necessidade primária de garantia de integridade.

Atualmente, as pesquisas em desenvolvimento em computação ubíqua focam nas questões de construção de infra-estruturas, conexão em redes perenes (ad hoc) ou criação de aplicações para explorarem as novas funcionalidades dos ambientes ubíquos. No entanto, as questões de segurança não têm sido tratadas e, segundo pesquisadores da área de computação ubíqua, essas questões no novo paradigma computacional já são problemáticas.

Nessa seção serão descritas algumas das principais considerações de segurança e privacidade levantadas para sistemas que façam uso das interações classificadas para sistemas em computação ubíqua: aplicações cientes de contexto, interfaces naturais e captura e acesso de atividades humanas (Abowd e Mynatt, 2000).

\subsubsection{Trabalhos relacionados}

Há diversos trabalhos relacionados visando apresentar novos meios de garantir a segurança de usuários e sistemas ubíquos. Algumas pesquisas em desenvolvimento nas áreas relacionadas foram analisadas e a seguir serão 
destacados os trabalhos considerados relevantes e relacionados com os requisitos deste trabalho.

A primeira área de pesquisas relacionada com o trabalho trata de gerenciamento de propriedade intelectual e comércio de conteúdo digital. Koenen (2001) apresenta os esforços do grupo de pesquisas MPEG (Motion Picture Experts Group ${ }^{8}$ na definição de padrões multimídia com características de gerenciamento de propriedade intelectual e proteção de sinais de áudio e vídeo. No padrão MPEG-2, por exemplo, são apresentadas soluções de codificação diferenciada de parte do sinal e troca de mensagens de controle de forma criptografada para controle de acesso (ECM - Encryption Control Message e EMM - Encryption Management Message).

Apesar de não serem tema freqüente de pesquisas na área de computação ubíqua, as considerações de privacidade, uma das principais preocupações em segurança, já são analisadas por alguns pesquisadores. Langheinrich (2001), por exemplo, alerta para o contínuo desenvolvimento de pesquisas nas áreas de computação ubíqua sem as definições de requisitos de privacidade, enquanto Stajano (2002) destaca que mesmo as vulnerabilidades mais simples, que já possuem contra-medidas nos paradigmas tradicionais de segurança, estão sendo exploradas facilmente em sistemas ubíquos inseguros.

Diversos trabalhos também tratam do equilíbrio entre personalização de serviços on-line e riscos à segurança e privacidade pessoal. Ralph e Searby (2004) dedicaram um livro para descrever os principais desafios e pesquisas nas áreas de serviços baseados em localização (LBS ou Location-Based Services), privacidade em serviços de personalização automática de conteúdo, serviços emergenciais de localização pessoal, publicidade personalizada, personalização de serviços on-line e mineração de dados, entre outras considerações.

Kagal et al. (2002) admitem também que estratégias para segurança e privacidade em sistemas ubíquos exigem desafios adicionais, pois os mesmos recursos que podem facilitar a interação entre humano e máquina podem potencializar as ameaças.

Nas seções a seguir serão apresentados alguns dos principais conceitos de segurança relacionados a computação ubíqua e as principais pesquisas em desenvolvimento envolvendo considerações de segurança e privacidade com ubiqüidade.

\section{Integridade e controle}

A integridade e o controle são alguns dos requisitos que devem ser garantidos para que um sistema de natureza ubíqua possa estar em conformidade

\footnotetext{
8 http://mpeg.telecomitalialab.com/
} 
com um nível de risco aceitável. A garantia de integridade das mensagens e o controle de acesso e autenticação das partes que se comunicam em um sistema computacional, especialmente em sistemas ubíquos, é uma tarefa difícil. Há novas condições que devem ser consideradas na segurança de sistemas desta natureza, por exemplo, a ausência de servidores centralizados para autenticação.

A primeira opção nesses casos é a adoção de criptografia por par de chaves ou de chaves públicas (Garfinkel et al., 2003). Dessa forma, cada entidade móvel e independente deverá possuir uma chave pública assinada por uma autoridade certificadora e que não necessariamente precisará estar on-line para garantir a autenticação de cada elemento do sistema. Apesar de ser um método de criptografia e assinatura digital que também garante o controle de acesso e a irretratabilidade de ações das partes em comunicação, alguns problemas devem ser tratados.

Segundo Stajano (2002), um dos problemas do uso de par de chaves criptográficas em computação ubíqua é a ausência de uma entidade central e confiável que garanta a validade das identificações das entidades clientes. Em intervalos de tempo entre a revogação e a emissão de um novo certificado (ou a sua negação), entidades mal intencionadas podem usar a identificação por certificados antigos para atividades teoricamente autênticas (Figura 3.2).

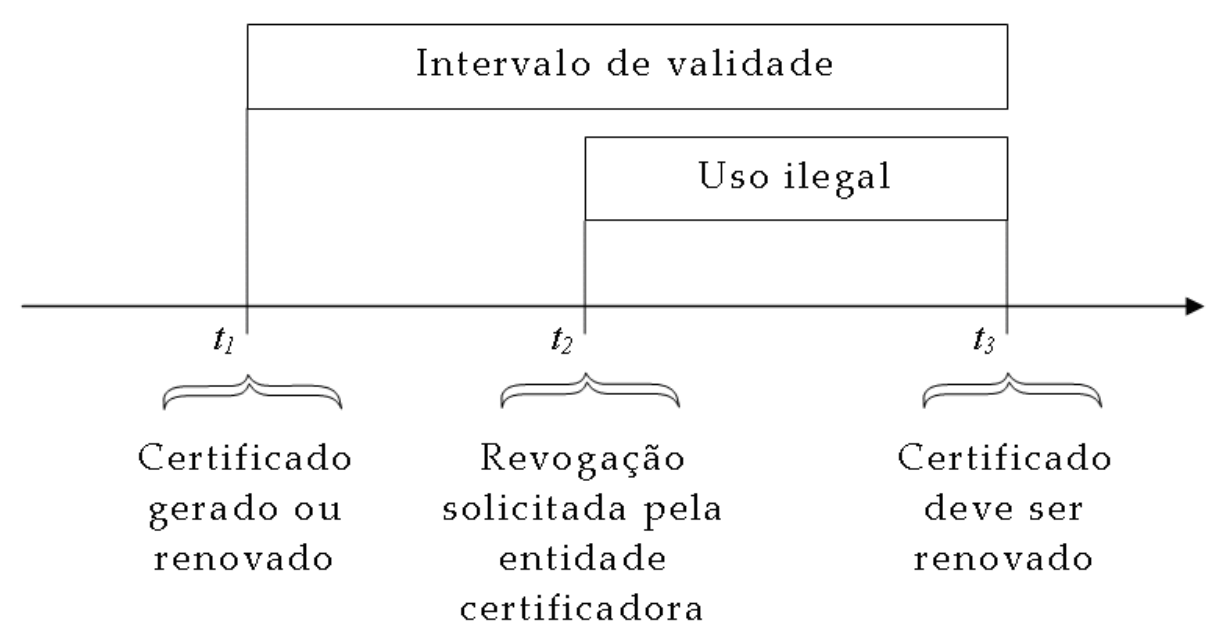

Figura 3.2: O período de validade de um certificado digital.

Uma solução para este problema é diminuir o prazo de validade dos certificados para um nível de risco aceitável. Deve ser observado também que, nessa solução, as entidades ubíquas devem possuir relógios sincronizados, o que adiciona outro item para processamento. Um equilíbrio entre o gasto em processamento na geração de novos certificados, sincronização dos relógios e o nível de risco aceitável deve ser analisado para cada caso. 


\section{Privacidade}

Segundo Schneier (2000), há alguns anos vêm se desenvolvendo protocolos de criptografia que visam garantir, dentro de níveis de risco calculados, a segurança das informações durante o trajeto ou armazenamento. Assim, pode-se dizer que os protocolos de criptografia deixaram de ser o elo mais fraco em cadeias que visam garantir a segurança da informação (Stajano, 2001).

Em sistemas ubíquos e móveis, geralmente compostos de dispositivos de tamanho reduzido e de menor capacidade de processamento e armazenamento se comparados com computadores pessoais, há restrições, por exemplo, na complexidade que pode ser usada em algoritmos criptográficos. Além da garantia de sigilo de informações transmitidas, deve ser considerado o tratamento específico das informações que são armazenadas nos dispositivos portáteis.

Um sistema ubíquo deve estar ciente às preferências do usuário e sensível à sua presença, devendo servir ao usuário como um mordomo, reconhecendo informações sensíveis e mantendo-as em segredo. A seguir são apresentadas algumas ameaças a privacidade de usuários de sistemas ubíquos (Stajano, 2001):

- Se a computação ubíqua permite a tecnologia pervasiva e de forma transparente, cada vez mais atividades comuns devem então ser conduzidas através de dispositivos eletrônicos. Desta forma, será mais fácil coletar informações de comportamento e preferências de usuários, facilitando o dia-a-dia, bem como reduzindo a sua privacidade;

- Se sistemas ubíquos permitem que nossos ambientes sejam sensiveis e personalizados, um dos objetivos principais destes sistemas é obter o máximo de informações possível sobre nós e nossas preferências, o que pode ser crítico se não for bem controlado. Um exemplo desta característica pode ser observado na obra de Dick (1992) - The Minority Report quando o personagem John Anderton entra em um centro comercial e é recepcionado por sistemas que detectam sua presença e, de acordo com suas preferências, apresentam ofertas de produtos;

- A computação ubíqua adiciona a questão da escala de uso das informações. Se forem consideradas dados pessoais parciais que podem ser coletados em sistemas computacionais, geralmente não é possível inferir muito sobre tal pessoa, por exemplo, em contas de banco e operações com cartão de crédito. No entanto, se houver uma integração entre esses sistemas, com objetivo de criação de um sistema ubíquo, grande parte da informação que precisaria ser inferida em sistemas não monolíticos já estará disponível; 
- Não será incomum o uso de tecnologias criadas originalmente para um uso aceitável de forma ilegal, como por exemplo, para espionagem ou mensagens não solicitadas - spam.

\subsection{Considerações finais}

O Gerente de Segurança em questão possui integração com informações de contexto do sistema TV-I e as estrutura de forma a permitir seu uso em um sistema integrado de proteção à privacidade. Foram apresentados diversos trabalhos relacionados a este que visam tratar os requisitos de segurança.

Pôde-se perceber que dentre as maiores ameaças, o acesso não autorizado a informações pessoais - violação de privacidade - mostrou-se o de maior preocupação. No Capítulo 4 serão apresentados os conceitos relacionados a privacidade em maior detalhe, bem como estratégias de controle de exposição de informações pessoais. 


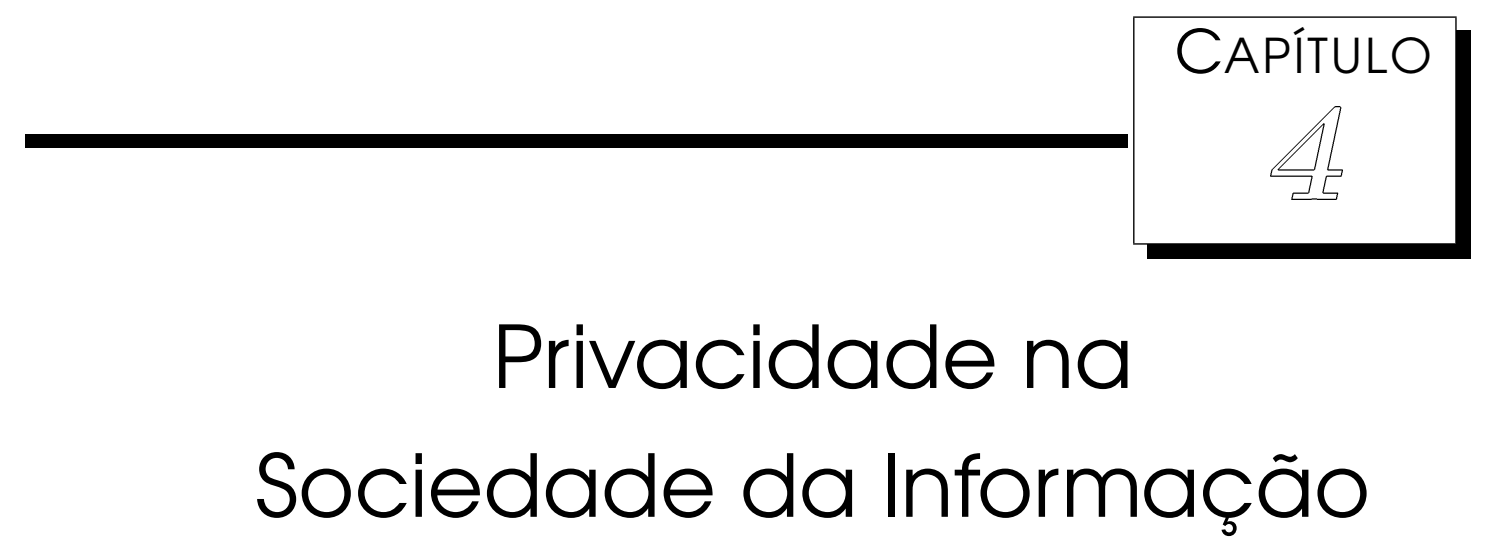

$\mathcal{A}$ privacidade ou sigilo é uma preocupação antiga, principalmente, de cientistas sociais, filósofos e advogados. Com o desenvolvimento de soluções de tecnologia da informação e de comunicação, as ameaças à privacidade pessoal aumentaram, especialmente no escopo do que se convencionou chamar Sociedade da Informação.

O uso de informações pessoais pode ser considerado desde benéfico em algumas situações até criminoso em outras, dependendo de suas aplicações e do ponto de vista. Exemplos recentes incluem os serviços de rede de relacionamentos Orkut ${ }^{1}$ e de e-mail Gmail ${ }^{2}$, ambos de propriedade da Google Inc ${ }^{3}$ e que possuem políticas de privacidade consideradas invasivas por entidades como a EPIC (Electronic Privacy Information Center) ${ }^{4}$.

Apesar do direito à privacidade ser reconhecido pela Declaração Universal dos Direitos Humanos das Nações Unidas, constituições nacionais, tratados regionais e códigos de ética profissional, a sua garantia deve ser um requisito na sociedade da informação. Segundo Fischer-Hübner (2001), a proteção da privacidade pode ser feita de algumas formas:

- Leis de proteção de dados e privacidade sancionadas pelos governos;

- Controle de práticas de acesso a informações através de códigos profissionais de conduta;

\footnotetext{
${ }^{1}$ http://www.orkut.com/about.html

2 http://gmail.google.com/gmail/help/about.html

3 http://www.google.com/about.html

4 http://www.epic.org/privacy/gmail/agltr5.3.04.html
} 
- Uso de tecnologias de controle de privacidade pessoal;

- Conscientização de consumidores e profissionais de tecnologia da informação e comunicação com relação à privacidade.

Nas seções a seguir serão tratadas as questões relativas à privacidade no presente trabalho. Inicialmente, serão apresentados os conceitos de privacidade e proteção de dados (Seção 4.1), uma perspectiva histórica e legal de privacidade (Seção 4.2) e os princípios básicos para sua garantia (Seção 4.3). Em seguida serão discutidas as maiores ameaças à privacidade pessoal (Seção 4.4) e as principais tecnologias de controle de privacidade (Seção 4.5). Finalmente, serão apresentadas algumas considerações finais no encerramento deste capítulo (Seção 4.6).

\subsection{Conceitos de privacidade e proteção de dados}

A Internet e suas aplicações são geralmente vistas como ferramentas de acesso a informações por seus usuários. Paralelamente à facilidade que adiciona à vida de seus usuários em atividades que antigamente eram restritas a sistemas não conectados à rede, a Internet permite acesso quase irrestrito a informações pessoais de qualquer pessoa que já possua seus dados em sistemas on-line. A captura e o processamento de tais informações por aplicações que têm como objetivo a personalização e a adaptação de conteúdo on-line permitem serviços de melhor qualidade e eficiência, enquanto que o uso de informações pessoais para roubo de identidade e mineração de dados não são alternativas aceitas pelos usuários.

Por ser um conceito abstrato e relativo a opiniões pessoais e a contextos de aplicação, há diversas definições que podem ser aplicadas a privacidade e proteção de dados. Há situações, por exemplo, onde uma invasão de privacidade para uma pessoa pode não ser considerada uma invasão para outra. Assim, o conceito a ser adotado deve estar relacionado à diferenciação entre o que as pessoas podem ou não ver e conhecer (Elgesem, 1996). Para alguns usuários dos serviços da Google Inc., por exemplo, o acesso a informações pessoais é considerado benéfico (facilitando contatos ou personalizando anúncios) enquanto para outros, a disponibilização de tais informações é considerada invasão de privacidade. Na Figura 4.1 é destacado um modelo definido por Abelson et al. (1998) que ilustra o balanceamento que deve existir entre a privacidade e a necessidade de identificação de informações pessoais para uma personalização de serviços, caracterizando a natureza abstrata do conceito de privacidade pessoal. 


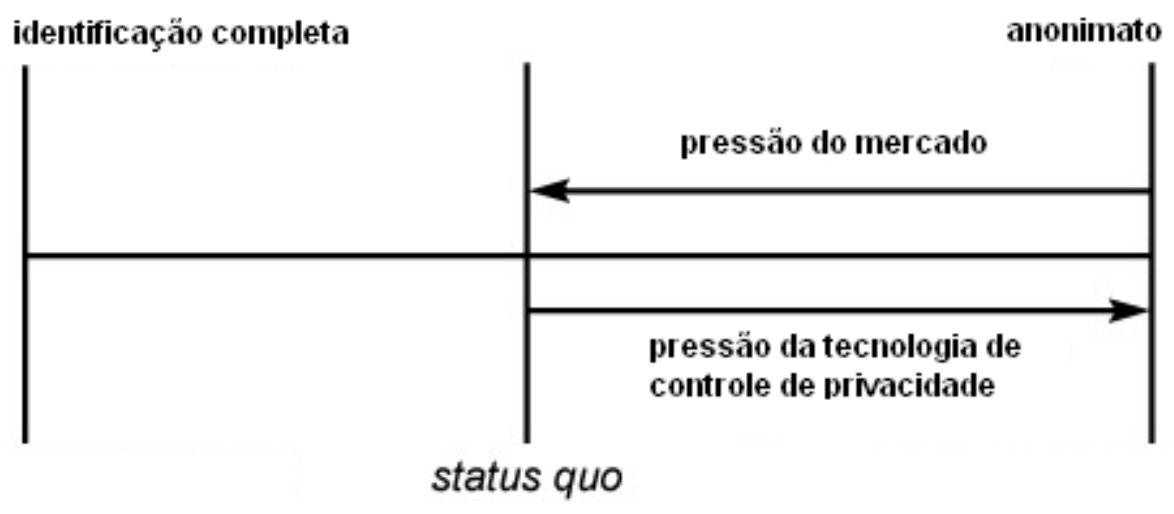

Figura 4.1: Balanceamento de privacidade para personalização (adaptação de Abelson et al. (1998)).

A primeira definição de privacidade data de 1890 no artigo The Right to Privacy, publicado na Harvard Law Review por Warren e Brandeis (1890). Os dois advogados norte-americanos definiram privacidade como "o direito de estar sozinho". Eles adicionaram ainda a regra para a limitação do direito a privacidade, quando ocorre a divulgação de informações pessoais pelo próprio indivíduo ou com seu consentimento.

Acompanhando o desenvolvimento tecnológico e a computação cada vez mais presente no cotidiano, as pessoas tendem a perder a privacidade de maneira proporcional a intensificação do uso da tecnologia. Exemplos de perda da privacidade na sociedade moderna incluem sistemas de vigilância e controle de acesso físico, compras efetuadas com cartão de crédito ou pagamento automatizado de pedágios.

O conceito mais comum de privacidade é apresentado por Westin (1987) professor emérito de legislação pública e governamental na Universidade de Colúmbia, nos Estados Unidos - como "a reinvindicação de indivíduos, grupos ou instituições de poderem determinar quanto, quando e como suas informações podem ser divulgadas a terceiros”.

Em geral, o conceito de privacidade ou sigilo pode ser dividido em três aspectos:

Territorial: proteção da área física próxima a uma pessoa, por exemplo, sua residência, trabalho ou áreas públicas;

Pessoal: proteção pessoal contra interferências em excesso, por exemplo, na realização de testes toxicológicos ou na violação de senso moral;

De informações: controle de condição e forma de acesso, armazenamento, processamento e disseminação de informações pessoais.

As informações pessoais são qualquer tipo de informação relativa às circunstâncias pessoais e materiais de uma pessoa identificada ou identificável. 
A proteção de dados é a proteção de privacidade pessoal e é somente uma parte do conceito global de privacidade.

\subsection{Perspectiva histórica e legal}

O interesse por privacidade e formas de garantia de sua proteção cresceu nas décadas de 60 e 70 com o advento de tecnologias da informação e o seu potencial para vigilância eletrônica. Com a necessidade de regulamentação de uso de informações pessoais, seja na forma eletrônica ou não, governos de diversos países realizaram esforços com objetivo de protegerem o direito de privacidade dos cidadãos.

Desde 2000, duas entidades — Eletronic Privacy Information Center (EPIC) ${ }^{5}$ e Privacy International ${ }^{6}$ - organizam um relatório periódico de análise da legislação internacional que trata de privacidade. Na edição de 2003 da pesquisa organizada (Laurant et al., 2003), foram avaliados 56 países e os resultados mais importantes são destacados a seguir :

- Na União Européia e Oceania há um rígido conjunto de leis que regula o acesso a informações pessoais. Em 1981 foi aprovada a Convenção 108 (Convention for the protection of individuals with regards to automatic processing of personal data) ${ }^{7}$ que trata de limitações de acesso a dados pessoais na coleta, processamento e armazenamento por membros do setor público ou privado;

- No continente africano, somente a África do Sul iniciou um processo de legislação para tratamento de privacidade pessoal;

- O artigo 43 da Constituição Argentina dá aos indivíduos o direito de saberem o conteúdo e o objetivo de todos os dados arquivados, a eles associados. Em novembro de 2000 foi aprovada também a "Lei para Proteção de Dados Pessoais";

- O Chile foi o primeiro país da américa latina a aprovar uma lei de proteção de dados, em 1999. Essa lei cobre os direitos das pessoas, quanto ao acesso, correção e controle de dados pessoais;

- O artigo quinto da Constituição brasileira de 1988 dá a todos os cidadãos o direito da privacidade. Em 1999, foi proposto um projeto de lei (PL 84/1999) de autoria do deputado Luiz Piauhylino que dispõe sobre

\footnotetext{
5 http://www.epic.org/

6 http: //www.privacyinternational.org/

7 http://www. conventions. coe.int/Treaty/en/Treaties/Html/108.htm
} 
os crimes de informação, dentre eles, os que incluem a coleta, processamento e distribuição de informação pessoal de forma ilegal;

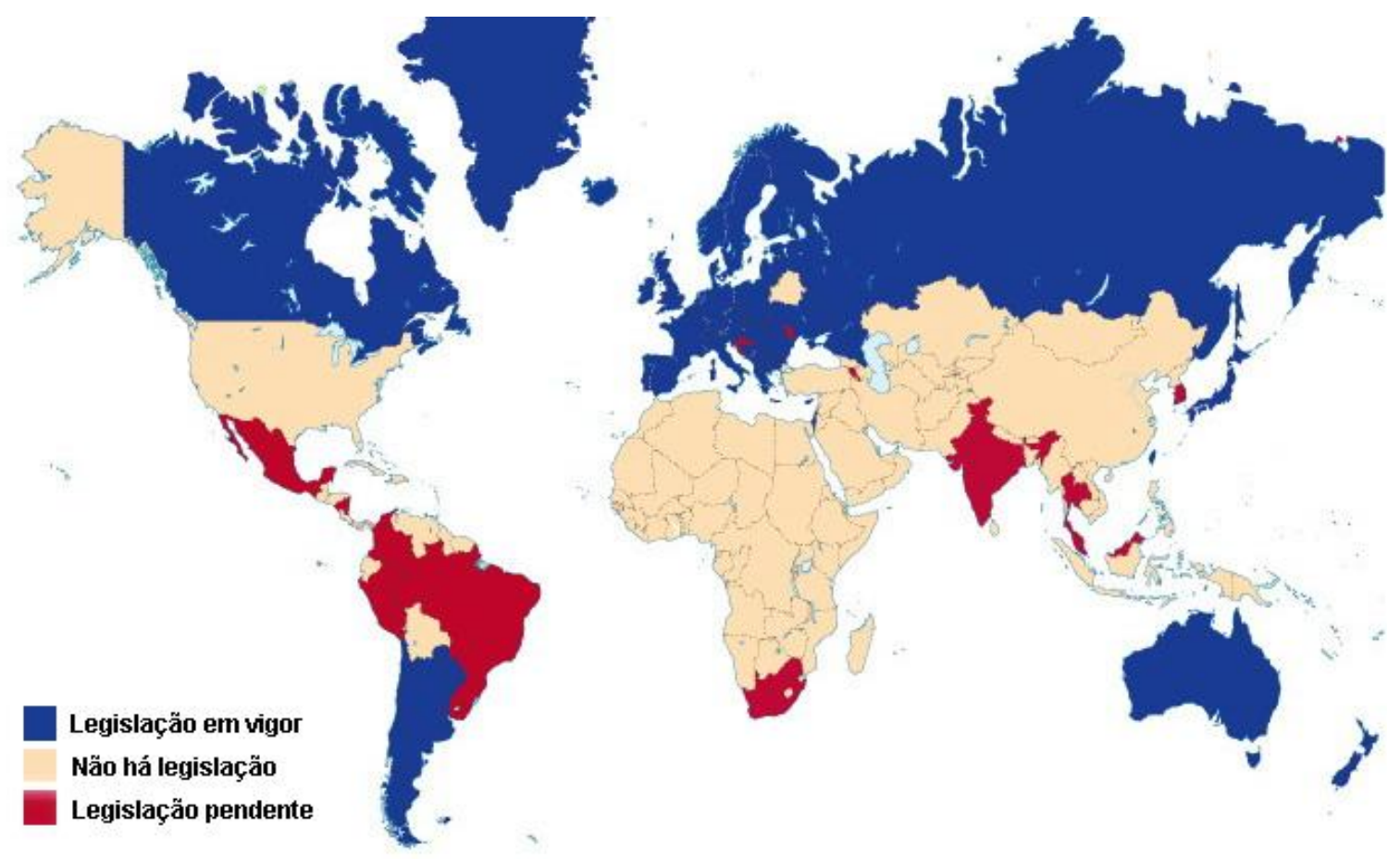

Figura 4.2: O mapa mundial das leis de proteção de privacidade (Laurant et al., 2003).

Há diversas outras leis, medidas provisórias e portarias relacionadas com tecnologia da informação, segurança e privacidade em vigor em diversos estados brasileiros, bem como na esfera federal ${ }^{8}$. No estado de São Paulo, por exemplo, há o Projeto de Lei 1692/03, que está na Comissão de Trabalho, de Administração e Serviço Público. A proposta pretende manter as mensagens de serviço em caráter público, com permissão de leitura por qualquer servidor, desde que autorizada por titular do órgão ou setor responsável pelo sistema. Já as mensagens pessoais serão de responsabilidade de seus autores e terão o tratamento de correspondência pessoal, sendo asseguradas a privacidade e a inviolabilidade. Segundo Tuma, o ambiente de trabalho deverá ser aberto e transparente e toda ação sujeita à fiscalização. Se o servidor desejar privacidade, deverá usar uma área apropriada, com endereço eletrônico diferenciado (Ravazzolli, 2004).

Nos Estados Unidos, desde 1996 o Health and Human Services Department ${ }^{9}$ (Departamento de Serviços Humanos e de Saúde) regula com o HIPAA (Health Insurance Portability and Accontability Act) ${ }^{10}$ o direito dos pacientes norte-americanos sobre o acesso às suas informações pessoais em registros

\footnotetext{
8 http://www.mct.gov.br/legis/tecnologia_informacao.htm

9 http://www.hhs.gov/

10 http://www.hhs.gov/ocr/hipaa/
} 
médicos. As diretrizes do HIPAA são utilizadas atualmente em diversos países como um guia inicial para tratamento de informações pessoais, seja de pacientes e médicos ou de usuários de diversos outros tipos de sistemas de informação (Beaver e Harold, 2004).

\subsection{Princípios básicos de privacidade}

Como a proteção de privacidade no âmbito legal geralmente não cruza fronteiras e não é integrada entre países, para proteger a privacidade de usuários de Internet e tecnologias de telecomunicação, surgiram propostas para regularizar essa proteção no âmbito internacional: a Organization for Economic Cooperation and Development (OECD) ${ }^{11}$ e a Federal Trade Commission (FTC) ${ }^{12}$.

O conjunto de princípios estabelecidos pela OECD em 1980 especifica de que forma os dados pessoais devem ser protegidos e são resumidos nessa seção (Ishitani, 2003; Fischer-Hübner, 2001; Cavoukian, 1998):

Principio da legalidade e justiça: informações pessoais devem ser coletadas e processadas de maneira legal e justa;

Princípio da limitação de finalidades: as razões pelas quais os dados pessoais são coletados e processados devem ser especificadas e legítimas, bem como o uso subsequente dessas informações, que deve ser feito com consentimento do sujeito dos dados ${ }^{13}$. Também conhecido como princípio do limite de coleta;

Princípio da necessidade de coleta e processamento de dados: a coleta e o processamento de dados pessoais deve ser permitida somente se eles forem necessários para execução de tarefas de responsabilidade de uma agência de processamento de dados ${ }^{14}$;

Informação e direito de acesso aos dados: os sujeitos cujas informações pessoais estejam sendo utilizadas possuem direito de serem informados sobre ações utilizando seus dados, bem como possuem direito de acesso para modificação ou remoção de dados inconsistentes ou ilegais a seu respeito;

Princípio da segurança e exatidão: mecanismos de segurança devem ser utilizados para garantir o sigilo, integridade e disponibilidade de dados pessoais, bem como eles devem ser mantidos exatos, relevantes e atualizados;

\footnotetext{
11 http://www.oecd.org/

12 http: / / www. ftc.gov/

13 Indivíduo ou organização que forneceu suas informações pessoais.

14 Entidade responsável por coletar e processar os dados sigilosos de terceiros.
} 
Princípio da partição individual: um indivíduo deve ter o direito de obter e pesquisar dados relativos a si mesmo;

Principio da transparência: deve haver uma política geral de divulgação sobre práticas e políticas com respeito a dados pessoais;

Supervisão e sanções: uma autoridade independente ${ }^{15}$ deve ser designada responsável pela supervisão do cumprimento da politica de privacidade $^{16}$. A autoridade interna da organização responsável por essas tarefas é denominada CPO (Chief Privacy Officer). Esse princípio também é conhecido como principio da responsabilidade.

De forma análoga à OECD, a Federal Trade Comission especifica os princípios para práticas de informação justas (Fair information practices), com foco em sites da Web (Pitofsky et al., 2000):

Informação: os sites devem informar aos usuários quais informações pessoais, de que forma e por quais razões elas são coletadas, bem como de que forma são disponibilizados os serviços descritos a seguir: escolha, acesso e segurança;

Escolha: os sites na Web devem disponibilizar meios para que os seus usuários optem pelas formas de uso das informações fornecidas, por exemplo, para envio de ofertas ou somente para manutenção dos serviços;

Acesso: os sites devem disponibilizar formas dos usuários acessarem suas informações pessoais, podendo atualizá-las ou removê-las;

Segurança: os sites devem utilizar recursos de proteção das informações pessoais coletadas de seus usuários.

É possivel observar que os esforços da OECD e da FTC visam reduzir ao máximo ou eliminar a coleta de informações pessoais. Conseqüentemente, sistemas de informação devem garantir, se possivel, que seus usuários ajam anonimamente (Fischer-Hübner, 2001).

Na Seção 4.4 seguinte serão descritas as principais categorias de ameaças à privacidade em sistemas de informação.

\footnotetext{
15 Também conhecida como autoridade supervisora, comissário de proteção de dados ou ouvidor (ombudsman).

${ }^{16}$ Conjunto de normas que visam garantir os princípios de privacidade.
} 


\subsection{Ameaças à privacidade}

Apesar de ser um direito conhecido e aplicado em grande parte da sociedade, aplicações que utilizam informações pessoais geralmente não disponibilizam recursos para controle contra ameaças a privacidade pessoal. O uso de ferramentas de tecnologia da informação - como as redes de computadores ou sistemas de vigilância e captura de informações pessoais - maximiza os malefícios que podem ser causados por mau uso dos privilégios de acesso a informações pessoais.

Segundo Elgesem (1996), há duas formas principais de ameaça à privacidade pessoal: a primeira delas consiste na divulgação de informações sem o consentimento de seu sujeito e a segunda é o uso não autorizado de informações pessoais para tomada de decisão em nome de outro.

Com a expansão das redes de computadores e a crescente quantidade de informações pessoais que nelas circulam, aumenta a preocupação dos usuários sobre a forma como são capturados, armazenados e processados seus dados pessoais. Segundo Wang et al. (1998), há preocupação dos usuários com relação à própria privacidade no uso da Internet como ferramenta de compra, devido à possibilidade de monitoramento de atividades sem consentimento ou aviso prévio. A preocupação se amplia quando as atividades não autorizadas passam a ser de análise de informações ou de comportamento, armazenamento de informações pessoais de forma insegura ou até mesmo transferência de tais informações a terceiros sem autorização prévia.

Como ainda não há confiança plena nas políticas de privacidade declaradas pelos prestadores de serviços on-line, as melhores metodologias de controle de privacidade são as executadas na perspectiva dos usuários. Nas seções a seguir serão explanadas as principais ameaças contra privacidade pessoal no uso da Internet, segundo Ishitani (2003).

\subsubsection{Informações em navegadores}

Os navegadores (browsers) Web, ao iniciarem uma conexão com um servidor que disponibiliza informações através do protocolo HTTP (Hypertext Transfer Protocol), podem enviar dois tipos principais de informações: informações de controle do navegador, sistema operacional e do usuário ou informações de aplicações em execução no servidor Web.

As informações de controle enviadas pelos navegadores Web geralmente são utilizadas por aplicações de análise de tráfego ou de comportamento de usuários que visitam o servidor. Algumas informações enviadas pelos navegadores são: sistema operacional do visitante, versão do navegador, endereço IP (Internet Protocol) e site Web que originou a conexão, por exemplo. 
As informações de aplicações em execução no servidor Web podem ser enviadas de maneiras mais seguras, por exemplo, utilizando SSL (Secure Sockets Layer) para envio de informações cifradas. A forma mais insegura de envio de informações por navegadores é através da URL (Uniform Resource Locator), com a criação de variáveis para envio de informações de forma dinâmica. Por meio da verificação dos históricos de navegação armazenados pelos navegadores, é possível, por exemplo, capturar informações pessoais como frases utilizadas em mecanismos de buscas, resultados de formulários submetidos ou identificações e senhas de acesso.

\subsubsection{Cookies}

Cookies são arquivos gerados por aplicações Web armazenados geralmente por navegadores, contendo informações de controle trocadas entre os clientes e servidores Web. Esses arquivos são usados para registrar informações de preferências de usuário, acessos a sites e informações referentes a uma sessão de uso, por exemplo, uma identificação de usuário ou as seções prediletas em uma loja on-line (Kabir, 2002).

Por armazenarem informações pessoais em formato texto, os cookies podem ser alvo de ataques para quebra de privacidade ou roubo de identidade, permitindo, por exemplo, que um atacante utilize informações de terceiros para efetuar compras em lojas na Web. Segundo Tulloch (2003), ataques baseados em informações de cookies são conhecidos como cookie hijacking ou cookie poisoning (respectivamente seqüestro ou envenenamento de cookies).

Há opções na maioria dos navegadores para desabilitar o uso de cookies, no entanto, tal escolha impossibilita o funcionamento de diversos serviços como personalização de acesso a lojas on-line.

\subsubsection{Código móvel}

Para expandir o paradigma tradicional de cliente-servidor, as tecnologias de código móvel podem ser utilizadas para a avaliação remota, execução de código sob demanda ou aplicações em agentes móveis (Uto, 2003).

Geralmente são de tamanho reduzido e de execução automática em aplicativos como clientes de e-mail e navegadores compativeis com sistema operacional Microsoft Windows. Alguns exemplos de códigos móveis permitem também a execução de funções hostis se não forem verificados em tempo de execução por sistemas anti-vírus ou filtros de conteúdo.

Exemplos de códigos móveis que podem executar ações ilícitas para quebra de privaciade em sistemas Microsoft Windows são códigos ActiveX ou JavaScript, por exemplo (Chuvakin e Peikari, 2004; Carl, 1996). 


\subsubsection{Ataques a cache}

Uma nova categoria de ataque contra privacidade consiste na medida do tempo de acesso a um site Web, diferenciando o acesso direto ao site ou a parte dele armazenada em um cache, geralmente com tempo menor para acesso. Caso o tempo de acesso ao site seja menor que o tempo médio para acesso direto, pode-se inferir que o site já havia sido visitado e possuía partes armazenadas no cache do cliente analisado (Ishitani, 2003).

Segundo Felten e Schneider (2000), as únicas soluções para ataques dessa natureza seriam desabilitar os caches ou utilizar técnicas de variação de tempo para carregar porções de sites Web, que degradariam significativamente a experiência de navegação.

\subsection{Controle de privacidade}

Segundo Ishitani (2003), é impossível definir uma taxonomia para níveis de proteção de privacidade, visto que o conceito associado à privacidade é relativo ao consentimento individual e, portanto, pessoal e abstrato. Diante dessa restrição de taxonomia para níveis de privacidade, Ishitani et al. (2003) definiram as camadas de exposição e proteção de privacidade pessoal, ilustrados na Figura 4.3.

Camadas

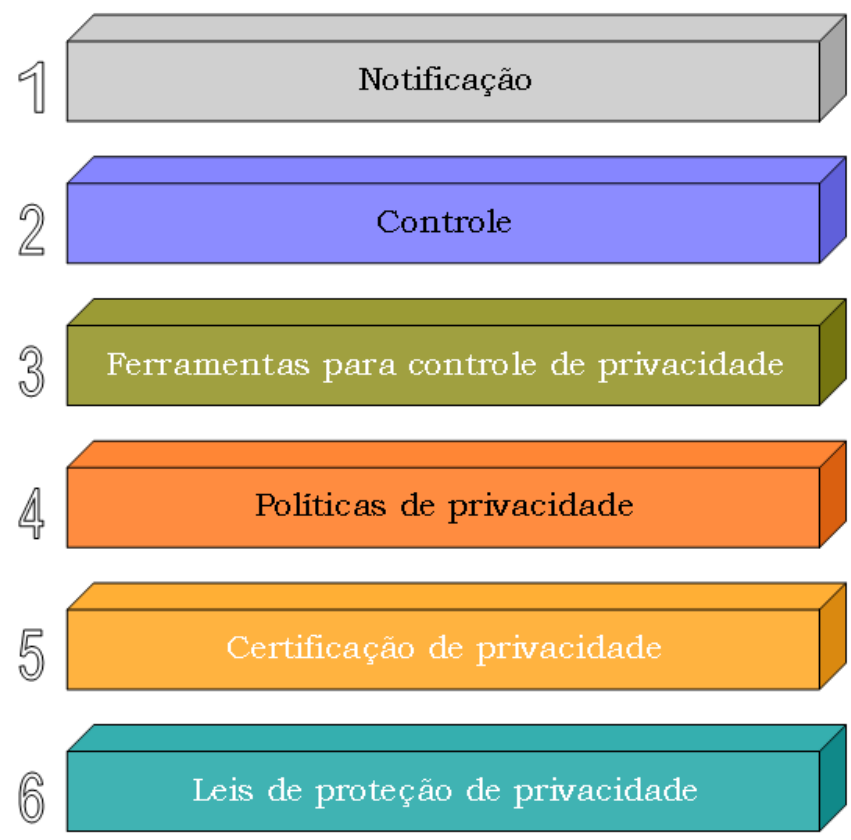

Responsabilidade e controle

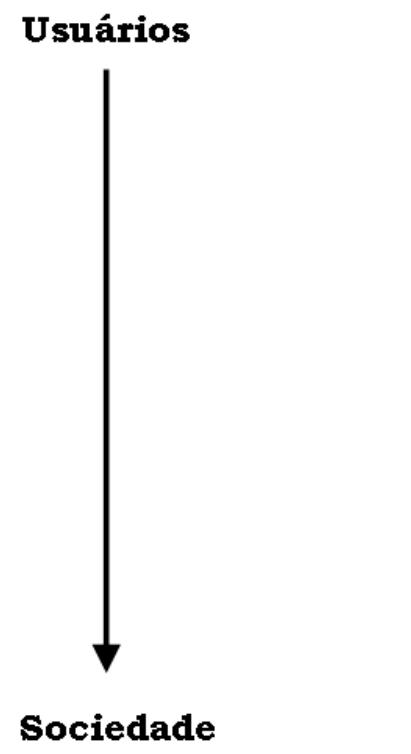

Figura 4.3: Camadas de exposição para proteção de privacidade (Ishitani et al., 2003).

De acordo com a organização de exposição para proteção de privacidade, 
não é possível afirmar que esse conceito impõe a existência das camadas inferiores para a existência das subseqüentes. Desse modo, as camadas são independentes e podem atuar em conjunto para proteção de privacidade pessoal, o que não é um requisito, apesar da disposição das camadas existentes dever seguir a ordem da definição original. A seguir serão descritas brevemente cada uma das seis camadas do modelo:

Camada 1 - Notificação: basicamente possui função informativa ao usuário sobre questões de privacidade;

Camada 2 - Controle: camada intermediária de controle dos usuários sobre sua privacidade pessoal;

Camada 3 - Ferramentas: aplicações que permitem um controle melhor do nivel de privacidade;

Camada 4 - Políticas: destaque para a declaração de políticas de privacidade por parte das empresas;

Camada 5 - Certificação: verificação das políticas de privacidade anunciadas;

Camada 6 - Leis: obrigações governamentais de implementação de controles de privacidade.

A captura de informações em sistemas Web é por natureza intrusiva já que há mecanismos nativos em sistemas de lojas eletrônicas, por exemplo, para mapear informações pessoais e comportamentos de seus visitantes. Ao contrário dessa tendência, as ferramentas para controle de privacidade na perspectiva dos usuários são bastante limitadas. Apesar dessa limitação, há diversas ferramentas que têm como objetivo auxiliar os usuários na manutenção de privacidade pessoal dentro das camadas de exposição de números um a cinco, já que a camada seis é de escopo do estado. Nas seções a seguir serão descritas as principais categorias de soluções para controle de privacidade.

\subsection{Banco de dados Hipocráticos}

Baseado no princípio de privacidade do juramento de Hipócrates, o conceito de banco de dados Hipocráticos, ele foi definido para permitir a inclusão de responsabilidade por privacidade em bases de dados, como uma forma natural de sua garantia por meio de políticas de privacidade. Os banco de dados dessa natureza devem respeitar dez fundamentos de privacidade, por exemplo, 
limitação de uso da informação, especificação da proposta para seu uso e salvaguarda dos dados, entre outros ${ }^{17}$.

Em sistemas com bases de dados Hipocráticas, antes dos dados serem coletados, os tipos de informações a serem consultadas e as regras para acesso devem ser decididas. Essas regras devem incluir informações como quem deve possuir o acesso à informação e por quanto tempo ela será retida. As aplicações que interagem com bancos de dados Hipocráticos devem possuir recursos para permitirem a verificação dessas condições em cada consulta ou armazenamento de dados, desse modo, auxiliando no controle da privacidade pessoal.

O presente trabalho está inserido na Camada 5, que trata da certificação de politicas de privacidade anunciadas pelas organizações que podem possuir informações de contexto para auxiliar o dimensionamento de políticas dinâmicas de privacidade.

A seguir será descrita a linguagem utilizada para descrever os elementos da política de privacidade, de modo que seja possível fazer a sua criação com elementos de contexto para posterior certificação de validade das regras estabelecidas.

\subsubsection{Linguagens para representação de políticas}

Uma política é definida como um conjunto de regras que definem escolhas de comportamento de um sistema (Damianou et al., 2001). Há diversos tipos de abordagens para gerenciamento baseado em políticas, inclusive para solução de problemas relacionados a segurança da informação.

As primeiras soluções foram baseadas na Camada 4 (políticas de privacidade), as quais visam principalmente traduzir em linguagens as políticas de privacidade que são declaradas nos Web sites, por exemplo, em formato XML.

Um exemplo de protocolo que atua nessa camada de exposição é o P3P (Protocol for Privacy Preferences), coordenado pelo $\mathrm{W}^{3} \mathrm{C}^{18}$. Dentre as principais características do P3P, é importante destacar:

- É um padrão já adotado por diversas empresas que permite que os usuários controlem o nível de privacidade aceitável ao visitarem Web sites;

- O P3P é baseado nos padrões XML do W3C, o que permite uma adoção rápida e fácil por novas empresas que desejam utilizar o padrão para declararem suas políticas e apresentarem termos de acordo de privacidade;

- Esse padrão é recomendado para efeitos de informação das políticas de privacidade praticadas nos Web sites, já que não há mecanismos para

\footnotetext{
17 http://www.zurich.ibm.com/pri/projects/hippocratic.html

18 http: //www.w3.org/P3P/
} 
efetuar a validação das informações apresentadas pelas políticas de privacidade em $\mathrm{P} 3 \mathrm{P}$.

Assim como o RBAC (Role Based Access Control) (Tipton e Krause, 2004, pág.212), o padrão P3P não permite que desenvolvedores sejam capazes de criar condições ou expressar regras de restrição a informações, por exemplo, especificando o que o usuário não pode fazer. Por outro lado, a linguagem EPAL fornece essa propriedade, pois é capaz de expressar tanto regras de permissão quanto de restrição a informações. Desse modo, é possível manipular ações de usuários em relação às informações. Além disso, a linguagem EPAL pode ser usada para a prevenção de acesso indevido a informações que não pertencem a um determinado usuário, por exemplo, devido à possibilidade de descrição de regras desse tipo.

\subsubsection{Autorização baseada em políticas de privacidade}

A linguagem EPAL (Enterprise Privacy Authorization Language - Linguagem para Autorização de Privacidade em Empresas) (Schunter et al., 2003) tem como objetivo formalizar a definição de políticas de privacidade para controle de acesso a informações. Desenvolvida no IBM Privacy Research Institute ${ }^{19}$, a linguagem EPAL tem como objetivo o controle de acesso a informações privadas utilizando regras detalhadas baseadas em modelos de dados e controle de acesso.

No vocabulário de uma política no formato EPAL, são definidas hierarquias de categorias de dados, de usuários, de finalidades e de conjuntos de ações, obrigações e condições. Nas categorias de dados são definidas as diferentes informações coletadas de acordo com suas perspectivas de privacidade (por exemplo, informações de contato ou pessoais). Os usuários são definidos em categorias de acordo com os dados coletados e os grupos dos quais os usuários possuem acesso. No modelo de finalidades são definidos os serviços associados a cada dado coletado (por exemplo, para processamento de solicitações de clientes ou para auditorias detalhadas).

Em modelos de ações são definidos como os dados são utilizados (por exemplo, para leitura ou divulgação) e em obrigações são definidas as ações que devem ser tomadas pelo sistema que controla os dados (por exemplo, remoção após 30 dias ou retenção indefinida). As condições de restrições para os elementos do vocabulário EPAL, armazenadas em uma política no formato EPAL, são expressões lógicas que avaliam o contexto do sistema de acordo com regras definidas (por exemplo, "a categoria de usuários deve ser de no

\footnotetext{
${ }^{19}$ http://www.zurich.ibm.com/pri/projects/epal.html
} 
mínimo 18 anos de idade" ou "a categoria de usuários deve ser de localização interna à empresa”).

Esses elementos que compõem o vocabulário da política de privacidade são então usados para formular regras de controle de privacidade. As regras de controle de privacidade podem, por exemplo, descrever controles para ações de usuários em categorias de dados para determinadas ações sob condições e obrigações bem definidas.

Atualmente na versão 1.2, a linguagem EPAL está em processo de avaliação do W3C, tendo sido submetida para tal pela IBM Research em Novembro de 2003. Maiores detalhes podem ser obtidos com o grupo de desenvolvimento da linguagem EPAL (Schunter et al., 2003).

\subsection{Considerações finais}

A linguagem EPAL foi escolhida neste trabalho devido a um conjunto de características distintas em relação aos padrões P3P e ao RBAC (Role Based Access Control), um método mais difundido para controle de acesso, sem especialização em privacidade como é o caso de P3P e EPAL (Langheinrich, 2001; Lei et al., 2002). O objetivo da linguagem EPAL é formalizar políticas internas de privacidade, enquanto o padrão P3P define uma terminologia usada para descrever "promessas" de privacidade e o RBAC é utilizado para prover permissões baseadas em funções ou cargos. No Capítulo 5 será apresentada a implementação do Gerente de Segurança no protótipo do TV-I, utilizando a linguagem EPAL para a definição da política de privacidade baseada em informações de contexto. 


\section{- \\ Gerenciamento de Segurança}

cada vez mais comum a percepção da presença da tecnologia inserida em nosso cotidiano, facilitando desde as atividades mais sim-

ples como uma transferência de valores entre contas bancárias até reuniões com parceiros de negócios localizados a milhares de quilômetros de distância. Os principais conceitos das investigações que envolvem a computação ubíqua foram destacados no Capítulo 2. Especialmente na Seção 2.3 foi evidenciada a computação ciente de contexto, área da computação ubíqua escolhida para este trabalho. Para enriquecerem as interações entre humano e máquina, as pesquisas que envolvem a computação ciente de contexto têm como objetivo a troca transparente de informações contextuais entre as entidades envolvidas, sejam elas humanas ou não. Como a difusão da tecnologia de maneira cada vez mais transparente, os riscos naturalmente associados ao seu uso se multiplicam.

Com o aumento dos riscos decorrente da utilização de sistemas computacionais, especialmente os sistemas inseridos no cotidiano dos usuários, os seus requisitos mínimos de segurança e privacidade tendem a ser cada vez mais rígidos e detalhados. Para demonstrar a necessidade de segurança, no Capítulo 3 foram apresentados os resultados de algumas pesquisas compiladas nessa área, durante o ano de 2003. Foram descritos os conceitos envolvendo os riscos e as ameaças e também apresentados alguns trabalhos relacionados a este que envolvem segurança em computação ubíqua.

Dentre os principais riscos envolvendo a computação ubíqua, a privacidade é uma das maiores preocupações. Como a troca de informações entre as tecnologias integradas ao nosso cotidiano deve ser o mais transparente possível, muitas soluções não consideram os riscos envolvidos na captura, 
processamento e disponibilização de informações pessoais. Na Seção 4.1 foram apresentados os conceitos que envolvem a privacidade na sociedade da informação, incluindo uma abordagem histórica e legal (Seção 4.2) e algumas alternativas de controle de privacidade (Seção 4.5).

Como a promulgação de leis por entidades governamentais não garante a privacidade e segurança dos cidadãos e a adoção de ferramentas de controle por cada usuário é inviável, a viabilização de formas intermediárias de responsabilidade e controle sobre a segurança de tais sistemas é a solução mais razoável. Com objetivo de investigar as questões de segurança associadas à computação ubíqua e ciente de contexto, o Projeto TV-I - descrito na Seção 2.4 - foi definido como o escopo para esta investigação. Utilizando o modelo de informações contextuais do projeto em questão, este trabalho se propõe a utilizar informações contextuais de um serviço de gerenciamento de contexto do trabalho de Santos (2004) para gerenciamento de políticas de privacidade.

Na Seção 5.1 serão apresentadas as primeiras considerações de segurança no projeto TV-I. Serão detalhadas também as características de ciência e gerenciamento de contexto do protótipo de TV Interativa TV-I (Seção 5.1.1) e o Serviço de Gerenciamento de Segurança (Seção 5.1.2).

Na Seção 5.2 será apresentada a forma de gerenciamento das políticas de segurança e privacidade no protótipo, utilizando a linguagem EPAL (Schunter et al., 2003). Serão apresentados também o vocabulário (Seção 5.2.1) e a política de privacidade utilizados (Seção 5.2.2) adotados no trabalho.

Na Seção 5.3 será apresentada a validação do Gerente de Segurança, com um exemplo, implementado em conjunto com o trabalho de Santos (2004) e na Seção 5.4 serão apresentadas as considerações finais deste capítulo.

\section{1 Segurança no Projeto TV-I}

Em interações no mundo real, sempre há dados que permitem a identificação exata ou aproximada de informações pessoais. A escolha de uma loja, a maneira de se vestir ou o cargo ocupado em uma organização permitem que várias outras informações pessoas possam ser inferidas.

Ao mesmo tempo que informações detalhadas de identificação estão se tornando mercadorias para provedores de serviços, em especial de comércio eletrônico, um controle de privacidade faz-se necessário para permitir que no mundo virtual os usuários sintam-se confortáveis ao utilizarem serviços cada vez mais personalizados.

Paralelamento, há o crescente desenvolvimento de infra-estruturas conectadas por meio de redes de comunicação e a necessidade de garantia de se- 
gurança em tempo real, por meio do uso de ferramentas automatizadas para suporte dos administradores.

Considerando que requisitos de segurança e privacidade não foram incluídos nos requisitos originais do projeto TV-I (Goularte, 2003, pág. 205), este trabalho visa a adição de características que permitam o controle de requisitos de segurança e privacidade, utilizando as informações contextuais disponibilizadas pelo serviço de gerenciamento de contexto do protótipo para tal.

Soluções de gerenciamento de segurança baseadas em mapeamento de políticas como a proposta neste trabalho possibilitam a adaptação de controles de forma automatizada, reduzindo a necessidade de intervenção dos gestores das redes e das aplicações que necessitam de segurança.

As informações de contexto do projeto em questão, disponibilizadas pelo Gerente de Contexto (Santos, 2004), são utilizadas para auxiliar no dimensionamento das necessidades de diversas classes de serviços disponibilizados pelo Gerente de Serviços do sistema TV-I, dentre elas, segurança. Para adicionar características de gerenciamento de segurança, o sistema de gerenciamento de contexto disponibiliza informações ao Gerente de Segurança para a estruturação dinâmica das regras na política de privacidade. A Figura 5.1 ilustra a representação de contexto adotada no sistema TV-I, descrita na Seção 2.4 .2 .

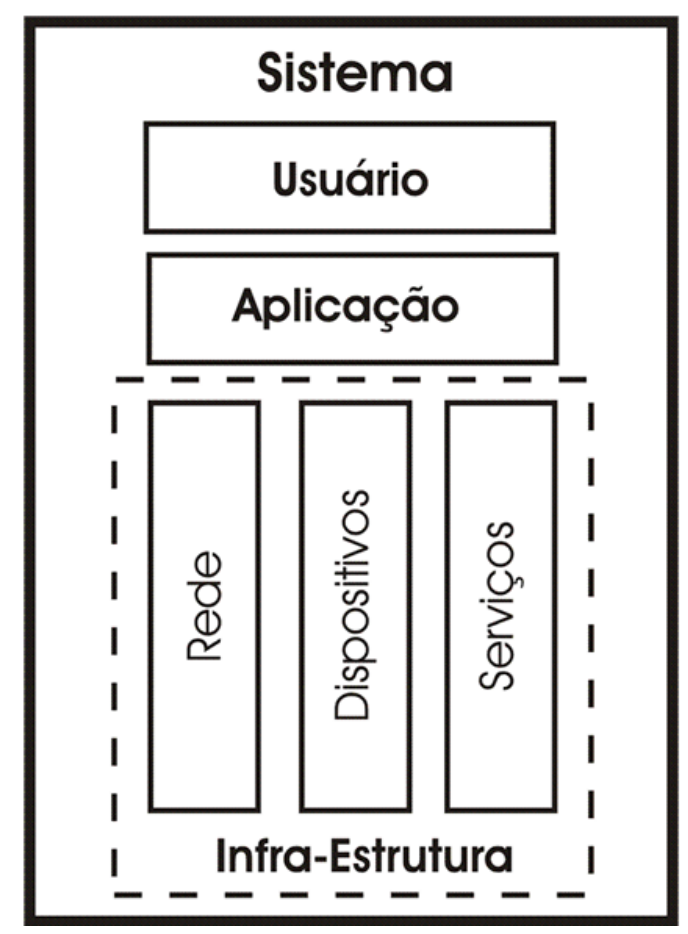

Figura 5.1: Componentes do contexto do sistema TV-I (Goularte, 2003).

Assim, para que informações de controle de segurança possam ser representadas e utilizarem informações contextuais para controle de acesso, por exemplo, há a necessidade de representar não apenas as permissões de usuá- 
rios, mas também restrições, condições para que a permissão ou restrição ocorra e ainda, descrições de eventuais detalhes das operações a serem realizadas. Segundo Lei et al. (2002), a privacidade é um tema identificado como um dos problemas principais que devem ser abordados em computação ubíqua envolvendo sistemas que necessitam de segurança.

Para efeitos deste trabalho, foram utilizadas as seguintes dimensões contextuais: IdentityType (referente a identificação), LocationType (referente a localização) e TimeType (e referente a tempo ou horário), cuja modelagem UML é ilustrada na Figura 5.2, (Goularte, 2003):

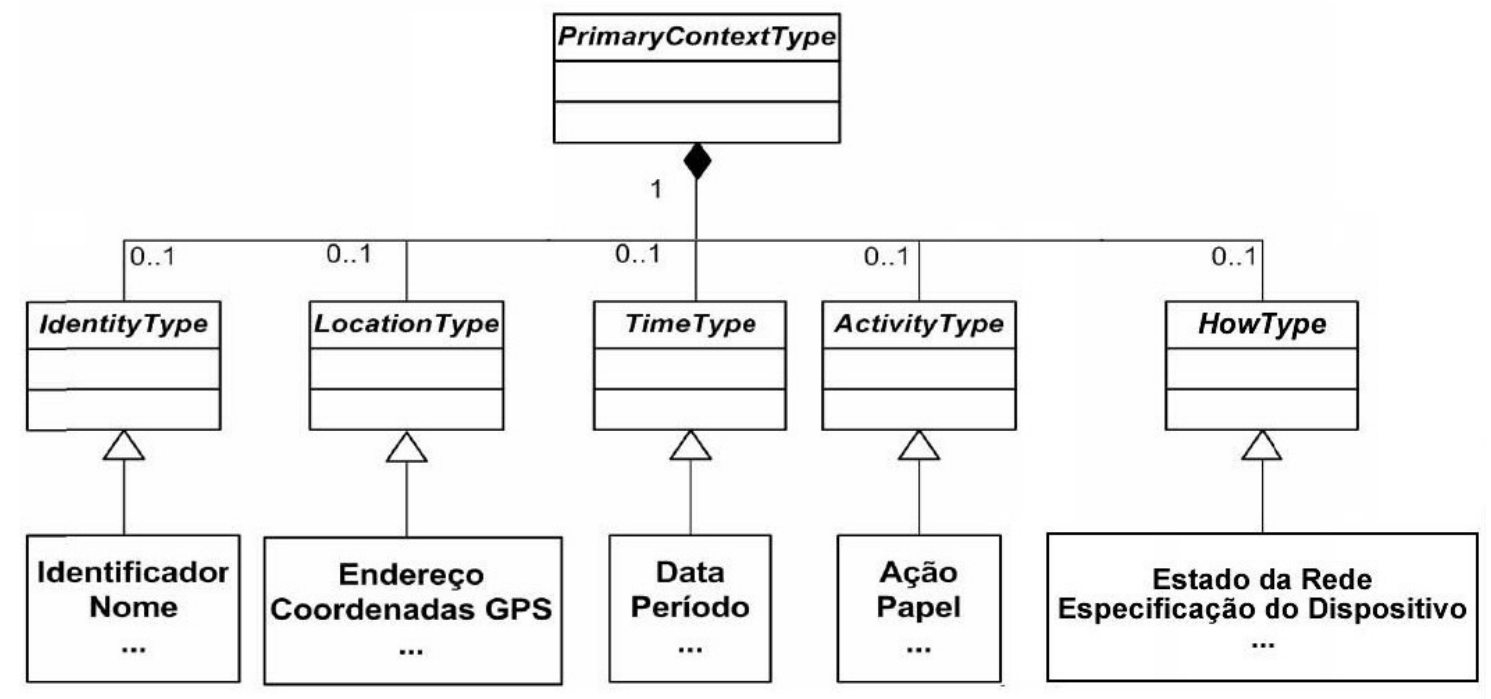

Figura 5.2: Diagrama de classes UML representando o contexto primário.

\section{1.1 Serviço de Gerenciamento de Contexto}

As aplicações que gerenciam informações de contexto necessitam de representações capazes de suportarem um número abrangente dessas informações, bem como prover subsídios para que, cada vez mais, desenvolvedores sejam capazes de aumentar o número de informações utilizadas. Para tanto, a representação contextual deve ser extensível, permitindo tal flexibilidade no uso de informações dessa natureza.

Os trabalhos mencionados na Seção 2.3.1 evidenciam alguns esforços no sentido de gerenciar informações de contexto. Esse gerenciamento é relevante em virtude da grande quantidade de informações contextuais, que podem ser utilizadas por uma aplicação ciente de contexto, da necessidade de consistência dessas informações e ainda, da manipulação das mesmas. Na Seção 2.4.2 também foi evidenciada a carência de abordagem da privacidade no desenvolvimento de serviços e aplicações cientes de contexto.

Com a motivação da necessidade de gerenciamento de informações de contexto baseada em uma representação extensivel e a aplicação de tais informa- 
ções para controle de segurança, a partir dessa seção serão apresentados os dois serviços desenvolvidos para esses objetivos: o serviço Gerente de Contexto e o serviço Gerente de Segurança. Para a validação de tais serviços foi implementada também uma aplicação ciente de contexto que provê conteúdo de acordo com informações contextuais dinâmicas do usuário e com as políticas de acesso ao conteúdo, a ser apresentada na Seção 5.3.

O serviço de gerenciamento de contexto proposto por Santos (2004) é composto por dois módulos: o serviço Web Gerente de Contexto e o Coletor Contextual. O primeiro é responsável pela disponibilização de informações contextuais. As informações de contexto disponibilizadas pelo Gerente de Contexto são fornecidas pelo Coletor Contextual, que é responsável pela coleta de informações contextuais referentes aos usuários, aos seus dispositivos e à rede. Esse módulo efetua a coleta das informações de contexto por meio de sensores e, dinamicamente, gera a representação de contexto dessas informações. Maiores detalhes sobre a representação de contexto de dispositivos e rede, bem como coleta e utilização das mesmas, podem ser encontrados no trabalho de Santos (2004).

É importante destacar que os serviços de gerenciamento de contexto e segurança, bem como a aplicação ciente de contexto, foram desenvolvidos em linguagem Java ${ }^{1}$, utilizando interfaces de serviços Web e padrões W3C (Bates, 2003). Tais escolhas foram feitas para facilitar a interoperabilidade entre as aplicações heterogêneas e também visando integração com demais padrões Web desenvolvidos por outros grupos de pesquisa.

\subsubsection{Serviço de Gerenciamento de Segurança}

O serviço Web de Gerenciamento de Segurança - ou simplesmente Gerente de Segurança - é responsável pelo monitoramento dinâmico de acesso a informações pessoais classificadas como privadas. Utilizando informações disponibilizadas pelo Serviço de Gerenciamento de Contexto (Santos, 2004), o Gerente de Segurança analisa as requisições de acesso de maneira dinâmica, sendo capaz de restringir os acessos utilizando informações contextuais.

A primeira etapa de desenvolvimento do Gerente de Segurança, em conjunto com o Gerente de Contexto e da aplicação ciente de contexto, foi a modelagem do cenário de validação dos trabalhos em questão. Foram considerados na modelagem a aplicação ciente de contexto (context-aware applications) e os subsistemas de gerenciamento de contexto (context manager) e de segurança (security services), sendo este último responsável pela autenticação dos usuários na aplicação e também pelo controle de acesso baseado nas políticas de

\footnotetext{
${ }^{1}$ http://java.sun.com/
} 


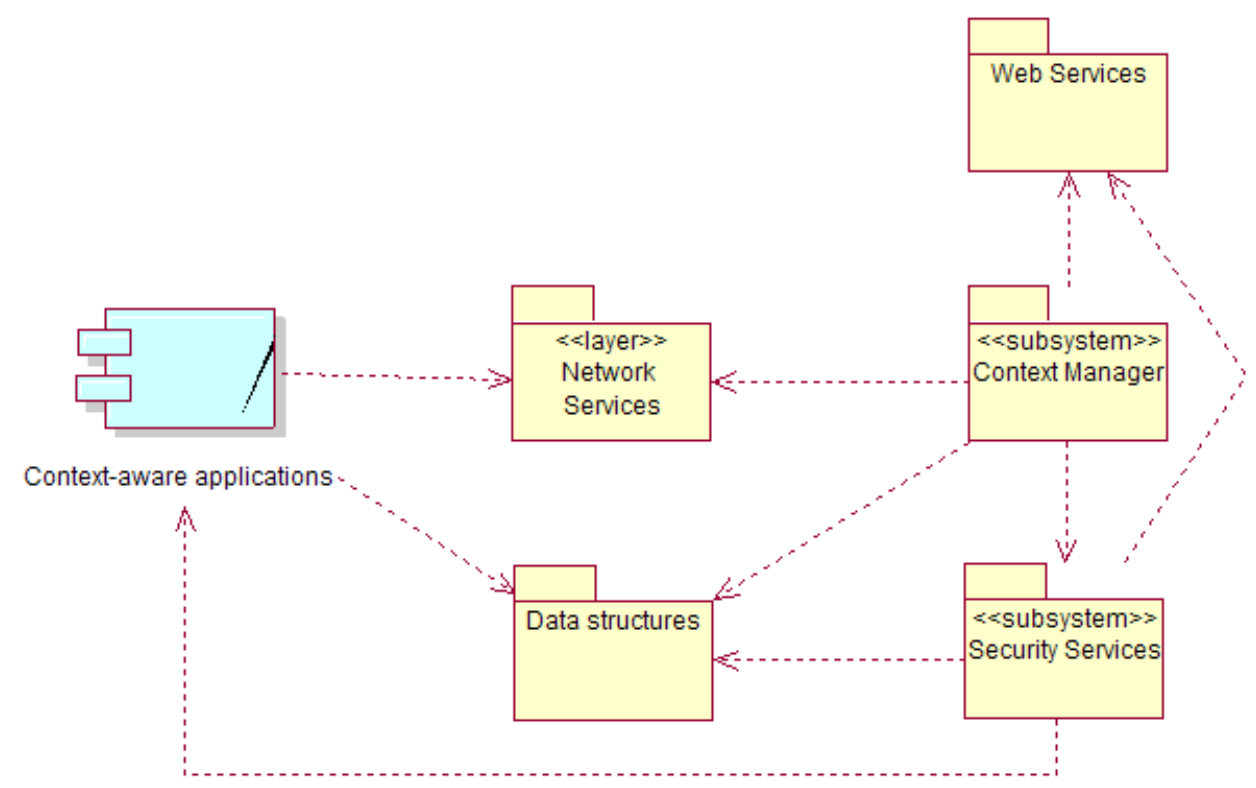

Figura 5.3: Modelagem em UML dos sistemas de gerenciamento cientes de contexto.

segurança (Figura 5.3).

Foram incluídos na modelagem também os sensores de monitoramento de informações contextuais na rede de comunicação (network services) e uma base de dados para armazenamento das informações contextuais (data structures). Para a interface com eventuais novos clientes dos gerenciadores de contexto e segurança, foi incluído também um subsistema para serviços Web (Web Services).

Para a implementação do Gerente de Segurança (Figura 5.4), o controle de acesso dos usuários foi dedicado para a aplicação ciente de contexto e o controle de acesso de cada usuário autenticado às informações privadas foi destinado aos gerentes de segurança e de contexto. Estão incluídas na definição do Gerente de Segurança as interfaces para serviços Web (Web Services), para aplicações cientes de contexto (Context-aware Applications) e também para o vocabulário da política de privacidade (Privacy Vocabulary).

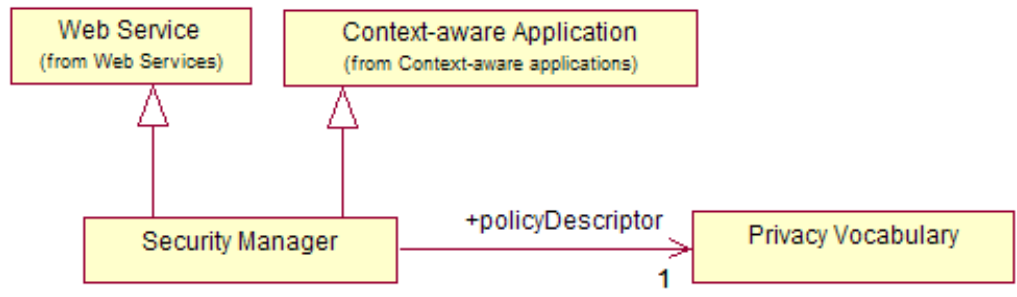

Figura 5.4: Modelagem em UML do serviço Web de Gerenciamento de Segurança.

Na Seção 5.2 serão detalhados os principais elementos do serviço de geren- 


\begin{tabular}{|c|c|}
\hline Classificação & Elementos \\
\hline <user-category> & analista, gerente, consultor \\
\hline <data-category> & áudio, vídeo, modelagem, plano de negócios \\
\hline <purpose> & análise, desenvolvimento, teste, implantação \\
\hline <action> & acesso, cópia \\
\hline <container> & funcionário, horário de expediente, local de trabalho \\
\hline <obligation> & retenção de históricos de acesso \\
\hline
\end{tabular}

Tabela 5.1: Elementos classificados no vocabulário EPAL.

ciamento de segurança e privacidade: o vocabulário (Seção 5.2.1) e a política de segurança (Seção 5.2.2).

\subsection{Políticas de privacidade}

Após a modelagem da aplicação ciente de contexto (neste caso, um site para o TV-I) e do Gerente de Segurança, além do Gerente de Contexto (Santos, 2004), a etapa seguinte foi definir, baseado nos elementos principais do cenário escolhido, as instâncias do vocabulário e da política de segurança para o cenário de validação a ser apresentado na Seção 5.3. Na Seção 5.2.1 serão apresentados detalhes do vocabulário EPAL que tem seu código fonte no Apêndice A.

\subsection{Vocabulário EPAL}

O vocabulário tem como objetivo validar os elementos das políticas de segurança e privacidade. Em vocabulários da linguagem EPAL (como descrito na Seção 4.5.3), as informações dos objetos da política de segurança são validadas, verificando, por exemplo, se são valores com instâncias válidas e se não há elementos obrigatórios ausentes.

Na Tabela 5.1 são listados os elementos e suas respectivas classificações no vocabulário para o cenário do TV-I que foi modelado para este trabalho e na Tabela 5.2 são resumidas as definições dos elementos deste trabalho no vocabulário EPAL. É importante destacar que, para que seja possível a interoperabilidade entre sistemas que adotam políticas de privacidade comuns, o vocabulário deve ser compartilhado.

O vocabulário da política de privacidade, como já destacado, define os tipos de dados e elementos que deverão fazer parte da política de segurança. Na Figura 5.5 é ilustrada parte do vocabulário adotado para este trabalho, com destaque para as categorias user-category, data-category, purpose e action. 


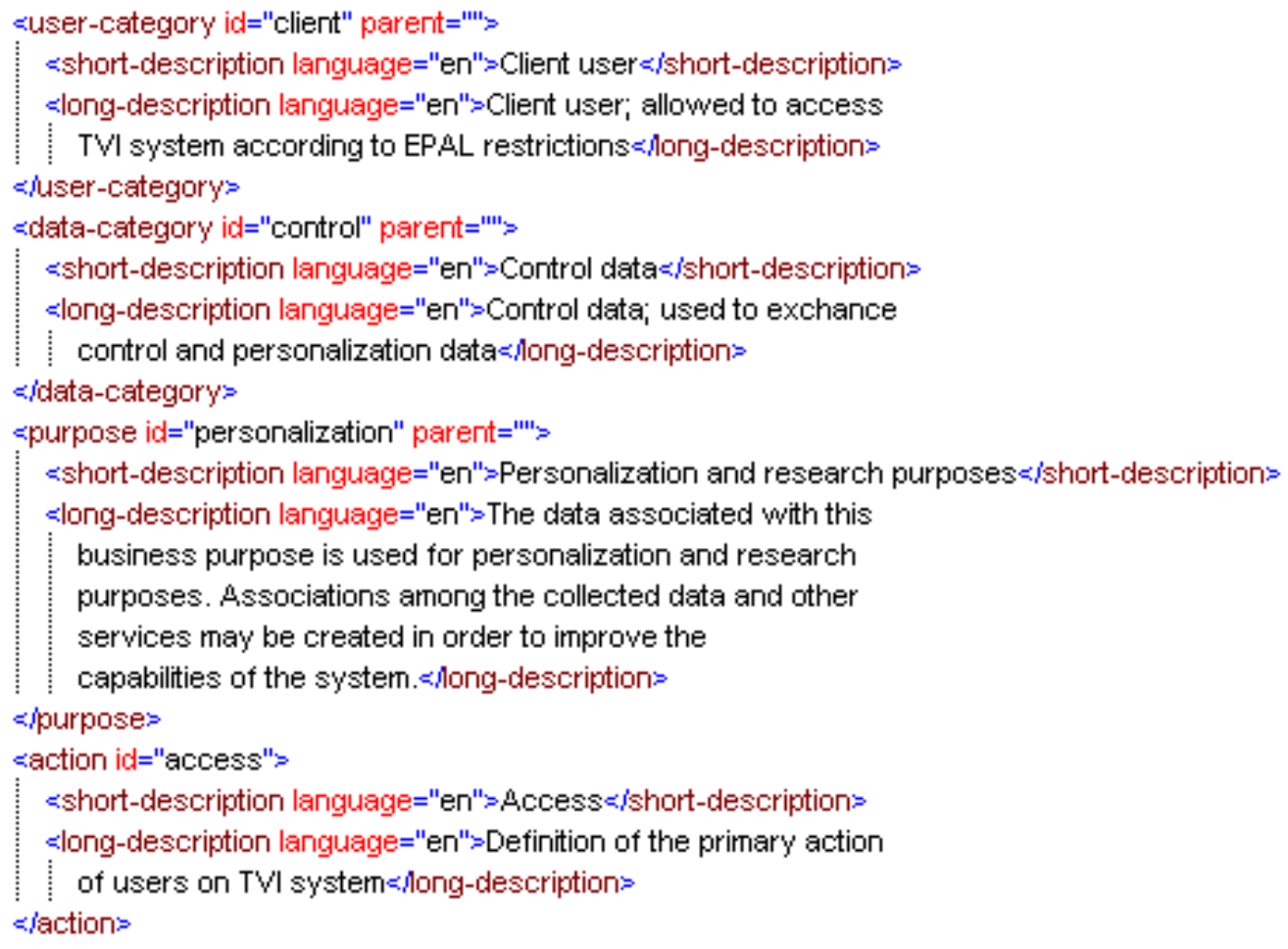

Figura 5.5: Segmento do vocabulário da política de privacidade

\begin{tabular}{|c|c|}
\hline Classificação & Descrição \\
\hline <user-category $>$ & Categorias de usuários \\
\hline <data-category $>$ & Categorias de dados \\
\hline <purpose> & Finalidades para acesso a dados \\
\hline <action> & Ações de privacidade controlada \\
\hline <container $>$ & Definição de informações a serem avaliadas \\
\hline <obligation> & Obrigações que podem ser solicitadas \\
\hline
\end{tabular}

Tabela 5.2: Definições de elementos de um vocabulário EPAL.

\subsubsection{Política de privacidade EPAL}

Para exemplificar a aplicação da política de privacidade e do vocabulário em linguagem EPAL já apresentados, foram definidos no cenário de aplicação alguns casos de uso válidos e inválidos de acesso a informações classificadas na organização que possui os controles de privacidade em questão implementados. Os casos de uso são restritos de acordo com as dimensões contextuais escolhidas, baseando-se na representação de contexto apresentada na Seção 2.3.5. Para efeitos deste trabalho, foram escolhidas as dimensões relativas às informações de identificação (who), localização (where) e tempo (when).

Utilizando os elementos do vocabulário listados na Tabela 5.1, é possível perceber as dimensões primárias de contexto, segundo Goularte (2003), que 
podem ajudar a compor as regras da politica de privacidade. A Figura 2.6 exemplifica a maneira como são organizadas as informações contextuais que são recebidas pelo Gerente de Segurança, geradas pelo Gerente de Contexto.

Adotando essas informações contextuais e validando de acordo com as regras da política de privacidade (cujo código fonte está listado no Apêndice B), o Gerente de Segurança é responsável então por retornar as regras que validam a requisição de acesso baseada em informações contextuais. Tais regras são formatadas no padrão para controle de acesso baseado em XML, o XACML (Extensible Access Control Markup Language), que será descrito na Seção 5.2.3.

\subsubsection{Regras de validação XACML}

Após a análise das informações contextuais e da validação das regras descrita na política de privacidade utilizada pelo serviço, é gerada uma regra de acesso que define a permissão ou a restrição ao conteúdo. Um exemplo de regra de acesso gerada é ilustrado na Figura 5.6.

Para que um sistema que utilize o sistema de gerenciamento de privacidade possa validar as regras de acesso, esse deve implementar sistemas de validação de regras XACML (Extensible Access Control Markup Language) (Griffin, 2004).

É importante destacar que o serviço de gerenciamento de segurança recebe as informações contextuais e gera dinamicamente as regras de acesso, não estando responsável por aplicação destas regras e garantia de seu cumprimento. O objetivo desse serviço é efetuar comparações entre informações de contexto dinâmicas e políticas de privacidade e, a partir dessas comparações, gerar regras de acesso que devem ser validadas pelo Gerente de Serviços do TV-I, no caso deste trabalho.

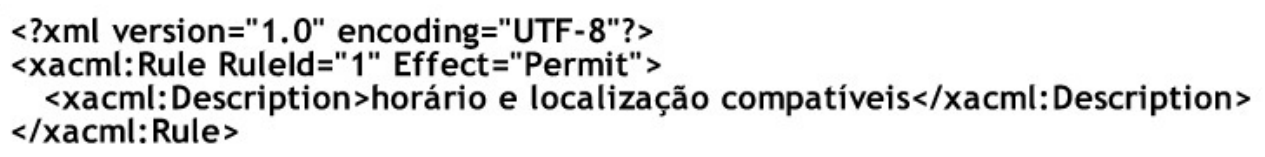

Figura 5.6: Regra de acesso gerada dinamicamente pelo serviço de gerenciamento de segurança.

Na Seção 5.3 será apresentado o exemplo implementado para a validação deste trabalho.

\subsection{Exemplo de uso}

A aplicação ciente de contexto implementada é capaz de prover acesso ao conteúdo do protótipo do TV-I (Figura 5.7). Com objetivo de disponibilizar 
acesso a conteúdo multimídia com serviços baseados em ciência de contexto, o TV-I possui um Gerente de Serviços (Goularte, 2003) que inclui dois serviços, o Gerente de Contexto (Santos, 2004) e o Gerente de Segurança, que é o tema deste trabalho.

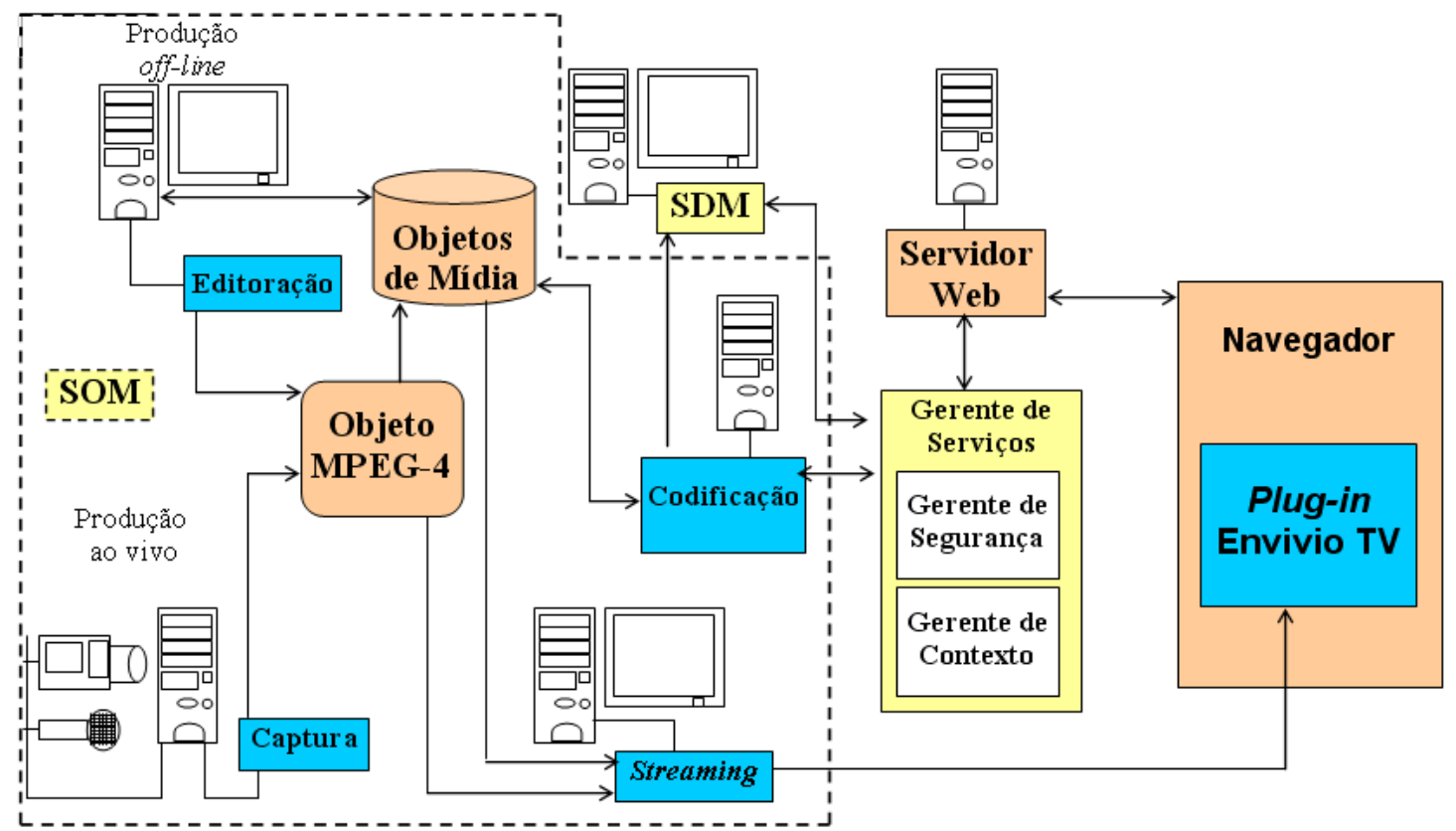

Figura 5.7: Modelo resumido da arquitetura do protótipo TV-I (Goularte, 2003).

O objetivo da aplicação implementada é prover controle de acesso a informações pessoais de acordo com a política de privacidade definida. Ao acessar o site principal da aplicação, é exibida uma tela que solicita as informações de acesso do usuário (Figura 5.8). É importante destacar que, por ser uma aplicação de testes, a informação de localização do usuário pode ser informada na efetivação do acesso. Em um sistema ubíquo, as informações de localização, identificação e tempo já devem ser fornecidas no primeiro acesso.

Para a disponibilização do acesso, as informações de contexto utilizadas são referentes à identidade (quem é o usuário (who)), localização (where) e tempo (o momento em que o usuário está requisitando o acesso (when)) do usuário. Beneficiando-se dessas três categorias de informações é possível alcançar um alto nível de dinamismo, pois as informações relacionadas à localização e tempo geralmente não são estáticas em sistemas dessa natureza. Neste trabalho, apenas as alterações destas informações são informadas ao Gerente de Segurança, que então verifica se há alguma eventual violação da política de privacidade.

Na Figura 5.9 é ilustrada a implementação da aplicação ciente de contexto e dos serviços de gerenciamento de contexto e segurança.

Um cenário de uso da aplicação TV-I que foi definido consiste de um usuá- 


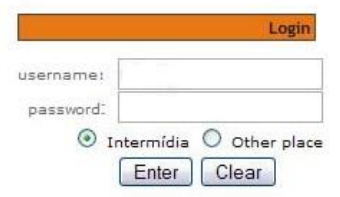

Figura 5.8: Tela da aplicação ciente de contexto, com as opções de login, senha e localização.

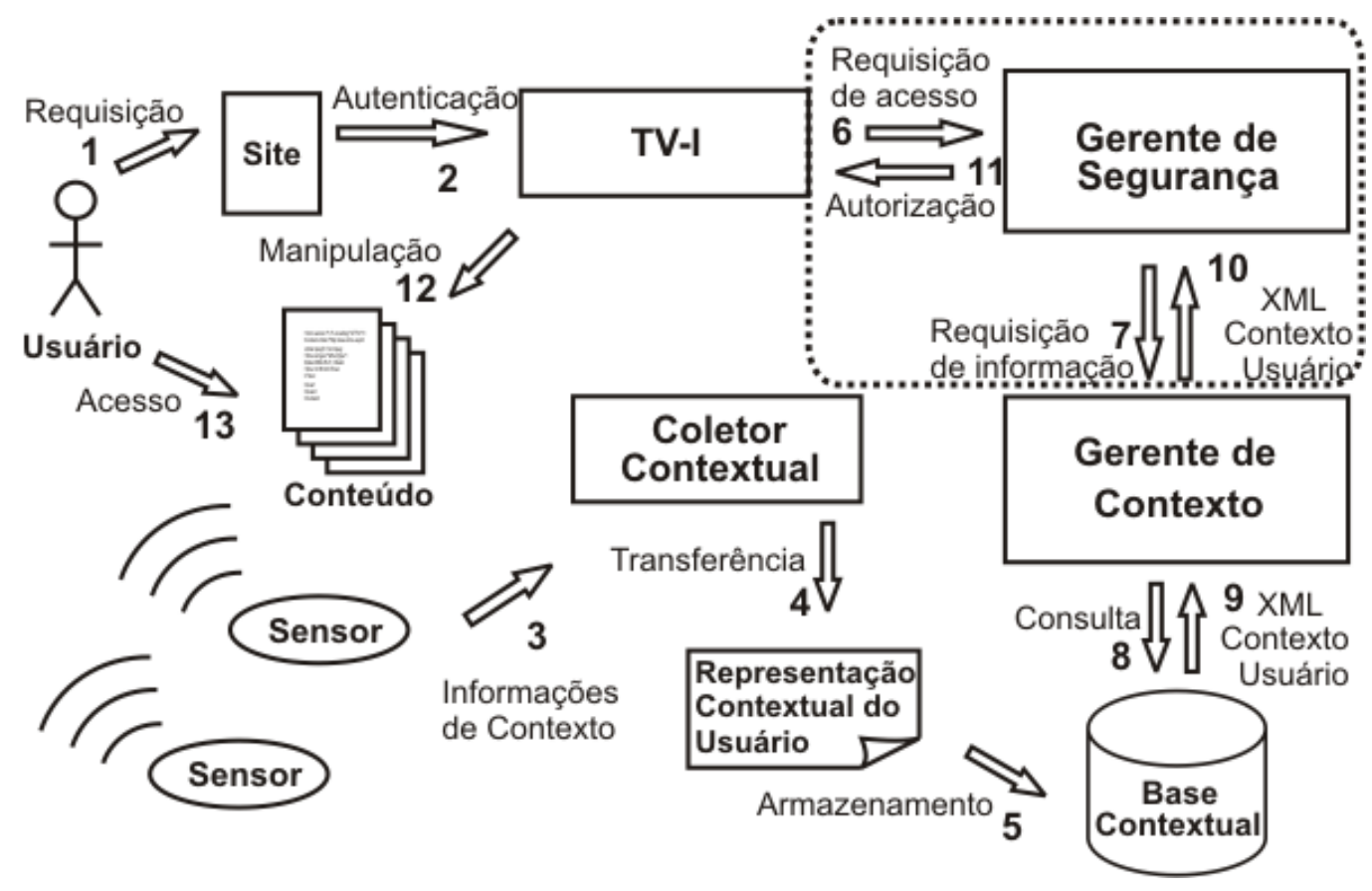

Figura 5.9: Fluxograma da interação entre a aplicação ciente de contexto e os gerentes de segurança e contexto.

rio que é um colaborador de uma empresa que possui alguns recursos de computação ubíqua em seu ambiente de trabalho. Para obter acesso ao site da empresa, o funcionário deve ser identificado e ser autorizado (identificação), deve estar nas dependências da empresa (localização) e ainda, deve efetuar o acesso em um horário intervalo pré-estabelecido (tempo), por exemplo, em seu horário de expediente (entre 8 h00 e 19h00).

Ao solicitar o conteúdo (passo 1) o usuário fornece sua identificação e senha no site principal. Essas informações são enviadas ao TV-I que se encarrega de efetuar a autenticação do usuário no sistema (passo 2). Após a autenticação do usuário, as informações de contexto do mesmo (identificação, localização e tempo) são coletadas pelo Coletor Contextual do Gerente de Contexto por meio de sensores (passo 3) para a geração dinâmica da representação de contexto do usuário (conforme Figura 2.6). 
Essa representação de contexto é então adicionada à base contextual para ser disponibilizada posteriormente pelo serviço de gerenciamento de contexto (passos 4 e 5). Após a autenticação do usuário, geração dinâmica e armazenamento da representação contextual do mesmo, o Gerente de Serviços do TV-I deve solicitar a regra de acesso referente ao usuário autenticado para o serviço de gerenciamento de privacidade (passo 6).

Como o Gerente de Segurança necessita das informações de contexto do usuário para gerar a regra de acesso, ele então efetua a requisição da representação contextual do usuário (passo 7), que já foi armazenada na base contextual pelo coletor contextual, ao serviço de gerenciamento de contexto por meio de um dos métodos fornecidos por esse serviço para manipulação de informações de contexto de usuários.

O Gerente de Contexto então realiza uma consulta à base contextual (passo 8) e posteriormente retorna a representação de contexto do usuário (passo 9), que é enviada como resposta à requisição efetuada pelo serviço de gerenciamento de privacidade (passo 10).

Depois de receber a representação dinâmica de contexto do usuário, o Gerente de Segurança extrai as informações relevantes do documento em formato XML para a geração da regra de acesso, consultando a política de privacidade em linguagem EPAL (Apêndice B). Em seguida, é feita uma análise das informações de contexto obtidas com as condições descritas na política em linguagem EPAL para verificar se efetivamente as regras são válidas em todas as dimensões contextuais.

Após tal análise, o Gerente de Segurança dinamicamente gera e envia a regra de acesso em XACML (como ilustrada na Figura 5.6) para o Gerente de Serviços do TV-I (passo 11) em resposta à requisição efetuada anteriormente. O Gerente de Serviços do TV-I então realiza a análise da regra de acesso e toma a decisão de liberar ou restringir o acesso do conteúdo ao usuário.

Em caso de permissão, o Gerente de Serviços do TV-I deve manipular o conteúdo de modo a organizá-lo de acordo com a preferência do usuário (passo 12), liberando efetivamente o seu acesso ao conteúdo multimídia (passo 13).

Embora o contexto em que essa aplicação está inserida seja simples, é possível utilizar informações de contexto dinâmicas com privacidade em cenários mais abrangentes. Diversas aplicações mais complexas podem ser elaboradas a partir de modelos de representação de contexto utilizados em políticas de segurança.

É importante destacar que no exemplo descrito neste trabalho, o TV-I e seu Gerente de Serviços se comunicam diretamente com os Serviços de Contexto e Segurança. Novas alternativas de acesso podem ser analisadas, por exemplo, por meio de serviços Web. 


\subsection{Considerações finais}

Nesta seção foi apresentada a implementação de um serviço de gerenciamento de segurança que utiliza informações contextuais para controle dinâmico de privacidade. Há inúmeras vantagens na adoção de informações de contexto para validação de políticas de segurança: é possivel obter uma atualização dinâmica do modelo de sistema de informação (nas três dimensões contextuais adotadas neste caso) e há uma maior aproximação de modelos de interação humanos, o que facilita a administração de sistemas por usuários leigos (baseados em informações com identificação, localização e horário), por exemplo.

A implementação apresentada na Seção 5.3 é um exemplo simplificado de uma aplicação do sistema de gerenciamento de segurança utilizando informações contextuais. Alguns novos cenários onde o Gerente de Segurança pode ser aplicados podem ser extraídos de trabalhos relacionados nas áreas de sistemas baseados em localização e para controle dinâmico de propriedade intelectual em conteúdo digital (Seção 3.3.1). No Capítulo 6 serão apresentadas as conclusões deste trabalho. 


\section{Conclusões}

$\mathcal{A}$

liada à necessidade de controle de acesso a sistemas on-line, a preocupação com a privacidade cresce, principalmente com a onipresença de tecnologia em nosso cotidiano. Este trabalho visou investigar os principais requisitos de segurança para os sistemas dessa natureza os sistemas ubíquos.

Com o mapeamento de informações de contexto presentes em um sistema ubíquo, foi possivel restringir acesso a informações pessoais de acordo com políticas de privacidade e com as mudanças de informações contextuais.

A investigação e a implementação que validam este trabalho resultaram em algumas contribuições diretas para o protótipo do TV-I, trabalho iniciado por Goularte (2003), e para a comunidade científica. É importante destacar que, mesmo antes de sua conclusão, o presente trabalho teve resultados parciais apresentados em publicações especializadas, o que lhe rendeu uma menção por profissionais de segurança da informação ${ }^{1}$.

Nas seções a seguir serão listadas as principais contribuições deste trabalho (Seção 6.1), as suas limitações (Seção 6.2), as sugestões de trabalhos futuros (Seção 6.3) e serão tecidas também as considerações finais (Seção 6.4).

\subsection{Contribuições}

Diversas contribuições científicas podem ser atribuídas ao presente trabalho. A principal delas foi agregar caracteristicas de gerenciamento de segurança e privacidade ao protótipo do projeto TV-I (Goularte, 2003).

${ }^{1}$ Para mais informações sobre as publicações e citações deste trabalho, visite http:// www.milagres.com/msc/ 
Esta investigação tem como resultado a implementação de um serviço adicional ao protótipo do projeto TV-I, o Gerente de Segurança, integrado com o Gerente de Contexto, trabalho de Santos (2004). Dentre as demais contribuições, convém destacar:

- A definição de requisitos de segurança em um ambiente ubíquo. No trabalho de Goularte (2003), não foram considerados requisitos mínimos para garantia de segurança das informações que eram transportadas pelo sistema TV-I. Para a validação do Gerente de Segurança os requisitos de segurança em um sistema ubíquo considerados foram: especificação de informações de contexto e comunicação distribuída e transparente (Seção 2.3.3);

- Definição de uma solução de gerenciamento de políticas baseada em uma linguagem aberta de validação de políticas de privacidade. A adoção da solução aberta EPAL neste trabalho é uma das primeiras iniciativas, devido à recente definição de tal linguagem. É importante destacar que tal padrão foi apresentado para avaliação da comunidade científica (ao W3C em especial) durante uma fase inicial da implementação deste trabalho, o que permitiu uma adoção sem grandes alterações no curso da pesquisa;

- Implementação e validação dos requisitos de segurança e privacidade de um ambiente ubíquo por meio da implementação do Gerente de Segurança no protótipo TV-I (como detalhado na Seção 5.3).

\subsection{Limitações}

Com o desenvolvimento deste trabalho, especificamente para o escopo do projeto TV-I, há algumas limitações inerentes ao trabalho e que não foram consideradas adversas aos requisitos definidos previamente.

Tais eventuais limitações devem ser consideradas em caso de adoção dos resultados deste trabalho para eventuais adições de recursos ou implementação em novos sistemas que requerem controle de segurança e privacidade. Dentre as limitações deste trabalho, pode-se citar:

- Restrição quanto à versão da especificação EPAL versão 1.1. Por este projeto estar restrito a controle de segurança e privacidade baseado na linguagem EPAL (Seção 4.5.3), a política de segurança e seu vocabulário foram definidos em tal linguagem, na versão 1.1. Para que novas versões desta linguagem possam ser utilizadas, devem ser feitas atualizações da implementação deste trabalho; 
- Dependência do Gerente de Serviços do protótipo do TV-I. Como a implementação do Gerente de Segurança foi feita considerando que este trabalho é um serviço adicional agregado ao Gerente de Serviços do TV-I, este trabalho depende de rotinas implementadas originalmente por Goularte (2003). Para que a efetiva aplicação das regras validadas pelo Gerente de Segurança seja feita, devem ser implementadas algumas funções nativas do Gerente de Serviços.

\subsection{Trabalhos futuros}

Com a apresentação dos resultados do presente trabalho, diversas novas pesquisas podem se beneficiar de tais resultados para darem continuidade a investigações nas áreas de segurança da informação e computação ubíqua. Algumas sugestões para trabalhos futuros são listadas a seguir:

- Gerenciamento integrado de sistemas: além de recursos de gerenciamento de segurança e privacidade como os propostos neste trabalho, pode-se implementar controles adicionais para gerenciamento de níveis de serviços (SLA ou Service Level Agreement) e qualidade de serviço (GoS ou Quality of Service), por exemplo;

- Disponibilização para validação de regras por meio de serviços Web: uma alternativa à implementação monolítica em classes da linguagem Java é a disponibilização de interfaces para validação de regras das políticas de segurança e privacidade por meio da Web. A adoção de serviços Web, aliada com padrões para troca de informações seguras e assinadas digitalmente permite uma integração com um número maior de ferramentas de gerenciamento e segurança;

- Até a conclusão deste trabalho, não havia uma implementação completa e aberta de funções para validação de regras de políticas em linguagem EPAL. Uma sugestão de trabalho futuro inclui a atualização das regras de validação para a versão definitiva da linguagem EPAL, que no momento encontra-se em avaliação no W3C.

\subsection{Considerações finais}

Com a conclusão do trabalho proposto, deve-se analisar se os seus principais requisitos foram cumpridos. Dentre os principais requisitos e principios básicos para implementação de aplicações cientes de contexto (Seção 2.3.3), 
os requisitos que foram levados em consideração para este trabalho foram especificação de informações de contexto e comunicação distribuída e transparente.

Quanto à especificação de informações de contexto, foram bem definidas as dimensões contextuais a serem tratadas neste trabalho (identificação, localização e tempo). Relativo à comunicação distribuída e transparente, a implementação em diferentes gerenciadores no TV-I (além do Gerente de Segurança, Gerente de Serviços e de Contexto) permite uma distribuição dos serviços e da comunicação para um efetivo funcionamento do sistema ciente de contexto proposto.

Deve-se considerar também que os princípios básicos da privacidade são respeitados na execução do TV-I e de seus serviços (Seção 4.3). Todas as informações inseridas e verificadas na política de privacidade são declaradas por meio da política de privacidade, que não é secreta (princípio da legalidade e justiça). As informações pessoais que são verificadas para a execução do TV-I são também válidas quanto aos princípios da limitação de finalidades e da necessidade de coleta e processamento de dados, já que somente as informações essenciais de localização, identificação e tempo são analisadas.

Devido ao exemplo estar em um escopo de atuação restrito, ou seja, não há um uso extensivo de informações pessoais, não houveram validações explícitas de princípios como partição individual, transparência e supervisão $e$ sanções, por exemplo. 


\section{Referências Bibliográficas}

Abelson, H.; Lessig, L.; Covell, P.; Gordon, S.; Hochberger, A.; KoVACS, J.; Krikorian, R.; SCHneck, M. Digital identity in cyberspace. 6.805/Law of Cyberspace: Social Protocols, 1998.

Disponível em <<http: //tinyurl. com/3ab2y >> (Acessado em 23 de Julho de 2004)

ABNT NBR ISO/IEC 17799:2000 - Código de Prática para a Gestão da Segurança da Informação. 2001.

ABowd, G. D. Classroom 2000: An experiment with the instrumentation of a living educational environment. IBM Systems Journal, v. 38, n. 4, p. 508-530, 1999.

Abowd, G. D.; Dey, A. K.; Brown, P. J.; Davies, N.; Smith, M.; Steggles, P. Towards a better understanding of context and context-awareness. In: Proceedings of the 1st International Symposium on Handheld and Ubiquitous Computing, Springer-Verlag, 1999, p. 304-307.

Aвowd, G. D.; Mynatt, E. D. Charting past, present, and future research in ubiquitous computing. ACM Transactions on Computer-Human Interaction, v. 7 , n. 1, p. 29-58, 2000.

Abowd, G. D.; Mynatt, E. D.; Rodden, T. The human experience. IEEE Pervasive Computing, v. 1, n. 1, p. 48-57, 2002.

Ambrósio, D. R. Alternativas de implementação de reconhecimento de padrões para agentes móveis em ambiente de segurança computacional. Dissertação (Mestrado), Instituto de Ciências Matemáticas e de Computação, Universidade de São Paulo, São Carlos, 2002.

ARRUdA JÚNIOR, C. R. E. Context Kernel: um web service baseado nas dimensões de informação de contexto. Dissertação (Mestrado), Instituto de 
Ciências Matemáticas e de Computação, Universidade de São Paulo, São Carlos, 2003.

BAtes, C. XML in theory and practice. John Wiley \& Sons, Inc., 2003.

BeAver, K.; HAROLD, R. The practical guide to HIPAA privacy and security compliance. Auerbach Publications, 2004.

Berinato, S. The State of Information Security 2003. CIO Magazine, v. 10, n. 20, 2003.

Disponivel em <<http: / / tinyurl.com/2hl6d >> (Acessado em 23 de Julho de 2004)

Bernardes, M. C. Avaliação do uso de agentes móveis em segurança computacional. Dissertação (Mestrado), Instituto de Ciências Matemáticas e de Computação, Universidade de São Paulo, São Carlos, 1999.

Bonifácio Júnior, J. M. Sistemas de segurança distribuído: integração de firewalls com sistemas de detecção de intrusão. Dissertação (Mestrado), Instituto de Ciências Matemáticas e de Computação, Universidade de São Paulo, São Carlos, 1998.

Brotherton, J. A.; ABowd, G. D. Rooms take note: Room takes notes! In: Proceedings of the Spring AAAI Symposium on Intelligent Environments, 1998, p. 23-31.

Brown, P. J.; Bovey, J. D.; Chen, X. Context-aware applications: from the laboratory to the marketplace. IEEE Personal Communications, v. 4, n. 5, p. 58-64, 1997.

Cansian, A. M. Desenvolvimento de um sistema adaptativo de detecção de intrusos em redes de computadores. Tese (Doutorado), Instituto de Física de São Carlos, Universidade de São Paulo, São Carlos, 1997.

CARL, J. ActiveX security: under the microscope. Web Week, v. 2, n. 17, 1996.

Disponível em $<<$ http: //tinyurl. com/2r7pu $>>$ (Acessado em 23 de Julho de 2004)

Cavoukian, A. Data mining: staking a claim on your privacy. Relatório técnico, Information and Privacy Commissioner, Ontário, Canadá, 1998. Disponível em <<http: / / tinyurl. com/32dva >> (Acessado em 23 de Julho de 2004) 
Chalmers, D. Contextual mediation to support ubiquitous computing. Tese (Doutorado), Imperial College of Science, Technology and Medicine, London University, Londres, Inglaterra, 2002.

Chuvakin, A.; Peikari, C. Security warrior. O'Reilly \& Associates, 2004.

Cicilini, R. Desenvolvimento de um agente SNMP para plataformas rodando DOS. Dissertação (Mestrado), Instituto de Ciências Matemáticas e de Computação, Universidade de São Paulo, São Carlos, 1994.

Crichton, M. Presa. Editora Rocco, 474 p., 2003.

Crowley, J. L.; Coutaz, J.; Rey, G.; Reignier, P. Perceptual components for context-aware computing. In: Proceedings of the International Conference on Ubiquitous Computing, Heidelberg, Alemanha: Springer-Verlag, 2002, p. 117-134 (Lecture Notes in Computer Science, v.2498).

Culler, D. E.; Mulder, H. Smart sensors to network the world. Scientific American, v. 6, n. 6, p. 85-91, 2004.

Disponível em <<http: / / tinyurl. com/4px3x>> (Acessado em 23 de Julho de 2004)

Damianou, N.; Dulay, N.; Lupu, E.; Sloman, M. The ponder policy specification language. In: Proceedings of the International Workshop on Policies for Distributed Systems and Networks, Bristol, Reino Unido: SpringerVerlag, 2001, p. 18-39 (Lecture Notes in Computer Science, v. 1995).

DEY, A. K. Providing architectural support for building context-aware applications. Tese (Doutorado), Georgia Institute of Technology, Atlanta, EUA, 2000.

DEY, A. K. Understanding and using context. Personal and Ubiquitous Computing Journal, v. 5, n. 1, p. 4-7, 2001.

Dick, P. K. The Minority Report. Citadel Press, 1992.

Dix, A.; Rodden, T.; Davies, N.; Trevor, J.; Friday, A.; Palfreyman, K. Exploiting space and location as a design framework for interactive mobile systems. ACM Transactions on Computer-Human Interaction, v. 7, n. 3, p. 285-321, 2000.

DufFy, D. The FUD Factor. CSO Magazine, v. 2, n. 4, p. 8 páginas, 2003. Disponível em <<http: / / tinyurl. com/2oncu $>>$ (Acessado em 23 de Julho de 2004) 
Elgesem, D. Privacy, respect for persons, and risk, cáp. 3. Suny Series in Computer-Mediated Communication New York, EUA: State University of New York Press, p. 45-66, 1996.

Faria, G. B.; Santos Júnior, J. B.; Goularte, R.; Moreira, E. S. Uso de perfis em aplicações de televisão interativa conscientes de contexto. In: Anais do VII Simpósio Brasileiro de Sistemas Multimídia e Hipermídia, Florianópolis, 2001, p. 139-154.

Felten, E. W.; Schneider, M. A. Timing attacks on web privacy. In: Proceedings of the ACM Conference on Computer and Communications Security, ACM Press, 2000, p. 25-32.

FISCHER-HÜBNER, S. IT-security and privacy: design and use of privacyenhancing security mechanisms, v. 1958 de Lecture Notes in Computer Science. Suécia: Springer-Verlag, 2001.

Garfinkel, S.; Schwartz, A.; Spafford, G. Practical UNIX \& internet security. 3 ed. Sebastopol, EUA: O’Reilly \& Associates, 2003.

Garção, A. S.; Sousa, P. A.; Pimentão, J. P.; Santos, B. R.; Blazguéz, V.; OBRATANSKI, L. Annex to DEEPSIA's deliverable 4 - system architecture. Relatório Técnico IST Project-1999-20483, DEEPSIA Consortium, 2002.

Goularte, R. Utilização de meta-dados no gerenciamento de acesso a servidores de vídeo. Dissertação (Mestrado), Instituto de Ciências Matemáticas e de Computação, Universidade de São Paulo, São Carlos, 1998.

Goularte, R. Personalização e adaptação de conteúdo baseadas em contexto para TV interativa. Tese (Doutorado), Instituto de Ciências Matemáticas e de Computação, Universidade de São Paulo, São Carlos, 2003.

Goularte, R.; Moreira, E. S. Representação de objetos de mídia em aplicações conscientes de contexto em TV interativa. In: Anais do VIII Simpósio Brasileiro de Sistemas Multimídia e Hipermídia, Fortaleza, 2002, p. 150-165.

GRIFFIn, P. Introduction to XACML. BEA XML and Web Services Technologies, 2004.

Disponivel em <<http: / / tinyurl. com/542rq >> (Acessado em 23 de Julho de 2004)

Harrison, B.; Fishkin, K.; Gujar, A.; Mochon, C.; Want, R. Squeeze me, hold me, tilt me! An exploration of manipulative user interfaces. In: Proceedings of the ACM Conference on Human Factors in Computing Systems, Los Angeles, EUA, 1998, p. 17-24. 
Hashi, B.; Malabarda, S.; PAndey, R.; Bishop, M. Supporting reconfigurable security policies for mobile programs. Computer Networks, v. 33, p. 33-93, 2000.

Herrera, J. A. F. Uso de data warehousing e data mining na busca de relações e conhecimento em um ambiente de comércio eletrônico. Qualificação (Mestrado), Instituto de Ciências Matemáticas e de Computação, Universidade de São Paulo, São Carlos, 2002.

Herrera, J. A. F.; Martins Júnior, J.; Moreira, E. S. A model for data manipulation and ontology navigation in DEEPSIA project. In: Proceedings of the First Seminar on Advanced Research in Electronic Business, Rio de Janeiro, 2002, p. 139-145.

HONG, J. I.; LANDAY, J. A. An infrastructure approach to context-aware computing. Human-Computer Interaction, v. 16, n. 2-4, p. 287-303, 2001.

Houaiss, A.; Villar, M. S.; Franco, F. M. M. Dicionário Houaiss da língua portuguesa. Rio de Janeiro: Editora Objetiva, 2001.

IsHiI, H.; Ullmer, B. Tangible bits: towards seamless interfaces between people, bits and atoms. In: Proceedings of the ACM Conference on Human Factors in Computing Systems, 1997, p. 234-241.

ISHITANI, L. Uma arquitetura para controle de privacidade na Web. Tese (Doutorado), Universidade Federal de Minas Gerais, Belo Horizonte, 2003.

Ishitani, L.; Almeida, V.; Meira Junior, W. Masks: bringing anonymity and personalization together. IEEE Security \& Privacy, v. 1, n. 3, p. 18-23, 2003.

KABIR, M. J. Apache server 2 bible. New York, EUA: Hungry Minds, Inc., 2002.

Kagal, L.; Undercoffer, J.; Perich, F.; Joshi, A.; Finin, T. A security architecture based on trust management for pervasive computing systems. In: Proceedings of Grace Hopper Celebration of Women in Computing, 2002.

KOENEN, R. Intellectual property management and protection in MPEG standards. 2001.

Disponível em <<http: //tinyurl. com/2me $5 \mathrm{~g}>>$ (Acessado em 23 de Julho de 2004)

LANGHEINRICH, M. Privacy by design - principles of privacy-aware ubiquitous systems. In: Proceedings of the Ubicomp International Conference, Atlanta, 
EUA: Springer-Verlag, 2001, p. 273-291 (Lecture Notes in Computer Science, v.2201).

Disponível em <<http: / / tinyurl. com/3ns15>> (Acessado em 23 de Julho de 2004)

LAURAnT, C.; ET AL. Privacy \& human rights 2003: an international survey of privacy laws and developments. Electronic Privacy Information Center and Privacy International, 2003.

Disponível em <<http: / / tinyurl. com/35k 8n $>>$ (Acessado em 23 de Julho de 2004)

Lei, H.; Sow, D. M.; Davis, II, J. S.; Banavar, G.; Ebling, M. R. The design and applications of a context service. ACM SIGMOBILE Mobile Computing and Communications Review, v. 6, n. 4, p. 45-55, 2002.

LIEIRA, J. F. Utilização de áudio e vídeo em sistemas gerenciadores de redes de computadores. Dissertação (Mestrado), Instituto de Ciências Matemáticas e de Computação, Universidade de São Paulo, São Carlos, 1995.

Módulo Security Nona pesquisa nacional de segurança da informação. 2003.

Disponivel em <<http://tinyurl. com/2q2hc $>>$ (Acessado em 23 de Julho de 2004)

Milagres, F. G.; Moreira, E. S. Detecção de intrusões com auxílio de agentes móveis. Revista Eletrônica de Iniciação Científica, v. 1, n. 2, 2001. Disponível em <<http: / / tinyurl. com/3f3sa >> (Acessado em 23 de Julho de 2004)

Milagres, F. G.; Moreira, E. S.; Pimentão, J. P.; Sousa, P. A. C. Security analysis of a multi-agents system in EU's DEEPSIA project. In: Proceedings of the First Seminar on Advanced Research in Electronic Business, Rio de Janeiro, 2002, p. 155-162.

Moraes, S. Voz em sistemas computacionais: projeto e implementação de módulos de processamento de voz em gerenciamento de redes. Dissertação (Mestrado), Instituto de Ciências Matemáticas e de Computação, Universidade de São Paulo, São Carlos, 1995.

MorishitA, F. T. Uma avaliação evolutiva dos protocolos de gerenciamento da internet: SNMPv1, SNMPv2 e SNMPv3. Dissertação (Mestrado), Instituto de Ciências Matemáticas e de Computação, Universidade de São Paulo, São Carlos, 1997. 
ODA, C. S. Desenvolvimento de um sistema monitor gráfico baseado em protocolo de gerenciamento SNMP. Dissertação (Mestrado), Instituto de Ciências Matemáticas e de Computação, Universidade de São Paulo, São Carlos, 1994.

Oliveira, F. A. Extração de informação sobre produtos comercializados em páginas brasileiras para a alimentação de catálogos eletrônicos. Qualificação (Mestrado), Instituto de Ciências Matemáticas e de Computação, Universidade de São Paulo, São Carlos, 2002.

PASCOE, J. Adding generic contextual capabilities to wearable computers. In: Proceedings of the International Symposium on Wearable Computers, Pittsburgh, EUA, 1998, p. 92-99.

Pereira Filho, S. F. Avaliação para ambientes servidores para agentes móveis. Dissertação (Mestrado), Instituto de Ciências Matemáticas e de Computação, Universidade de São Paulo, São Carlos, 2001.

Pimentel, M. G. C.; Kerimbaev, Y. I. B.; Abowd, G. D.; Guzdial, M. Supporting long-term educational activities through dynamic web interfaces. Interacting With Computers Journal, v. 13, p. 353-374, 2001.

Pitofsky, R.; ET AL. Privacy online: fair information practices in the electronic marketplace. Report to congress, Federal Trade Commission, 2000.

Disponível em <<http: / / tinyurl. com/2vpje >> (Acessado em 23 de Julho de 2004)

RALPH, D.; SEARBY, S. Location and personalisation: delivering online and mobility services. Londres, Inglaterra: The Institution of Electrical Engineers, 2004.

Ravazzolli, S. Proposta limita uso de e-mail no serviço público. Agência Câmara, 2004.

Disponível em <<http: / / tinyurl. com/3f66t>> (Acessado em 23 de Julho de 2004)

REAMI, E. R. Especificação e prototipagem de um ambiente de gerenciamento de segurança apoiado por agentes móveis. Dissertação (Mestrado), Instituto de Ciências Matemáticas e de Computação, Universidade de São Paulo, São Carlos, 1998.

RICHARDSOn, R. CSI/FBI Computer Crime and Security Survey. Computer Security Institute / Federal Bureau of Investigation, v. 8, n. 1, p. 21, 2003. Disponível em <<http: / / tinyurl. com/2ouu5>> (Acessado em 23 de Julho de 2004) 
SAlBer, D.; Dey, A.; ABowd, G. Ubiquitous computing: defining an HCI research agenda for an emerging interaction paradigm. Relatório Técnico GIT-GVU-98-01, Georgia Institute of Technology, Atlanta, EUA, 1998.

Salber, D.; Dey, A. K.; Abowd, G. D. The Context Toolkit: aiding the development of context-enabled applications. In: Proceedings of the Conference on Human Factors in Computing Systems, Pittsburgh, EUA, 1999, p. 434-441.

Santa Eulália, L. A.; Moreira, E. S.; Carvalho, A. P. L. F.; Rozenfeld, $\mathrm{H}$. Using ontologies for intelligent information retrieval in an e-commerce application case study. In: Proceedings of the Fourth European Conference on Product and Process Modelling in the Building and Related Industries, Portoroz, Slovênia, 2002, p. 277-284.

SAntos, R. F. Gerenciamento de contexto: uma abordagem baseada em representações extensíveis. Dissertação (Mestrado), Instituto de Ciências Matemáticas e de Computação, Universidade de São Paulo, São Carlos, 2004.

SAntos Júnior, J. B. Modelagem de ambientes interativos conscientes de contexto: uma abordagem baseada nos padrões MPEG-4 e MPEG-7. Tese (Doutorado), Instituto de Ciências Matemáticas e de Computação, Universidade de São Paulo, São Carlos, 2002.

Santos Júnior, J. B.; Goularte, R.; Moreira, E. S.; Faria, G. B. The modeling of structured context-aware interactive environments. In: Transactions of the SDPS Journal of Integrated Design and Process Science, 2001, p. 77-93.

Schilit, B.; Theimer, M. Disseminating active map information to mobile hosts. IEEE Network, v. 8, n. 5, p. 22-32, 1994.

SCHILIT, B. N.; ADAMS, N.; WANT, R. Context-aware computing applications. In: Proceedings of the IEEE Workshop on Mobile Computing Systems and Applications, Santa Cruz, EUA, 1994, p. 85-90.

Schilit, B. N.; Golovchinsky, G.; Price, M. N. Beyond paper: supporting active reading with free form digital ink annotations. In: Proceedings of the ACM Conference on Human Factors in Computing Systems, New York, EUA: ACM Press/Addison-Wesley Publishing, 1998, p. 249-256.

Schilit, W. N. A system architecture for context-aware mobile computing. Tese (Doutorado), Graduate School of Arts and Sciences, Columbia University, 1995. 
SCHNEIER, B. Applied cryptography: protocols, algorithms and source code in C. 2 ed. John Wiley \& Sons, Inc., 1996.

SCHNEIER, B. Secrets and lies: digital security in a networked world. John Wiley \& Sons, Inc., 2000.

Schunter, M.; Ashley, P.; Hada, S.; KarJoth, G.; Powers, C. Enterprise Privacy Authorization Language (EPAL 1.1). IBM Research Report 1.86, International Business Machines Corporation, 2003.

Disponível em <<http: / / tinyurl. com/2bl $8 \mathrm{~h}>>$ (Acessado em 23 de Julho de 2004)

StAJANO, F. The Resurrecting Duckling - what next? In: Proceedings of the 8th Security Protocols Workshop, Springer-Verlag, 2001, p. 204-214 (Lecture Notes in Computer Science, v.2133).

StajAno, F. Security for ubiquitous computing. John Wiley \& Sons, Inc., 2002.

TAVARES, D. M. Avaliação de técnicas de captura para sistemas detectores de intrusão. Dissertação (Mestrado), Instituto de Ciências Matemáticas e de Computação, Universidade de São Paulo, São Carlos, 2002.

Tavares, D. M.; Castejon, E. F.; Rossi, G. B.; Cansian, A. M.; Moreira, E. S. ACME! (Advanced Counter-Measures Environment): um mecanismo de captura e análise de pacotes para aplicação em detecção de assinaturas de ataque. In: Anais do Primeiro Simpósio de Segurança em Informática, São José dos Campos, 1999, p. 39-46.

Tipton, H. F.; KRAUSE, M., eds. Information security management handbook. 5 ed. Auerbach Publications, 2004.

Truong, K. N.; Abowd, G. D.; Brotherton, J. A. Who, what, when, where, how: design issues of capture \& access applications. In: Proceedings of the International Conference on Ubiquitous Computing, Heidelberg, Alemanha, 2001, p. 209-224 (Lecture Notes in Computer Science, v.2201).

Tulloch, M. Microsoft encyclopedia of security. Redmond, EUA: Microsoft Press, 2003.

Uto, N. Segurança de sistemas de agentes móveis. Dissertação (Mestrado), Universidade Estadual de Campinas, Campinas, 2003.

WAnG, H.; LeE, M. K. O.; WANG, C. Consumer privacy concerns about internet marketing. Communications of the ACM, v. 41, n. 3, p. 1-4, 1998. 
Want, R.; Hopper, A.; Falco, V.; Gibbons, J. The Active Badge location system. ACM Transactions on Information Systems, v. 10, n. 1, p. 91-102, 1992.

Warren, S. D.; Brandeis, L. D. The right to privacy. Harvard Law Review, v. 4, n. 5, p. 193-220, 1890.

Webster, M. Merriam-Webster's collegiate dictionary \& thesaurus. 11 ed. Merriam-Webster, Inc., 2003.

Weiser, M. The computer for the 21st century. Scientific American, v. 265, n. 3, p. 94-104, 1991.

Weiser, M. Some computer science issues in ubiquitous computing. Communications of the ACM, v. 36, n. 7, p. 75-84, 1993.

Westin, A. Privacy and freedom. Bodley Head, 1987.

Witbrock, M. J.; Hauptmann, A. G. Speech recognition for a digital video library. Journal of the American Society of Information Science, v. 49, n. 7, p. 619-632, 1998. 


\section{APÊNDICE}

\section{Vocabulário EPAL}

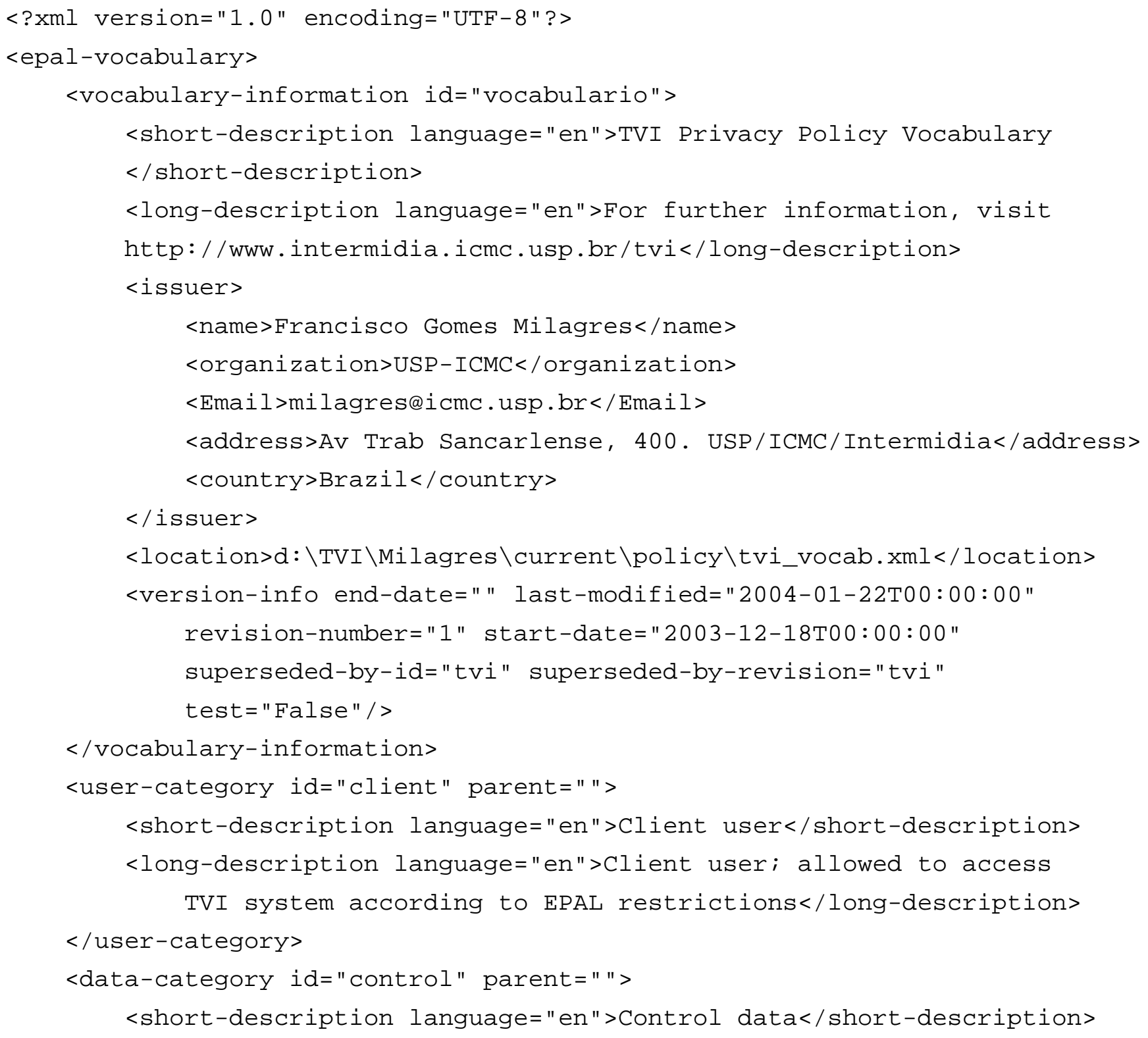


<long-description language="en">Control data; used to exchance control and personalization data</long-description $>$

$</$ data-category $>$

<purpose id="personalization" parent="">

<short-description language="en">Personalization and research

purposes $</$ short-description $>$

<long-description language="en"> The data associated with this

business purpose is used for personalization and research

purposes. Associations among the collected data and other

services may be created in order to improve the

capabilities of the system.</long-description>

$</$ purpose $>$

$<$ action id="access">

<short-description language="en" $>$ Access $<$ /short-description $>$

$<$ long-description language="en" $>$ Definition of the primary action

of users on TVI system</long-description>

$</$ action $>$

<container id="context_container">

<short-description language="en">Main container</short-description $>$

<long-description language="en"/>

<attribute auditable="false" id="location" maxOccurs="2"

minoccurs="1" simpleType="http://www.w3.org/2001/XMLSchema\#string">

<short-description>User location</short-description>

<long-description>User location information</long-description>

$</$ attribute $>$

<attribute auditable="false" id="time" maxOccurs="1"

minOccurs="1" simpleType="http://www.w3.org/2001/XMLSchema\#dateTime">

<short-description>Time information</short-description>

<long-description>System time information.</long-description>

$</$ attribute $>$

$</$ container $>$

<obligation id="retention">

<short-description language="en">Retention period</short-description>

<long-description language="en">Maximum information retention

period</long-description>

<parameter id="max_retention_period" maxOccurs="1" minoccurs="0"

simpleType="http://www.w3.org/2001/XMLSchema\#date">

<short-description>Maximum retention period</short-description>

$<$ long-description>Maximum information retention period allowed

$</$ long-description $>$

$</$ parameter $>$

</obligation>

</epal-vocabulary> 


\section{APÊNDICE}

\section{Política de Segurança EPAL}

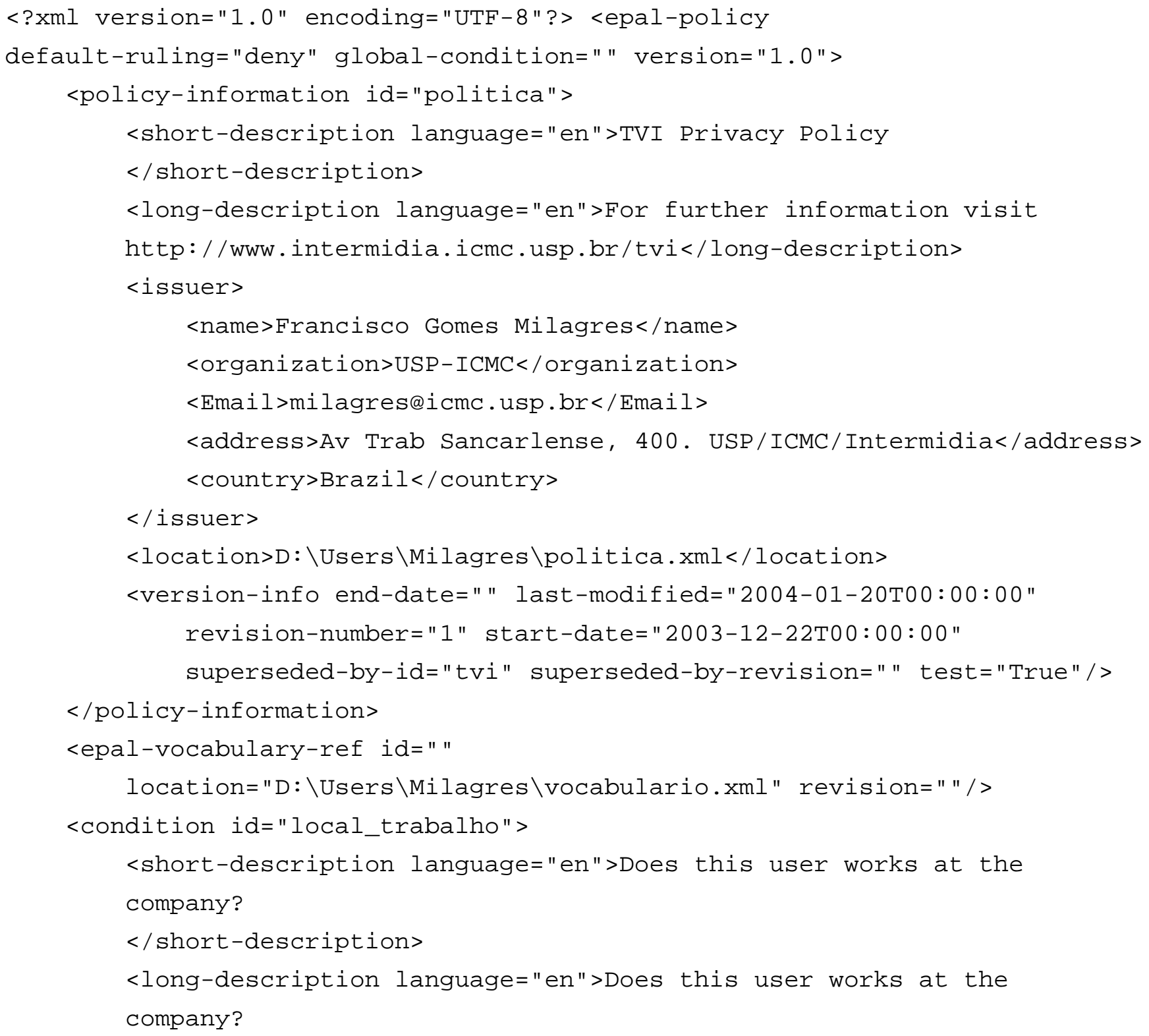









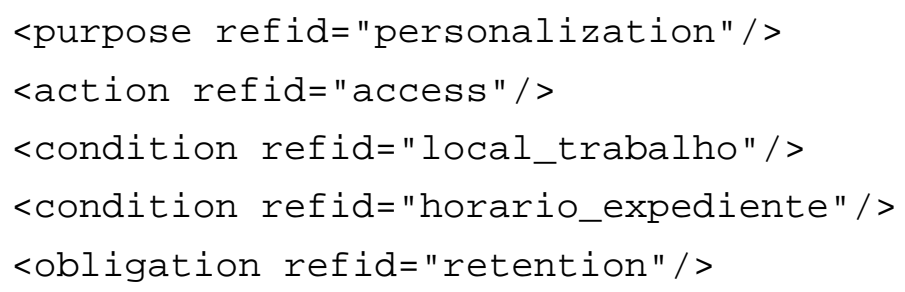

